\title{
Early Detection of Oral Cancer Through Dental Practice in Jazan Region of Saudi Arabia
}

Citation for published version (APA):

Jafer, M. A. (2019). Early Detection of Oral Cancer Through Dental Practice in Jazan Region of Saudi Arabia: The Development of A Dental Public Health Intervention (ISAC). [Doctoral Thesis, Maastricht University]. Maastricht University. https://doi.org/10.26481/dis.20190830mj

Document status and date:

Published: 01/01/2019

DOI:

10.26481/dis.20190830mj

Document Version:

Publisher's PDF, also known as Version of record

\section{Please check the document version of this publication:}

- A submitted manuscript is the version of the article upon submission and before peer-review. There can be important differences between the submitted version and the official published version of record.

People interested in the research are advised to contact the author for the final version of the publication, or visit the DOI to the publisher's website.

- The final author version and the galley proof are versions of the publication after peer review.

- The final published version features the final layout of the paper including the volume, issue and page numbers.

Link to publication

\footnotetext{
General rights rights.

- You may freely distribute the URL identifying the publication in the public portal. please follow below link for the End User Agreement:

www.umlib.nl/taverne-license

Take down policy

If you believe that this document breaches copyright please contact us at:

repository@maastrichtuniversity.nl

providing details and we will investigate your claim.
}

Copyright and moral rights for the publications made accessible in the public portal are retained by the authors and/or other copyright owners and it is a condition of accessing publications that users recognise and abide by the legal requirements associated with these

- Users may download and print one copy of any publication from the public portal for the purpose of private study or research.

- You may not further distribute the material or use it for any profit-making activity or commercial gain

If the publication is distributed under the terms of Article $25 \mathrm{fa}$ of the Dutch Copyright Act, indicated by the "Taverne" license above, 
Early Detection of Oral Cancer Through Dental Practice in Jazan Region of Saudi Arabia: The Development of a Dental Public Health Intervention (ISAC)

Mohammed Abdurabu Jafer

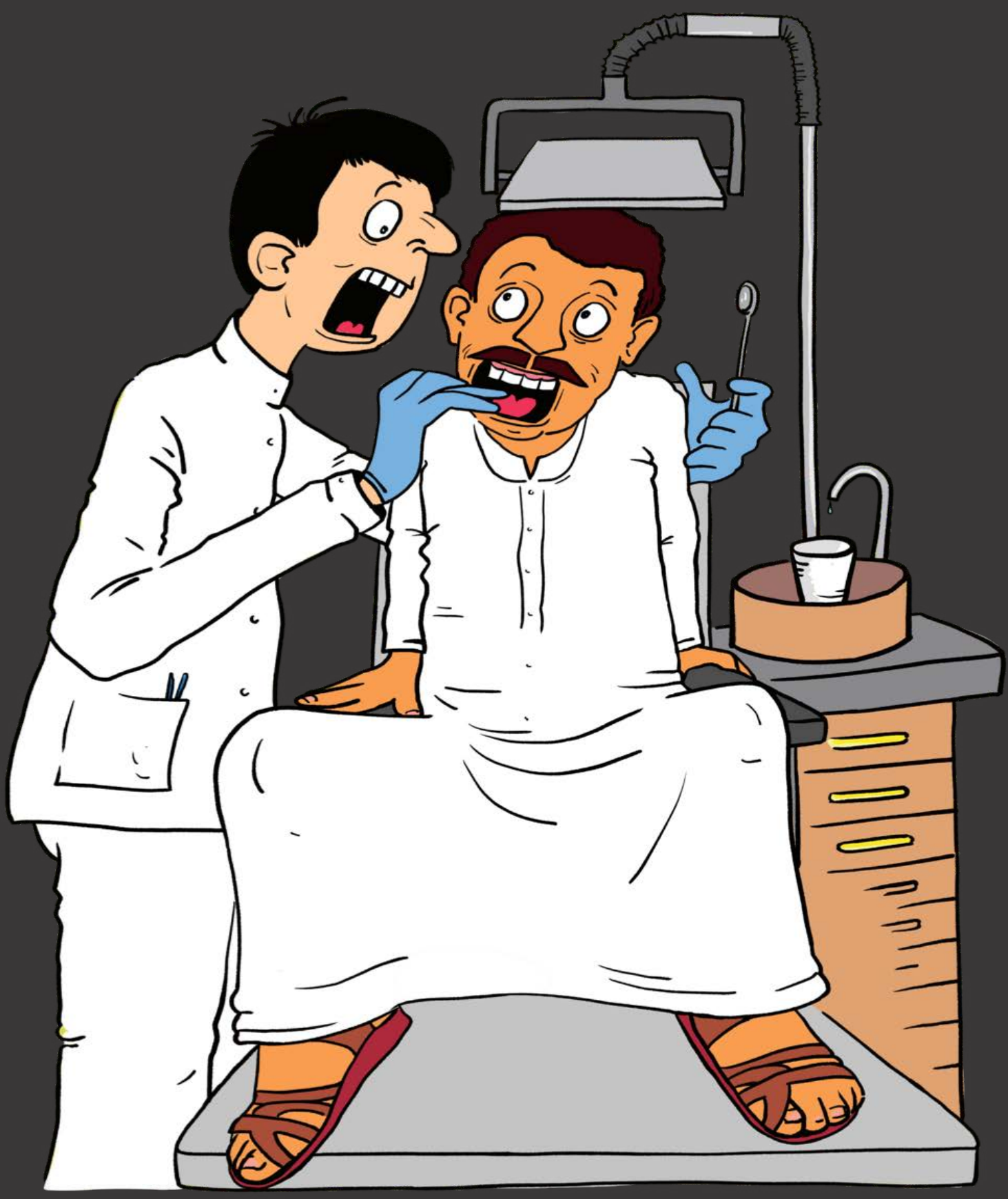



Early Detection of Oral Cancer Through Dental Practice in Jazan Region of Saudi Arabia: The Development of a Dental Public Health Intervention (ISAC) 



\title{
Early Detection of Oral Cancer Through Dental Practice in Jazan Region of Saudi Arabia: The Development of a Dental Public Health Intervention (ISAC)
}

\section{DISSERTATION}

\begin{abstract}
To obtain the degree of Doctor at Maastricht University, on the authority of the Rector Magnificus, Prof. dr. Rianne M. Letschert, in accordance with the decision of the Board of Deans, to be defended in public on Friday 30th August 2019, at 12:00 hours.
\end{abstract}

By

Mohammed Abdurabu Jafer 


\section{Supervisors}

Prof. dr. R. Crutzen

Prof. dr. B. van den Borne

\section{Assessment committee}

Prof. dr. H. de Vries (Chairman)

Dr. C. Hoving

Prof. dr. G.J Kok

Prof. dr. L. Lechner (Open University of the Netherlands)

Prof. dr. Olalekan Abdulwahab Ayo-Yusuf (Sefako Makghato Health Sciences University,

Pretoria, Gauteng, South Africa) 


\section{Table of contents}

$\begin{array}{lll}\text { Chapter } 1 & \text { General Introduction } & 7\end{array}$

Chapter 2 What do Dental College Clinicians Know about Oral Cancer and its Risk Factors? An Assessment among Final Year Students, Interns and Faculty Members in Saudi Arabia

Chapter 3 What do Dentists and Dental-Students Think of Oral Cancer and Its Control and Prevention Strategies? A Qualitative Study in Jazan Dental School

Chapter 4 Dentists Behavioral Factors Influencing Early Detection of Oral Cancer: Direct Clinical Observational Study

Chapter 5 Dental Patients'Views and Need for Oral Cancer Examination, Preventive Measures and Information in the Jazan Region of Saudi Arabia: A Mixed Methods Qualitative and Quantitative Study 85

Chapter 6 Introducing ISAC for Oral Cancer Comprehensive Dental Practice

Chapter 7 General Discussion

Summary

Valorization addendum

Acknowledgements

Curriculum Vitae

Publications 
CHAPTER 1 
General Introduction 
8 Chapter 1 


\section{Oral cancer biology}

The complexity surrounding cancer biology and chemistry began to be unraveled by the middle of the 20th century, when it was found to be caused by carcinogens (e.g. chemicals in tobacco), viruses (e.g. EBV, HBV, HPV), radiation and hereditary factors [1]. Oral cancer is known to be very aggressive, and has a serious impact on individuals, families and societies. Oral cancer occurs where abnormal cell growth arises in the oral cavity, such as on the lips, tongue and floor of the mouth, which encompass the most-affected sites of oral cancer $[2,3]$. Oral cancer includes different types of cancer because every part of the oral cavity is distinctive from the others. Squamous cell carcinoma (SCC) is the most common type of oral cancer (90\%), and occurs when the squamous cells lining the mouth exhibit abnormal behavior. SSC is considered aggressive, grows rapidly, and can metastasize to other organs. Verrucous carcinoma (5\%) is another type of oral cancer that develops from the abnormal squamous cells and is widely considered a very slow growing cancer. Verrucous carcinoma rarely metastasizes to other organs, but it can invade the adjacent tissue. Salivary gland carcinoma comprises cancer that occurs in salivary glands found throughout the lining of the mouth. Salivary gland carcinoma includes adenoid cystic carcinoma, mucoepidermoid carcinoma and low-grade polymorphous adenocarcinoma. When oral cancer occurs in the lymphoid tissue (immune system), located in the mouth, such as the tongue and tonsils, it is known as lymphoma. Other types of non-cancerous tumor, such as conditions that develop in the mouth or oropharynx, include Fibroma, Odontogenic tumor, Granular cell tumor, Papilloma, Condyloma acuiminatum and others. These types are considered benign but may convert to cancer and they should therefore be excised surgically [3].

Oral cancer is used as a general term in this dissertation, and this is comparable with the World Health Organization's (WHO's) reporting that covers the broader scope of the disease burden. The use of this general term also facilitates the utilization of the findings by the general public and different health professions; health promoters, health policymakers and others [4]. Squamous cell carcinoma (SCC) is the most common type of oral cancer in Jazan, Saudi Arabia, which is the region of focus for this dissertation [5].

\section{Oral cancer is a public health problem}

Oral cancer represents a serious public health problem. Overall, oral cancer is the eighth most common cancer worldwide [6], with international oral cancer cases reaching 260,000 in 2008 [7]. Higher incidence and mortality rates of oral cancer are observed in developing countries $[7,8]$. For instance, in India in 2008 , the new cases of oral cancer incidences amounted to roughly 70,000 new cases and was predicted to increase by the year 2020 
[8]. Among the Arabian Gulf countries, Saudi Arabia carries the heaviest burden in terms of oral cancer $[5,9,10]$. According to the Saudi National Cancer Registry, most diagnosed cases of oral cancer have been reported in the Jazan region $[5,11]$. Based on the latest population report by the Saudi General Authority for Statistics in April 2010, Jazan's citizens comprised only $4.5 \%$ of the total Saudi population [12], yet the region claims the highest oral cancer rate $-35 \%[5,11]$. Oral cancer in Jazan is reported more among females than males, which contrasts with international figures regarding oral cancer, where males are usually more affected than females $[5,11]$.

Tobacco products, specifically the smokeless form of tobacco, is considered a major independent risk factor for oral cancer [13]. Smokeless tobacco (ST) was frequently associated with more than half of oral cancer cases in Libya, Iraq and Egypt [13]. Shammah is a form of ST that is linked with an increased risk of oral cancer in the Jazan region and Yemen. Moreover, Toombak dipping, which is another form of ST, had been used by almost half of oral cancer patients in Sudan [13]. In Jordan, water-pipe smoking has become linked to younger age incidences of oral cancer [13]. Betel/areca quid is a commonly used tobacco in Asian countries, such as India, and also raises the relative risk of developing oral cancer [14]. Other common forms of ST include Naswar used in Pakistan, as well as in Northern and Central Asia, and a sweetened type known as Sarda used in Bangladesh [15]. In general, the use of tobacco in Saudi Arabia is a serious issue. Various studies reported that $66 \%$ of individuals (both male and female) began smoking at age 12 [16, 17]. Moreover, Shammah is a traditional form of ST composed of a mixture of tobacco powder, ash, black pepper, flavorings and other custom ingredients, and is commonly used by the inhabitants of the Jazan region, by both genders and all age groups [5, 18]. The other risk factors that have a proven predisposition to oral cancer are alcohol, viral infections (HPV and EBV), fungal infections, sun exposure and a low intake of fruits and vegetables $[19,20]$.

\section{Oral cancer diagnosis}

Oral cancer can be detected by performing an oral cancer clinical examination, which encompasses observing and palpating the hard and soft tissue (extra-oral examination) of the patients' face, neck, lymph nodes, as well as visualizing and palpating intraoral soft and hard tissue for any abnormalities (intraoral examination) [44]. Following that, a biopsy would be taken clinically to check for any suspicious lesions and sent for histopathologic examination to achieve a definitive diagnosis. Even though the early stage of oral cancer is usually asymptomatic, early signs and symptoms that might be associated with oral cancer include: an unhealed ulcer for more than two weeks, unexplained loose teeth, 
unexplained lumps, difficult or painful swallowing, and red or white patches in the mouth lining $[10,20,21]$.

The TNM system is a common staging technique for oral cancer assessments that was introduced by the American Joint Committee on Cancer (AJCC). This system follows four key purposes: prognosis estimates, treatment planning, treatment effectiveness evaluation, as well as standardized nomenclature for results comparison [22]. The TNM system defines the anatomic and clinical extent of the tumor and assesses three components: $\mathrm{T}$ - The extent of the primary tumor, $\mathrm{N}$ - The presence, absence, and extent of regional lymph node involvement, and $\mathrm{M}$ - represents the presence or absence of distant metastasis. The numerical subsets of the TNM system represent the progressive extent of the malignant tumor; $T_{0}, T_{1}, T_{2}, T_{3}, T_{4}-N_{0}, N_{1}, N_{2}, N_{3}-M_{0}, M_{1}$. Another grading system used for oral cancer assessment is the histologic grade $(G)$. The histologic grade is a qualitative system that defines the tumor based on the differentiation of the cells, which is the extent to which tumor cells resemble normal cells in that site. Grades are elucidated in numerical grading from the most differentiated to the least differentiated, as follows: GX (e.g., carcinoma in situ), G1, G2, G3, G4 (e.g., SCC) [23].

\section{Early versus late detection of oral cancer}

Early detection of oral cancer leads to better survival rates for individuals. Previous studies have confirmed the relationship between the (earlier) stage of the disease at the time of diagnosis and (better) survival rates [24-28]. This relationship was investigated in a recent study by measuring tumor volume, and it was observed that there was a significant level of association [29]. A critical issue particularly associated with oral cancer relates to late detection, whereby oral cancer is often discovered after the tumor has metastasized to another location in the body e.g. lymph nodes [3, 30]. Furthermore, since the 1980s, the survival rate of oral cancer has not markedly improved, notwithstanding the technological advancements and ongoing research efforts in terms of treatment [31, 32]

Different factors were reported in the literature to be related to oral cancer late detection, including public knowledge and awareness of oral cancer, and its early signs and symptoms $[21,30,33]$. Further, it was evident in a meta-synthesis that patients with late detection of oral cancer are more likely to be in an advanced stage of oral cancer [34]. Behavioral factors, such as the lack of oral cancer examinations, the lack of patient education about oral cancer as well as oral cancer self-examination, and delaying seeking out medical care were also found to be associated with oral cancer late detection [35]. 
The problem of oral cancer late detection/delayed diagnosis might be better understood in view of behavior change theories, as an outcome of the interaction between multiple factors from the perspective of both patients and dentists at the individual level and other agents at the environmental level $[36,37]$. From a patient's perspective, knowledge, awareness and perceptions of oral cancer and its related aspects (including its signs, risk factors and oral cancer screening/clinical examination) as well as self-examination skills, might contribute to oral cancer late detection, due to patients delaying seeking out dental care $[38,39]$. Additionally, the dentist-seeking behavior of patients can be influenced by their background, with factors including age, gender, ethnicity, career, responsibilities and access to healthcare services [40]. Specifically, dentist-seeking behavior has been defined as the actions taken by an individual, who perceives they have an oral health problem, in order to find a suitable remedy [41]. Broadly speaking, delays in care-seeking can be classified as patient delay, healthcare provider delay, referral delay and system delay [42]. Patient delay is the time from their first awareness of the symptoms to seeking out the first consultation with an oral health care provider. Conversely, dentist delay is the time period from first consultation with an oral health provider to the first consultation with the treatment specialist or to the definitive treatment being administered to the patient [43]. Patient delay and dentist delay have been identified as having a significant influence on the prognosis of oral cancer $[40,44]$.

From the perspective of dental professionals, dentists are among the main contributors in the early detection and prevention of such devastating diseases, as they are the first line of defence in the detection of oral cancer [45]. Dentists'knowledge, perceptions of oral cancer screening/clinical examination and risk factors that are common in the region, (as well as their experience, skills and confidence in their ability to perform oral cancer screening/ clinical examination and patient communication skills), can have a significant influence on their oral cancer practice [46]. Studies done to evaluate oral cancer examination among dental students/dentists, showed that dental students perceived that they lack the knowledge and skills necessary to perform adequate oral cancer examination [47, 48]. In addition, many dental practitioners reported that oral cancer examination was not emphasized in their school curriculums as much as other subjects. Furthermore, there is considerable variation in knowledge and the thoroughness of oral cancer examinations among dentists [49]. Similarly, other studies identified gaps among dentists' knowledge and the practice of oral cancer examination $[50,51]$.

\section{Current treatments}

The treatment modalities for oral cancer differ according to the stage of the tumor, its histologic differentiation, its clinical condition and its location [52]. Oral cancer can be 
treated with surgical resection, radiotherapy, chemotherapy or a targeted reactive agent. New advances in cancer treatment technology include proton therapy, image-guided radiotherapy, intensity modulated radiotherapy, as well as ARC therapy.

Cancer therapy can significantly impact oral health, social health, emotional health and the overall systemic health of patients. Complications resulting from cancer therapy include mucositis, hyposalivation, dry mouth, speech impairment, facial disfigurement and the need to wear a dental prosthesis. Other chronic conditions involve osteoradionecrosis, dental caries, fibrosis, dysphagia, parageusia, and graft vs. host diseases in patients being treated with immunosuppressive therapy and others [52].

\section{Prevention strategies}

One primary emphasis for the 2030 vision for Saudi Arabia is to improve health and life expectancy, which will lead to a vibrant society with fulfilling lives for its citizens [53]. Effective oral cancer primary and secondary prevention strategies, which emphasize oral cancer examination, will not only aid in disease detection at its early stage, but will also help to prevent the diagnosed precancerous lesions from transforming into a malignant state by surgical excision as the first-line of treatment, or by other alternatives in the form of systemic/local medicines, e.g., corticosteroids and retinoid [54].

A primary prevention strategy entails dentists having a legitimate role in oral cancer prevention and early detection, and can be achieved with the following measures: raising public awareness and health literacy about oral cancer and its related aspects (risk factors, prevention, detection, and self-examination) through mass media and health communication campaigns, through dentists practicing full oral cancer examinations in their routine clinical examinations, inspection of tobacco use (including cessation counseling), and oral health education for their patients [45, 55-58]. An intervention carried out to increase youth knowledge of oral cancer among secondary school learners and university students in the Jazan region resulted in improved oral cancer knowledge [39]. However, no follow up assessment was done, which may call into question the effect of the intervention in the long term. Finally, focusing on knowledge alone (without studying other influential factors that contribute to the problem of oral cancer in Jazan), may not be an effective approach to deal with this problem. Another study among dentists, in which the effectiveness of three interventions on skills training for oral cancer screening was studied, revealed that dentists' confidence and skills in oral cancer screening were significantly improved by hands-on and video instructions that were implemented into the design of the curriculum for oral cancer examinations [59]. A secondary prevention strategy has the objective of encouraging the detection of oral cancer at its earlier stages, 
especially among high-risk group individuals (Shammah users). This can be achieved through educating patients on performing oral cancer self-examinations with good lighting conditions and in front of a mirror [60].

Therefore, integrated research efforts are highly necessary to identify aspects of the current state of oral cancer practices in the Jazan region, as well as the potential avenues for the development of effective oral cancer prevention interventions.

\section{Theoretical framework: The Intervention Mapping Approach (IM)}

Oral cancer is a complex issue that requires an evidence-based systemic approach to guide the planning process (from problem analysis until the implementation and evaluation) of comprehensive interventions. Therefore, the Intervention Mapping (IM) approach aids in developing health promotion interventions that are grounded on an integrated approach for psychosocial, organizational, community change theories as well as evidence-based methods on different levels. IM stresses the active involvement of important figures who are included in the problem; such as at-risk individuals and agents in the environment. These contributors should be the focus of the intervention. IM comprises six iterative steps that build on each other (Fig.1), with each step encompassing several tasks.

The first step is to formulate the logic model of the problem, based on a needsassessment that uses, for example, the PRECEDE model (Chapters 2, 3, 4, and 5 of this dissertation). This step should also specify the population, context and setting. The second step is to formulate the logic model of change (Chapter 7 of this dissertation). In this step, the planners reverse engineer the problem and state the expected outcomes, performance objectives, determinants for change as well as change objectives. Several health, behavioral and environmental-oriented theories can be integrated in this step to support the planner's decision regarding the change - such as information processing theories, reasoned action approaches, persuasive communication, social cognitive theory and others. Steps 3 and 4 are to design and produce the intervention - such as themes, components, evidence-based change methods, practical applications, draft materials, pretest and produce materials (Chapter 6 of this dissertation). The fifth step is to identify the intervention's potential users - for instance, adopters, implementers and end-users (Chapter 6 of this dissertation). Lastly, the sixth step is to specify an intervention evaluation plan, including the process, effect and economic evaluations (Chapter 6 of this dissertation). 


\section{Intervention Mapping Steps and Tasks}

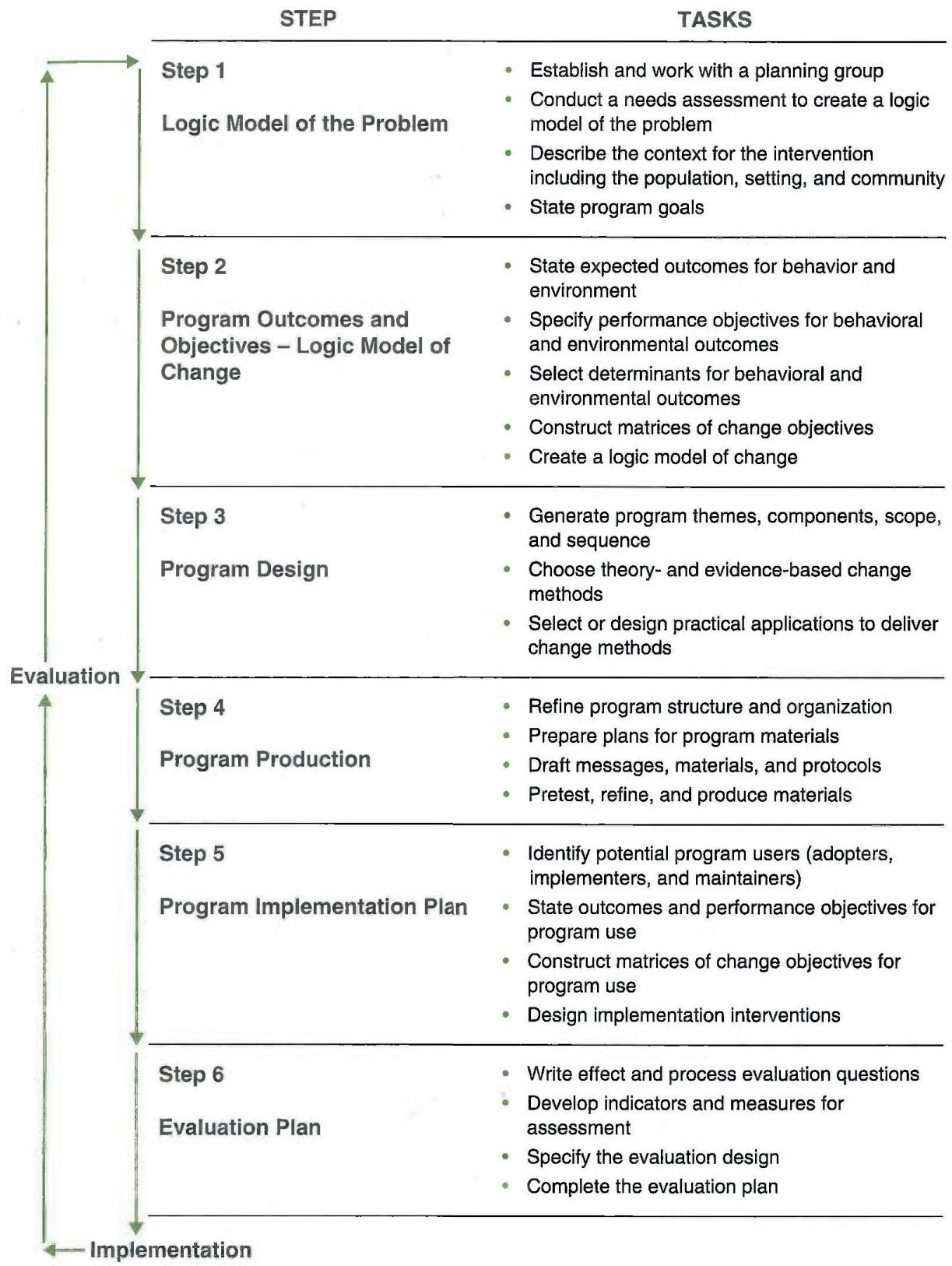

Figure.1: The Intervention Mapping Model for Planning Oral Cancer Early Detection Intervention [61]. 


\section{Dissertation Aim}

The overall aim of this dissertation is to develop a comprehensive intervention by means of IM that contributes to the early detection and prevention of oral cancer. The dissertation was built on stepwise and iterative processes that are in line with IM. This work was carried out in response to a call from Jazan Dental School (JDS) concerning the urgent need for oral cancer prevention/control programs in the Jazan region. Therefore, the underlining behavioral and environmental factors and conditions associated with oral cancer were identified thorough a needs assessment (Chapters 2, 3, 4 and 5), prioritized and matched with appropriate evidence-based and practical change methods (Chapter 6). Consequently, the first and second steps of the IM process were completed by conducting four studies (Chapters 2, 3, 4 and 5). The second chapter of this dissertation describes a study that assesses dentists' awareness and knowledge regarding oral cancer and its related aspects, including epidemiology, risk factors, signs and symptoms, clinical manifestations, examinations, oral cancer-specific issues in Jazan, as well as oral cancer prevention and control measures in a population study. The third chapter describes a study that explores dentists' beliefs and opinions toward oral cancer, oral cancer examination practices, and the difficulties they encounter in regard to oral cancer practices, which utilizes a Grounded Theory approach in a qualitative study. A study conducted to directly observe a dentist's practice of oral cancer examination, patient education/counseling, and to identify the possible influencing determinants on their behavior is described in the fourth chapter. The fifth chapter includes study that investigate and assess patients, who are visiting JDS, in regard to their awareness, knowledge, perceptions, and opinions toward oral cancer, as well as its related aspects and oral cancer practice by dentists. Among the valuable benefits of including dental patients in this study (Chapter 5), is to provide a further objective assessment of dentists' behavior in the clinical setting. The insights gained from these four studies constitute solid information to proceed along the next steps of the IM process.

A comprehensive approach for oral cancer practice (ISAC intervention) is the main outcome of this dissertation, which aims for a comprehensive oral cancer practice and patient education among dentists (Chapter 6). The sixth chapter in this dissertation, therefore, covers the third, fourth, fifth, and sixth steps of the IM process and describes the development of the ISAC intervention and its proposed implementation plan. 


\section{References}

1. Sudhakar A. History of cancer, ancient and modern treatment methods. J Cancer Sci Ther. 2009;1(2):1-4. doi: 10.4172/1948-5956.100000e2

2. Grant E, Silver K, Bauld L, Day R, Warnakulasuriya S. The experiences of young oral cancer patients in Scotland: symptom recognition and delays in seeking professional help. Bdj. 2010;208:465. doi: 10.1038/sj.bdj.2010.450.

3. Montero PH, Patel SG. Cancer of the oral cavity. Surg Oncol Clin N Am. 2015;24(3):491-508. doi: 10.1016/j.soc.2015.03.006.

4. World Health Organization. Oral cancer [Internet]. Geneva: World Health Organization [cited 2019 Apr 1]. Available from: http://www.who.int/cancer/prevention/diagnosis-screening/oralcancer/en

5. Allard WF, DeVol EB, Te OB. Smokeless tobacco (Shamma) and oral cancer in Saudi Arabia. Community Dent Oral Epidemiol. 1999;27(6):398-405.

6. Petersen PE. Strengthening the prevention of oral cancer: the WHO perspective. Community Dent Oral Epidemiol. 2005;33(6):397-9. doi: 10.1111/j.1600-0528.2005.00251.x.

7. Lambert R, Sauvaget C, de Camargo Cancela M, Sankaranarayanan R. Epidemiology of cancer from the oral cavity and oropharynx. Eur J Gastroenterol Hepatol. 2011;23(8):633-41. doi: 10.1111/j.1875-595x.2012.00131.x.

8. Gupta B, Ariyawardana A, Johnson NW. Oral cancer in India continues in epidemic proportions: evidence base and policy initiatives. Int Dent J. 2013. doi: 10.2174/1389450120666190319125734.

9. Al-Jaber A, Al-Nasser L, El-Metwally A. Epidemiology of oral cancer in Arab countries. Saudi Med J. 2016;37(3):249-55. doi: 10.15537/smj.2016.3.11388.

10. Warnakulasuriya S. Global epidemiology of oral and oropharyngeal cancer. Oral Oncol. 2009;45(4-5):309-16. doi: 10.1016/j.oraloncology.2008.06.002.

11. Saudi Cancer Registry. Saudi Arabia cancer incidence report 2012 [document on the Internet]. Riyadh, Saudi Arabia: Saudi Cancer Registry; 2015 [cited 2019 Apr 1]. Available from: http:// ghdx.healthdata.org/organizations/saudi-cancer-registry

12. General Authority for Stattistics. Population statistics [Internet]. Saudi Arabia; 2010 Apr [cited 2019 Apr 1]. Available from: https://www.stats.gov.sa/ar/tags/population

13. Asthana S, Labani S, Kailash U, Sinha DN, Mehrotra R. Association of smokeless tobacco use and oral cancer: a systematic global review and meta-analysis. Nicotine Tob Res. 2018. doi: 10.1093/ ntr/nty074.

14. Chang MC, Lin LD, Wu HL, Ho YS, Hsien HC, Wang TM, et al. Areca nut-induced buccal mucosa fibroblast contraction and its signaling: a potential role in oral submucous fibrosis-a precancer condition. Carcinogenesis. 2013;34(5):1096-104. doi: 10.1093/carcin/bgt012.

15. Al-Rmalli SW, Jenkins RO, Haris PI. Betel quid chewing elevates human exposure to arsenic, cadmium and lead. J Hazard Mater. 2011;190(1-3):69-74. doi: 10.1016/j.jhazmat.2011.02.068.

16. Al Agili DE, Park HK. The prevalence and determinants of tobacco use among adolescents in Saudi Arabia. J Sch Health. 2012;82(3):131-8. doi: 10.1111/j.1746-1561.2011.00676.x. 
17. Abdalla AM, Al-Kaabba AF, Saeed AA, Abdulrahman BM, Raat H. Gender differences in smoking behavior among adolescents in Saudi Arabia. Saudi Med J. 2007;28(7):1102-8.

18. Bakdash A. Shammah (smokeless tobacco) and public health. Asian Pac J Cancer Prev. 2017; 18(5):1183-90. doi: 10.22034/APJCP.2017.18.5.1183

19. Maden C, Beckmann AM, Thomas DB, McKnight B, Sherman KJ, Ashley RL, et al. Human papillomaviruses, herpes simplex viruses, and the risk of oral cancer in men. Am J Epidemiol. 1992;135(10):1093-102.

20. Sankaranarayanan R, Ramadas K, Amarasinghe H, Subramanian S, Johnson N. Oral cancer: prevention, early detection, and treatment. In: Gelband H, Jha P, Sankaranarayanan R, Horton S, editors. Cancer: Disease Control Priorities [Internet]. 3rd ed (Volume 3). Washington (DC): The International Bank for Reconstruction and Development/The World Bank; 2015 [cited 2019 Apr 1]. Available from: https://www.ncbi.nlm.nih.gov/books/NBK343649/

21. Warnakulasuriya KA, Harris CK, Scarrott DM, Watt R, Gelbier S, Peters TJ, et al. An alarming lack of public awareness towards oral cancer. Br Dent J. 1999;187(6):319-22.

22. Pugliano FA, Piccirillo JF, Zequeira MR, Fredrickson JM, Perez CA, Simpson JR. Clinical-severity staging system for oral cavity cancer: five-year survival rates. OTO Open. 1999;120(1):38-45.

23. Amin MB, Greene FL, Edge SB, Compton CC, Gershenwald JE, Brookland RK, et al. The Eighth Edition AJCC Cancer staging manual: continuing to build a bridge from a population-based to a more "personalized" approach to cancer staging. CA. 2017;67(2):93-9.

24. Rodrigues PC, Miguel MC, Bagordakis E, Fonseca FP, de Aquino SN, Santos-Silva AR, et al. Clinicopathological prognostic factors of oral tongue squamous cell carcinoma: a retrospective study of 202 cases. Int J Oral Maxillofac Surg. 2014;43(7):795-801.

25. Rikardsen OG, Bjerkli IH, Uhlin-Hansen L, Hadler-Olsen E, Steigen SE. Clinicopathological characteristics of oral squamous cell carcinoma in Northern Norway: a retrospective study. BMC Oral Health. 2014;14:103.

26. Monteiro LS, Amaral JB, Vizcaino JR, Lopes CA, Torres FO. A clinical-pathological and survival study of oral squamous cell carcinomas from a population of the North of Portugal. Med Oral Patol Oral Cir Bucal. 2014;19(2):e120-6.

27. Ling W, Mijiti A, Moming A. Survival pattern and prognostic factors of patients with squamous cell carcinoma of the tongue: a retrospective analysis of 210 cases. J Oral Maxillofac Surg. 2013;71(4):775-85.

28. Dissanayaka WL, Pitiyage G, Kumarasiri PV, Liyanage RL, Dias KD, Tilakaratne WM. Clinical and histopathologic parameters in survival of oral squamous cell carcinoma. Oral Surg Oral Med Oral Pathol Oral Radiol 2012;113(4):518-25.

29. Mucke T, Mitchell DA, Ritschl LM, Tannapfel A, Wolff KD, Kesting MR, et al. Influence of tumor volume on survival in patients with oral squamous cell carcinoma. J Cancer Res Clin Oncol. 2015;141(6):1007-11. doi: 10.1007/s00432-014-1881-2.

30. Gomez I, Seoane J, Varela-Centelles P, Diz P, Takkouche B. Is diagnostic delay related to advancedstage oral cancer? A meta-analysis. Eur J Oral Sci. 2009;117(5):541-6. 
31. Carvalho AL, Nishimoto IN, Califano JA, Kowalski LP. Trends in incidence and prognosis for head and neck cancer in the United States: a site-specific analysis of the SEER database. Int J Cancer. 2005;114(5):806-16.

32. Mashberg A, Samit A. Early diagnosis of asymptomatic oral and oropharyngeal squamous cancers. CA. 1995;45(6):328-51.

33. Grant E, Silver K, Bauld L, Day R, Warnakulasuriya S. The experiences of young oral cancer patients in Scotland: symptom recognition and delays in seeking professional help. Br Dent J. 2010;208(10):465-71.

34. Cleveland JL,Thornton-Evans G. Total diagnostic delay in oral cancer may be related to advanced disease stage at diagnosis. J Evid Based Dent Pract. 2012;12(2):84-6.

35. Warnakulasuriya KA, Johnson NW. Dentists and oral cancer prevention in the UK: opinions, attitudes and practices to screening for mucosal lesions and to counselling patients on tobacco and alcohol use: baseline data from 1991. Oral Dis. 1999;5(1):10-4.

36. Bandura A. Self-efficacy : the exercise of control. New York: Freeman; 1997.

37. De Vries H. An integrated approach for understanding health behavior; the I-Change Model as an example. Psychol Behav Sci Int J. 2017; 2(2). doi:10.19080/PBSIJ.2017.02.555585.

38. Al-Maweri S, Al-Soneidar W, Dhaifullah E, Halboub E, Tarakji B. Oral cancer: awareness and knowledge among dental patients in Riyadh. J Cancer Educ. 2017; 32(2):308-313. doi: 10.1007/ s13187-015-0924-y.

39. Quadri MF, Saleh SM, Alsanosy R, Abdelwahab SI, Tobaigy FM, Maryoud M, et al. Effectiveness of an intervention program on knowledge of oral cancer among the youth of Jazan, Saudi Arabia. Asian Pac J Cancer Prev. 2014;15(5):1913-8.

40. Scott SE, Grunfeld EA, McGurk M. Patient's delay in oral cancer: A systematic review. Community Dent Oral Epidemiol. 2006;34(5):337-43.

41. Singh MP, Misra S, Rathanaswamy SP, Gupta S, Tewari BN, Bhatt MLB, et al. Clinical profile and epidemiological factors of oral cancer patients from North India. Natl J Maxillofac Surg. 2015;6(1):21-4.

42. McLeod NM, Saeed NR, Ali EA. Oral cancer: delays in referral and diagnosis persist. Br Dent J. 2005;198(11):681-4.

43. Allison $P$, Locker $D$, Feine JS. The role of diagnostic delays in the prognosis of oral cancer: a review of the literature. Oral Oncol. 1998;34(3):161-70.

44. Singh T, Schenberg M. Delayed diagnosis of oral squamous cell carcinoma following dental treatment. Ann R Coll Surg Engl. 2013;95(5):369-73.

45. Brocklehurst P, Kujan O, Glenny AM, Oliver R, Sloan P, Ogden G, et al. Screening programmes for the early detection and prevention of oral cancer. Cochrane Database Syst Rev. 2010(11):Cd004150.

46. Haresaku S, Makino M, Sugiyama S, Naito T, Marino RJ. Comparison of practices, knowledge, confidence, and attitude toward oral cancer among oral health professionals between Japan and Australia. J Cancer Educ. 2018;33(2):429-35.

47. Yellowitz JA, Horowitz AM, Drury TF, Goodman HS. Survey of U.S. dentists' knowledge and opinions about oral pharyngeal cancer. J Am Dent Assoc. 2000;131(5):653-61. 
48. Cannick GF, Horowitz AM, Drury TF, Reed SG, Day TA. Assessing oral cancer knowledge among dental students in South Carolina. J Am Dent Assoc (1939). 2005;136(3):373-8.

49. LeHew CW, Epstein JB, Kaste LM, Choi YK. Assessing oral cancer early detection: clarifying dentists' practices. J Public Health Dent. 2010;70(2):93-100.

50. Applebaum E, Ruhlen TN, Kronenberg FR, Hayes C, Peters ES. Oral cancer knowledge, attitudes and practices: a survey of dentists and primary care physicians in Massachusetts. J Am Dent Assoc (1939). 2009;140(4):461-7.

51. Patton LL, Elter JR, Southerland JH, Strauss RP. Knowledge of oral cancer risk factors and diagnostic concepts among North Carolina dentists. Implications for diagnosis and referral. J Am Dent Assoc (1939). 2005;136(5):602-10; quiz 82.

52. Epstein JB, Güneri $P$, Barasch A. Appropriate and necessary oral care for people with cancer: guidance to obtain the right oral and dental care at the right time. Support Care Cancer. 2014;22(7):1981-8.

53. Saudi Arabia Government. 2030 Vision [Internet]. Riyadh: Saudi Arabia Government; 2016 [cited 2019 Apr 1]. Available from: https://vision2030.gov.sa/en

54. Yardimci G, Kutlubay Z, Engin B, Tuzun Y. Precancerous lesions of oral mucosa. World J Clin Cases. 2014;2(12):866-72.

55. Purkayastha M, McMahon AD, Gibson J, Conway DI. Is detecting oral cancer in general dental practices a realistic expectation? A population-based study using population linked data in Scotland. BDJ. 2018;225:241.

56. Brocklehurst PR, Speight PM. Screening for mouth cancer: the pros and cons of a national programme. BDJ. 2018;225:815.

57. Bhatt S, Isaac R, Finkel M, Evans J, Grant L, Paul B, et al. Mobile technology and cancer screening: Lessons from rural India. J Glob Health. 2018;8(2):020421-.

58. Franzmann EJ, Donovan MJ. Effective early detection of oral cancer using a simple and inexpensive point of care device in oral rinses. Expert Rev Mol Diagn. 2018;18(10):837-44.

59. Clark NP, Marks JG, Sandow PR, Seleski CE, Logan HL. Comparative effectiveness of instructional methods: oral and pharyngeal cancer examination. J Dent Educ. 2014;78(4):622-9.

60. Mathew B, Sankaranarayanan R, Wesley R, Nair MK. Evaluation of mouth self-examination in the control of oral cancer. Br J Cancer Suppl. 1995;71(2):397-9.

61. Bartholomew Eldredge LK, Markham C, Ruiter R, Fernández M, Kok G, Parcel G. Planning health promotion programs: An intervention mapping approach. 4th ed. San Francisco: Jossey-Bass \& Pfeiffer Imprints, Wiley; 2016. 

CHAPTER 2 


\section{What do Dental College Clinicians Know about Oral Cancer and its Risk Factors? An Assessment among Final Year Students, Interns and Faculty Members in Saudi Arabia}




\section{Abstract}

\section{Background}

The ability of health care professionals to perform oral cancer examinations depends partly on their knowledge of the disease and its risk factors. This study aimed to assess and compare the knowledge of final year students, interns and faculty members regarding oral cancer and its risk factors.

\section{Material and Methods}

A 35-item questionnaire concerning knowledge of oral cancer and its risk factors was distributed among participants from Jazan University's Dental School. A minimum score of 18 was the cut-off point for an acceptable total score of oral cancer knowledge (OCTS). Descriptive statistics described the relations between demographics variables and knowledge levels of the participants. The differences between OCTS, diagnostic-clinical examination knowledge (DCK) and supportive knowledge (SK) and sex and occupation were analyzed using independent t-test and ANOVAs respectively.

\section{Result}

A total of 72 students, 68 interns and 88 faculty members completed the questionnaires $(\mathrm{N}=228)$, with an average age of $23.8 \pm 0.9$ years, $25.1 \pm 1.5$ years and $40.6 \pm 9.1$ years, with $55.1 \%$ males. OCTS was $20.2 \pm 3.6$ out of 35. No significant difference between OCTS and participants' sex was found $(\mathrm{t}(203)=1.342, \mathrm{p}=.181,95 \% \mathrm{Cl}$ for difference $-.302-1.589)$. There were no significant differences in OCTS between students, interns and faculty members $(F(2,225)=2.116, p=.123)$. A significant difference was observed in SK between final year students, interns, and faculty members $(F(2,194)=$ $5.62, \mathrm{p}=.004)$.

\section{Conclusion}

Knowledge of oral cancer and its risk factors among Jazan Dental School's final year students, interns and faculty members is acceptable. However, due to the high rate of oral cancer in Jazan, emphasizing knowledge of oral cancer and its risk factors in the curriculum of Jazan Dental School is required.

\section{Key words}

Oral Cancer, Risk factors, Knowledge, Dental Education, Curriculum, Dental students, Dentists. 


\section{Introduction}

Oral cancer is a debilitating disease that has a serious impact on individuals, families and societies. Although opportunities for cancer treatment are advancing, there is also an increase in the incidence of oral cancer, [1] with 5-year survival rates remaining low - 50\% [2]. According to the WHO, oral cancer is the eighth-most-common cancer worldwide [3]. The rate of oral cancer varies among different countries, with higher incidence rates of oral cancer being reported in developing countries [3]. Of all Gulf countries, Saudi Arabia exhibits the highest prevalence of oral cancer cases [4]. According to the latest published data from the Saudi Cancer Registry in 2014, cancers related to the oral cavity are the highest registered in the Jazan region of Saudi Arabia [5]. The definitive reason for this is still unknown.

Oral cancer is usually asymptomatic and frequently diagnosed at a late stage in its development $[6,7]$. However, early detection of oral cancer leads to better survival rates for individuals. Previous studies have confirmed reduced survival rates for higher stages of the disease at diagnosis $[8,9]$. Furthermore, the delay in detection of oral cancer was found to be associated with poor prognosis of the disease $[9,10]$. Health care providers' (HCPs) knowledge of oral cancer and its risk factors is an important element in regard to the examination of oral cancer [11], and was found to be strongly associated with the likelihood of performing oral cancer examinations $[12,13]$. Moreover, it was found that around a quarter of oral cancer patients had experienced an improper diagnosis of their conditions by their HCP [14]. A delay in oral cancer diagnosis and the misdiagnosis of oral cancer leads to a poor prognosis $[15,16]$, and this was found to be associated with a lack of knowledge regarding oral cancer among HCPs [17]. Indeed, $\mathrm{HCPs}^{\prime}$ knowledge of oral cancer and its risk factors is essential for their behavior related to oral cancer practice [18, 19].

Additionally, dentists should be the first line in diagnosing oral cancer [20]. Therefore, they have a duty to gain a good knowledge of oral cancer and its risk factors, and this is particularly important if they are working in areas with high rates of oral cancer incidence and prevalence. Thus, the objective of the present study was to investigate the knowledge level of final year students and dentists working at both male and female branches of Jazan Dental School (JDS), regarding oral cancer and its risk factors. This study also serves to investigate the differences in knowledge levels about oral cancer and its risk factors among different sexes and occupations of the participants. In addition, the same analyses were carried out for Saudi participants, who make up the majority of final year students and interns, and who will mostly work in the Jazan region after their graduation. To our knowledge, this is the first study to assess the knowledge of health care professionals in the field of oral cancer in the Jazan region of Saudi Arabia. 


\section{Material and Methods}

\section{Participants and procedure}

A descriptive cross-sectional study, using a convenience sampling technique, was conducted among all final year students, interns and faculty members of the male and female branches of the JDS. Participants were informed and invited to participate in the study by the JDS administration office. To avoid any potential bias, all final year students, interns and faculty member participants, of both JDS male and female branches, were invited to the JDS main auditorium at the same time, and was divided into male and female sections as requested by JDS. All participants signed the consent form, and questionnaires were distributed among the participants who filled it out on January 18, 2017 at 12:00 noon. All questionnaires were administered by the principal investigator ( $\mathrm{PI}$ ) and there were three assistants present (employees of the school's administration) of compatible sex for each section. All the distributed questionnaires were collected after approximately 60 minutes. Participation was voluntary with no incentives for participation.

\section{Measurement and pretesting}

A knowledge scale, measuring knowledge of oral cancer and its risk factors, was developed by the PI based on the current literature, in addition to specific oral cancer issues (high prevalence and its gender distribution) in the Jazan region, from related published data and the Saudi Cancer Registry $[5,21]$. The knowledge scale focused on investigating diagnostic-clinical examination knowledge (DCK) and supportive knowledge (SK) regarding oral cancer, such as epidemiology, etiology, risk factors, prevention, management, and prognosis. Subsequently, the knowledge scale was evaluated by three senior JDS faculty members, specialized in oral medicine, oral pathology and maxillofacial surgery, in terms of completeness, accuracy, and relevance of information included in the items.

The final knowledge scale consisted of 35 items, used to investigate the level of knowledge among participants, with 13 DCK items and 22 SK items. The main outcome was established as the total score of oral cancer knowledge [OCTS], which is a sum of all correct answers, with each correct answer being counted as one point. Due to the fact that participants were of different knowledge levels, experience and specializations, and due to some questions being of an advanced level (i.e., Q4, Q 5, Q 7, Q 22/4) or requiring numeracy skills (i.e., Q 1, Q 11, Q 22/3), a minimum score of 18 was chosen by the PI and the evaluators as a cut-off point for acceptable OCTS, which is just above half of the total OCTS. The final questionnaire also included additional questions measuring age, sex, occupation of participants (final year student, intern, or faculty member) and nationality. Subsequently, a pretest with fifteen participants from the targeted sample was conducted to identify problems with wording, understanding and interpretation of items, burden 
and duration, and organization and item sequence of the questionnaire. Accordingly, questions number Q 1, Q 13, Q 20 and Q 23 were rephrased to more familiarized wording and all questions with true/false answer options were highlighted for more visibility. Subsequently, the questionnaire was distributed among all participants to collect data on their knowledge of oral cancer and its risk factors. The full questionnaire is available at $<$ https://osf.io/umk4h/>.

\section{Data Analysis}

An overall picture of the knowledge level of oral cancer among final year students, interns, and faculty members at the School of Dentistry was obtained by means of descriptive statistics. There are two separate departments at JDS for male and females, which could lead to different educational exposure to oral cancer, as lectures, clinical exposure and experience could vary - for example, with different faculty members, clinical instructors and patients. For this reason, we used independent t-tests to investigate the relation between each of OCTS, DCK or SK, as well as sex. This was also relevant because most of the questions in the DCK pertain to basic diagnostic and clinical knowledge, and most of the advanced and epidemiological questions are found in the SK. Due to differences in experience levels, ANOVA (analysis of variance) was used to investigate the relation between each of the OCTS, DCK or SK, and occupation. Furthermore, because we were also interested in investigating the level of oral cancer knowledge among future dentists in the Jazan region, the same tests were conducted among a sub-sample made up of Saudi only participants, as almost all students and interns were of Saudi nationality. The level of significance for the analytical tests was set at an alpha level of .05 and we report $95 \%$ confidence intervals.

\section{Ethical Approval}

Ethical approval was obtained from Jazan University before conducting the present study, with Registry no. [CDREC-06], dated 21 December 2016. 


\section{Results}

All final year students, interns and faculty members from JDS were approached for the present study, with a total number of 263 members. Out of the 263 individuals approached, 237 participated (90\% response rate), while 9 did not complete the questionnaire and were excluded from the analysis. The sample consisted of 72 out of 80 students (90\%), 68 out of 70 interns (97\%) and 88 out of 113 faculty members (78\%). Of the sample, $55.1 \%$ were male and $44.9 \%$ were female, with an average student age of $23.8 \pm 0.9$ years (range of 22-26), average intern age of $25.1 \pm 1.5$ years (range of 24-32) and average faculty member age of $40.6 \pm 9.1$ years (range of $25-65$ ). The participants were of five different nationalities, as shown in Table 1.

Table 1: Demographics of the sample

\begin{tabular}{|c|c|c|c|c|c|}
\hline & $\mathbf{n}$ & M & SD & Frequency & $\%$ \\
\hline Age & *228 & 29.9 & 9.3 & & \\
\hline Student & 72 & 23.8 & 0.9 & & \\
\hline Intern & 68 & 25.1 & 1.5 & & \\
\hline Faculty member & 88 & 40 & 9.1 & & \\
\hline Sex & 205 & & & & \\
\hline Male & & & & 113 & 55.1 \\
\hline Female & & & & 92 & 44.9 \\
\hline Occupation & 228 & & & & \\
\hline Student & & & & 72 & 31.6 \\
\hline Intern & & & & 68 & 29.8 \\
\hline Faculty member & & & & 88 & 38.6 \\
\hline Nationality & 210 & & & & \\
\hline Yemen & & & & 7 & 3.3 \\
\hline Egypt & & & & 11 & 5.2 \\
\hline Sudan & & & & 6 & 2.9 \\
\hline India & & & & 40 & 19.1 \\
\hline Saudi & 146 & & & 146 & 69.5 \\
\hline${ }^{* *}$ Age & & 24.6 & 1.7 & & \\
\hline \multicolumn{6}{|l|}{${ }^{* *} \operatorname{Sex}$} \\
\hline Male & & & & 74 & 50.7 \\
\hline Female & & & & 72 & 49.3 \\
\hline \multicolumn{6}{|l|}{${ }^{* *}$ Occupation } \\
\hline Student & & & & 72 & 49.3 \\
\hline Intern & & & & 67 & 45.9 \\
\hline Faculty member & & & & 7 & 4.8 \\
\hline
\end{tabular}

${ }^{*}$ number of participants completed the questionnaire ** among Saudi 
The average total score for the participants' knowledge of oral cancer, OCTS, in the present study, was $20.2 \pm 3.6$ out of 35 . No significant relation between OCTS and sex (male $M=$ $20.5, S D=3.53$ and female $M=19.9, S D=3.32$ ) of the participants was found in the sample - indeed, there was no difference in sex $(\mathrm{t}(203)=1.342, \mathrm{p}=.181,95 \% \mathrm{Cl}$ for difference $-.302-1.589, d=0.175)$. Moreover, there was no significant difference found in relation to the participants' occupation, in terms of being students, interns or faculty members $(F(2$, 225) $=2.116, p=.123, \eta_{p}^{2}=0.18$; see Table 2 ).

Furthermore, out of 13 questions investigating diagnosis and clinical knowledge of oral cancer, the score of the sample ranged between 2 and 12 correct answers, with a mean average of $7 \pm 1.7$. Further, out of 22 questions investigating other supporting knowledge pertaining to oral cancer, the score ranged from 8 to 20 correct answers, with a mean level of 13.6 \pm 2.4 . Among participants from all different occupations, items Q15, Q16-2, Q19, Q21-1, Q21-2, Q21-3, Q22-3 and Q23 have the highest number of correct answers, whereas Q1, Q4, Q5, Q11, Q14, Q18-1, Q18-2 and Q20 have the lowest amount of correct answers. Bivariate analysis of this study did not reveal any significant differences relating to sex or occupation with regards to diagnosis and clinical knowledge (DCK). However, supportive knowledge (SK) was found vary significantly in the average scores for occupation (final year students $M=13.5, S D=2.31$, interns $M=12.9, S D=2.39$ and faculty members $M=14.3$, $\mathrm{SD}=2.19 ; \mathrm{F}(2,194)=5.62, \mathrm{p} .004, \eta_{\mathrm{p}}^{2}=0.055 ;$ see Table 2$)$.

Table 2: Individual statistical tests $\left(\mathrm{N}=228^{*}\right)$

\begin{tabular}{|c|c|c|c|}
\hline & $\begin{array}{l}\text { Oral cancer knowledge } \\
\text { total score }\end{array}$ & $\begin{array}{l}\text { Diagnosis and clinical } \\
\text { knowledge }\end{array}$ & Supportive knowledge \\
\hline $\begin{array}{l}\text { Sex } \\
N=205\end{array}$ & $\begin{array}{l}\delta^{7} \mathrm{M}=20.5, \mathrm{SD}=3.53 \\
+\mathrm{M}=19.9, \mathrm{SD}=3.32 \\
95 \% \mathrm{Cl} \text { for difference } \\
{[-.302-1.589]} \\
\mathrm{t}(203)=1.342 \\
\mathrm{p}=.181 \\
d=0.175\end{array}$ & $\begin{array}{l}\partial^{7} \mathrm{M}=7.1, \mathrm{SD}=1.81 \\
+\mathrm{M}=6.9, \mathrm{SD}=1.52 \\
95 \% \mathrm{Cl} \text { for difference } \\
{[-.299-.669]} \\
\mathrm{t}(182)=.755 \\
\mathrm{p}=.451 \\
d=0.119\end{array}$ & $\begin{array}{l}\delta^{7} \mathrm{M}=13.8, \mathrm{SD}=2.26 \\
+\mathrm{M}=13.2, \mathrm{SD}=2.47 \\
95 \% \mathrm{Cl} \text { for difference } \\
{[-.153-1.248]} \\
\mathrm{t}(161.8)=1.544 \\
\mathrm{p}=.125 \\
d=0.253\end{array}$ \\
\hline $\begin{array}{l}\text { Occupation } \\
N=228\end{array}$ & $\begin{array}{l}F=2.116 \\
p=.123 \\
\eta_{p}^{2}=0.180\end{array}$ & $\begin{array}{l}F=2.189 \\
p=.115 \\
\eta_{p}^{2}=0.022\end{array}$ & $\begin{array}{l}F=5.618 \\
p=.004 \\
\eta_{p}{ }^{2}=0.055\end{array}$ \\
\hline
\end{tabular}

* number of participants completed the questionnaire

Saudi nationals accounted for $64 \%$ of the participants in the present study, with an average age of $24.6 \pm 1.7$ years. The male and female representation for Saudis was almost equal $[50.7 \%$ and $49.3 \%$ respectively]. Among them, final year students represented 
49.3\%, interns $45.9 \%$ and faculty members only $4.8 \%$. There was no significant difference in the OCTS average score between Saudi male and female participants (male $M=20.1$, $\mathrm{SD}=2.81$ and female $\mathrm{M}=19.7, \mathrm{SD}=3.17 ; \mathrm{t}(140.9)=1.736, \mathrm{p}=.406,95 \% \mathrm{Cl}$ for difference $-.567-1.394, d=0.134)$, nor were there any significant differences found relating to DCK or SK. Moreover, within the group of Saudis, there were no significant differences in OCTS average, diagnosis and clinical knowledge, or supportive knowledge regarding oral cancer with the different occupations [Table 3]. Furthermore, among Saudi participants, $95 \%$ answered question number 23 correctly, which related to risk factors of oral cancer in the Jazan region. However, only $28 \%$ of them answered question 22.4 correctly, which focused on risk factors of oral cancer among females in the region of Jazan.

Table 3: Individual statistical tests among Saudi $(\mathrm{N}=146)$

\begin{tabular}{|c|c|c|c|}
\hline & $\begin{array}{l}\text { Oral cancer knowledge } \\
\text { total score }\end{array}$ & $\begin{array}{l}\text { Diagnosis and clinical } \\
\text { knowledge }\end{array}$ & Supportive knowledge \\
\hline Sex & $\begin{array}{l}\partial^{7} \mathrm{M}=20.1, \mathrm{SD}=2.81 \\
9 \mathrm{M}=19.7, \mathrm{SD}=3.17 \\
95 \% \mathrm{Cl} \text { for difference } \\
{[-.567-1.394]} \\
\mathrm{t}(140.9)=.834 \\
\mathrm{p}=.406 \\
d=0.134\end{array}$ & $\begin{array}{l}7 \mathrm{M}=6.8, \mathrm{SD}=1.61 \\
+\mathrm{M}=6.9, \mathrm{SD}=1.51 \\
95 \% \mathrm{Cl} \text { for difference } \\
{[-.597-.458]} \\
\mathrm{t}(133.8)=-0.262 \\
\mathrm{p}=.794 \\
d=-0.064\end{array}$ & $\begin{array}{l}\partial^{7} M=13.5, S D=2.21 \\
+M=12.9, S D=2.44 \\
95 \% C l \text { for difference } \\
{[-.275-1.292]} \\
t(131.6)=1.283 \\
p=.202 \\
d=0.258\end{array}$ \\
\hline Occupation & $\begin{array}{l}F=1.643 \\
p=.197 \\
\eta_{p}^{2}=0.022\end{array}$ & $\begin{array}{l}F=.730 \\
p=.484 \\
\eta_{p}^{2}=0.110\end{array}$ & $\begin{array}{l}F=2.099 \\
p=.127 \\
\eta_{p}^{2}=0.030\end{array}$ \\
\hline
\end{tabular}




\section{Discussion}

In general, most of treatments in dental school clinics are provided by students and trainees and are supervised by faculty members. Similarly, in JDS, most of the dental treatments provided in its clinics are administered by the final year students and interns. Additionally, they are the first to examine and diagnose the majority of the patients coming to JDS. Therefore, and because of the high prevalence of oral cancer in the region, they need to have adequate knowledge of oral cancer and its related risk factors and be competent in examining and assessing the disease. In this present study, the average knowledge of oral cancer and its risk factors among final year students, interns and faculty members was found to be at a moderate level, $20.2 \pm 3.6$, with no significant difference between them. The findings of this study are in line with findings reported in the literature regarding dental students' and dentists' knowledge of diagnostics, clinical aspects, risk factors and prevention of oral cancer [22-24].

Nevertheless, the majority of the participants (students, interns and faculty) had a high level of knowledge about how to perform oral cancer examination but a low level of knowledge regarding the sites and clinical manifestation of the disease, as well as its epidemiology. This is an important finding to be taken into consideration for dentist education and clinical training, as it will have effects relating to the proper examination of oral cancer. Therefore, JDS dental students and dentists should have this essential knowledge pertaining to oral cancer examination [12, 13, 25]. However, besides this knowledge, dental students and dentists require clinical practice and experience to perform oral cancer examinations [26]. The majority of the faculty members at JDS are from countries with similar oral cancer burdens, such as India, Yemen and Sudan [1]. Those faculty members with related backgrounds and experiences could provide the best support to JDS, with the aim of moving towards training competent dentists in the field of oral cancer and its related risk factors.

Although not significant, our study suggests that males had slightly better knowledge of oral cancer (OCTS, DCK and SK) compared to females. These slight differences could be attributed to a higher number of male faculty members who were specialized in disciplines that incorporated oral cancer advanced training. Similarly, among all-Saudi participants, males had slightly better knowledge of oral cancer (OCTS and SK) compare to females. These nominal variances could also be due to the higher number of faculty members who had received advanced training on oral cancer.

Additionally, since most of the dentists in the Jazan region undertook their education at JDS, a further investigation was carried out to assess the level of knowledge related to oral cancer and its local risk factors. Question 22.4, which was answered incorrectly by 
the majority of Saudi participants, assessed the knowledge of participants regarding the specific issue of oral cancer in the Jazan region, where females have a slightly higher rate of oral cancer than males [5,21], which contradicts the standard international distribution [1]. This could indicate that incorporating oral cancer and its local risk factors in the JDS curriculum is essential.

The study carried some limitations, as it was administrated in the middle of the academic year and knowledge of each participant could be at varying levels. Almost all final year students and interns have been taught by the same faculty members who participated in the present study. Additionally, some questions posed to the sample groups focus on knowledge that may not be required by final year students, interns and unspecialized dentists. However, the present study included $87 \%$ of the clinicians who are responsible for examining and educating patients in JDS clinics. The questionnaire was developed based on current knowledge and practice guidelines related to oral cancer and its risk factors and was validated by three JDS faculty members who are competent in the field. 


\section{Conclusion}

Even though JDS final year students, interns and faculty members have moderate levels of knowledge regarding oral cancer and its risk factors, there should be more emphasis in the curriculum and clinical training of the dental school on increasing diagnostic-clinical and supportive knowledge and skills with respect to oral cancer. In the curriculum, special attention should be paid to local risk factors and special needs in relation to oral cancer. Additionally, investigations of factors related to oral cancer and its high prevalence in Jazan as well as opportunities for primary prevention are highly recommended. 


\section{References}

1. Warnakulasuriya S. Global epidemiology of oral and oropharyngeal cancer. Oral Oncol. 2009;45(4-5):309-16. doi: 10.1016/j.oraloncology.2008.06.002.

2. Mashberg A, Samit A. Early diagnosis of asymptomatic oral and oropharyngeal squamous cancers. CA. 1995;45(6):328-51.

3. Petersen PE. Strengthening the prevention of oral cancer: the WHO perspective. Community Dent Oral Epidemiol. 2005;33(6):397-9. doi: 10.1111/j.1600-0528.2005.00251.x.

4. Salim El, Moore MA, Al-Lawati JA, Al-Sayyad J, Bazawir A, Bener A, et al. Cancer epidemiology and control in the Arab world - past, present and future. Asian Pac J Cancer Prev. 2009;10(1):316.

5. Saudi Cancer Registry. Saudi Arabia cancer incidence report 2010 [document on the Internet]. Riyadh, Saudi Arabia: Saudi Cancer Registry; 2014 [cited 2017 Nov 1]. Available from: http:// ghdx.healthdata.org/organizations/saudi-cancer-registry.

6. Rikardsen OG, Bjerkli IH, Uhlin-Hansen L, Hadler-Olsen E, Steigen SE. Clinicopathological characteristics of oral squamous cell carcinoma in Northern Norway: a retrospective study. BMC Oral Health. 2014;14:103.

7. Seoane J, Alvarez-Novoa P, Gomez I, Takkouche B, Diz P, Warnakulasiruya S, et al. Early oral cancer diagnosis: The Aarhus statement perspective. A systematic review and meta-analysis. Head Neck. 2016;38 Suppl 1:E2182-9. doi: 10.1002/hed.24050.

8. Mucke T, Mitchell DA, Ritschl LM, Tannapfel A, Wolff KD, Kesting MR, et al. Influence of tumor volume on survival in patients with oral squamous cell carcinoma. J Cancer Res Clin Oncol. 2015;141(6):1007-11. doi: 10.1007/s00432-014-1881-2.

9. Rodrigues PC, Miguel MC, Bagordakis E, Fonseca FP, de Aquino SN, Santos-Silva AR, et al. Clinicopathological prognostic factors of oral tongue squamous cell carcinoma: a retrospective study of 202 cases. Int J Oral Maxillofac Surg. 2014;43(7):795-801.

10. Gomez I, Seoane J, Varela-Centelles P, Diz P, Takkouche B. Is diagnostic delay related to advancedstage oral cancer? A meta-analysis. Eur J Oral Sci. 2009;117(5):541-6.

11. Guggenheimer J, Verbin RS, Johnson JT, Horkowitz CA, Myers EN. Factors delaying the diagnosis of oral and oropharyngeal carcinomas. Cancer. 1989;64(4):932-5.

12. Awan KH, Khang TW, Yee TK, Zain RB. Assessing oral cancer knowledge and awareness among Malaysian dental and medical students. J Cancer Res Ther. 2014;10(4):903-7.

13. Burzynski NJ, Rankin KV, Silverman S, Jr., Scheetz JP, Jones DL. Graduating dental students' perceptions of oral cancer education: results of an exit survey of seven dental schools. J Cancer Educ. 2002;17(2):83-4.

14. Crossman T, Warburton F, Richards MA, Smith H, Ramirez A, Forbes LJ. Role of general practice in the diagnosis of oral cancer. Br J Oral Maxillofac Surg. 2016;54(2):208-12.

15. Mitchell E, Macdonald S, Campbell NC, Weller D, Macleod U. Influences on pre-hospital delay in the diagnosis of colorectal cancer: a systematic review. Br J Cancer. 2008;98(1):60-70. 
16. Morelatto RA, Herrera MC, Fernandez EN, Corball AG, Lopez de Blanc SA. Diagnostic delay of oral squamous cell carcinoma in two diagnosis centers in Cordoba Argentina. J Oral Pathol Med. 2007;36(7):405-8.

17. McGurk M, Chan C, Jones J, O'Regan E, Sherriff M. Delay in diagnosis and its effect on outcome in head and neck cancer. Br J Oral Maxillofac Surg. 2005;43(4):281-4.

18. Corace K, Garber G. When knowledge is not enough: Changing behavior to change vaccination results. Hum Vaccin Immunother. 2014;10(9):2623-4.

19. Kelly MP, Barker M. Why is changing health-related behaviour so difficult? Public Health. 2016;136:109-16.

20. Gutmacher Z, Teich S, Lin S, Ghantous Y, Abu El-Naaj I. Practitioners' challenges in diagnosing oral and maxillofacial tumors. Quintessence Int. 2016;47(7):603-8. doi: 10.3290/j.qi.a36011.

21. Allard WF, DeVol EB, Te OB. Smokeless tobacco (Shamma) and oral cancer in Saudi Arabia. Community Dent Oral Epidemiol. 1999;27(6):398-405.

22. Applebaum E, Ruhlen TN, Kronenberg FR, Hayes C, Peters ES. Oral cancer knowledge, attitudes and practices: a survey of dentists and primary care physicians in Massachusetts. J Am Dent Assoc (1939). 2009;140(4):461-7.

23. Gonzalez-Martinez R, Delgado-Molina E, Gay-Escoda C. A survey of oral surgeons' tobacco-userelated knowledge and intervention behaviors. Med Oral Patol Oral Cir Bucal. 2012;17(4):e588-93.

24. Da Silva SR, Juliano Y, Novo NF, Weinfeld I. Comparative study of knowledge about oral cancer among undergraduate dental students. Einstein (Sao Paulo). 2016;14(3):338-45. doi: 10.1590/ S1679-45082016AO3729.

25. Clovis JB, Horowitz AM, Poel DH. Oral and pharyngeal cancer: practices and opinions of dentists in British Columbia and Nova Scotia. J Can Dent Assoc. 2002;68(7):421-5.

26. Ajzen I, Joyce N, Sheikh S, Cote NG. Knowledge and the prediction of behavior: the role of information accuracy in the Theory of Planned Behavior. Basic Appl Soc Psych. 2011;33(2):101-17. 
CHAPTER 3 


\section{What do Dentists and Dental-Students \\ Think of Oral Cancer and Its Control and Prevention Strategies? A Qualitative Study in Jazan Dental School}




\section{Abstract}

\section{Background}

The Jazan region of Saudi Arabia has a high prevalence of oral cancer - 35\% of overall total oral cancer cases. However, little is known about the view of dentists and dental students on possible factors that contribute to this high rate, as well as scarce efforts regarding prevention.

\section{Methods}

The study investigated possible factors related to oral cancer as perceived by dentists and dental students, using a qualitative approach. Six focus groups were conducted in Jazan Dental School (JDS), with participants including dental students, interns, faculty members and key decision-makers.

\section{Results}

All participants acknowledged oral cancer as a serious public health issue in Jazan, affecting all ages. The majority thought that tobacco was a major risk factor in this region, and one that can be easily obtained by individuals of any age or gender. Furthermore, formal dental education in JDS does not focus on local-related risk factors. Participants agreed that practicing examinations for oral cancer and education on its risk factors influenced clinicians' attitude and skills. Several participants declared that there were no organized efforts regarding oral cancer and its risk factors in the region. Cultural acceptance of oral cancer risk factors was mentioned as one of the key challenges for patients.

\section{Conclusion}

The findings indicate that dental education and training at JDS was not focusing on necessary related oral health issues and their risk factors in the community. Additionally, the findings cast a new light on the fact that dentists are not educating their patients because they lack the requisite knowledge and the skill in health education, as well as problems relating to methods for communicating with patients.

\section{Keywords}

Oral Cancer, Oral Cancer Screening, Early Detection, Dental Education, Curriculum, Risk factors, Patient Education, Perception 


\section{Introduction}

Oral cancer is a major dental public health issue in several developing countries [1]. Saudi Arabia has a high prevalence of oral cancer and the majority of diagnosed oral cancer cases are in the Jazan region [2]. The high consumption of tobacco products, particularly smokeless tobacco, was found to be a major risk factor for oral cancer [3, 4]. Shammah is a type of smokeless tobacco that is consumed in Saudi Arabia [5] and increases the risk of oral cancer [6]. Additionally, smoking tobacco is strongly associated with oral cancer [7-9] and is consumed at high rates in Saudi Arabia, and is not limited to a specific gender or age. For example, $34 \%$ of male and $11 \%$ of female secondary school students are smoking cigarettes, shisha or hookah, the latter two of which are synonyms for water pipes for tobacco smoking [10-12].

A key issue related to oral cancer is the delay in diagnosing oral cancer cases, which was identified as a risk factor for mortality [13]. The delay of oral cancer diagnosis leads to delay in treatment delivery and decreases the survival rate of patients [14, 15]. Multiple factors contribute to the delay of oral cancer diagnosis, such as health care providers' knowledge [16], which was found to be strongly associated with performing full oral cancer examinations $[17,18]$. Additionally, health care providers generally do not perform full oral cancer examinations, but mainly focus on previous existing health conditions [19, 20]. In addition to health care providers' behavior, patients' behavior could contribute to such delays in oral cancer diagnosis [21]. Delays in seeking medical care due to improper interpretation of symptoms leads to delayed detection of oral cancer [22]. Such behavior could be attributed to the low level of awareness among patients [23].

Incidence of oral cancer can be reduced through prevention of its risk factors. In addition, the cost-effectiveness of prevention and early detection has been documented [24]. Health care providers could help to reduce the oral cancer burden by increasing patients' awareness of oral cancer risk factors [25]. Furthermore, early detection of oral cancer through full oral cavity clinical examinations is critical [26]. The earlier the detection of oral cancer, the better the prognosis $[14,27,28]$. Therefore, dentists play an important role in detecting oral cancer and educating individuals who are at risk of oral cancer [29].

The aim of the present qualitative study was to obtain insights into the factors that were perceived by dentists and dental students to contribute to the high prevalence of oral cancer in the Jazan region of Saudi Arabia, while the broader aim was to assess oral cancer practices in Jazan, which has a high rate of oral cancer, using a bottom-up approach. Therefore, the first step toward assessing oral cancer practices was to investigate the first line of oral healthcare providers. 


\section{Methods}

The present study investigated factors perceived to be related to oral cancer using a qualitative approach via the focus group discussion (FGD) method and was reported according to the consolidated criteria for reporting qualitative research (COREQ) [30]. All FGDs were facilitated by a male main-facilitator (MF), who was the principal investigator, and a female co-facilitator (CF). Both individuals are dental public health specialists and faculty members of the Dental School at Jazan University. Both are also Saudi nationals and $\mathrm{PhD}$ candidates at Maastricht University in the Netherlands. The MF was trained in designing and conducting qualitative research. The MF and the CF had additional training in facilitating FGDs on two mock-FGDs, with participants similar to the targeted sample under supervision of an expert Professor of Health Promotion from Jazan Applied Sciences School. Moreover, a mediator, who is an expert Professor of Health Promotion from Jazan Dental School (JDS) observed all FGDs to ensure that all the relevant topics were thoroughly discussed. All participants were dentists or students at the JDS. Participant were informed of the purpose of the focus group discussion and were willing to share their ideas and experiences. All discussions were observed by an expert Professor of Health Promotion from JDS, who was independent of the study. Furthermore, the present study considered a serious dental public health issue, oral cancer, in the Jazan region: an uninvestigated topic about which limited knowledge is available. The present study used a grounded theory methodology to explore the ideas and thoughts of JDS members and clinicians regarding oral cancer. See figure 1. 
Figure 1: Methodology Sequence

\section{Openness Question}

What are the perceptions of clinicians working at the Jazan dental school clinics toward oral cancer and its control and prevention strategies?

$\downarrow$

Ethical approval obtained

Jazan University; registry no. [CDREC-06], dated 21 December 2016

$\downarrow$

Initial purposive sampling

(two focus groups from the target)

$\downarrow$

Focus group discussion 1 (6 participants)

Focus group discussion 2 (8 participants)

$\downarrow$

Analysis

$\downarrow$

Theoretical sampling

- Adding key decision makers

$\downarrow$

Focus group discussion 3 (8 participants)

Focus group discussion 4 (11 participants)

$\downarrow$

Analysis

$\downarrow$

Male focus group of interns/students (8 participants)

Female focus group of interns/students (8 participants)

- More free space for them to talk

- More experience

$\downarrow$

Analysis

$\downarrow$

Themes evolved

$\downarrow$

Theory generated 


\section{Participant Selection}

Initial purposive sampling was obtained, using a general invitation from the clinic's administration delivered to faculty members, interns and students of Jazan Dental School (JDS). A total of 14 participants were assigned to two Focus Group Discussions (FGDs) as follows: the first FGD involved two male and one female faculty member, one male and one female intern and one male student. The second FGD had two male and two female faculty members, one male and two female interns and one female student. Initial analysis of the first two FGDs indicated the importance of adding certain individuals academic administrators and oral cancer-related course Directors - who could enrich the discussion on the topic because of their direct involvement. The influence of the formal dental education and training at JDS seemed to be the main focus of previous FGDs. A theoretical sample was acquired, as several key decision-makers in JDS were invited by the main facilitator (MF) to participate in the third and fourth FGDs. Additionally, interns and students were invited to participate in the FGDs.

The third FGD included the Dean of JDS and two Directors of courses, who were involved in oral cancer education, oral medicine and oral radiology. A total of four male and one female faculty members participated in this FGD, in addition to one male and one female intern and one male student. The fourth FGD included the Academic Vice-Dean and the Head of the Quality and Academic Development Department of JDS. It also included two Course Directors of courses with major links to oral cancer education, oral pathology and oral surgery. A total of six male and two female faculty members; one male intern; one male and one female student participated in this FGD.

While analyzing the collected data, students' and interns' interactions in the previous four FGDs seemed to be fairly limited. Therefore, two FGDs consisting of only students and interns were established. This provided them with more space to interact independently from dental supervisors or trainers and to express their thoughts, ideas and experiences freely. Furthermore, to comply with JDS administration regulations, separate male and female FGDs were conducted. Each FGD included four students and four interns from JDS.

\section{Data Collection}

Starting on 15 December 2016, a total of 6 FGDs, with the number of participants varying from 6 to 11 , took place in JDS's main faculty meeting room. A period of two months was the time difference between the three sampling phases described above (FGDs 1-2, 3-4, and 5-6), with one week gaps between all phases. Beside the female students and interns' FGD, which was conducted by the Coordinating Facilitator (CF), all FGDs were facilitated by the MF and the mediator. A semi-structured FGD guide, including ten open-ended questions (appendix 1), was developed by the authors. The developed FGD guide was sent to three oral cancer specialists for content evaluation, who all agreed on limiting the topic to oral 
cancer without investigating Pharynx cancer, which has different risk factors compared to oral cancer. The FGD guide was discussed thoroughly with three specialized Professors from JDS, including the mediator who acknowledged the previously-mentioned point on Pharynx cancer and added that this disease was not prevalent in the Jazan region of Saudi Arabia, where the present study was going to be conducted. Furthermore, the FGD guide was piloted with a group of five faculty members from JDS and used at the training sessions of the MF and CF. In the last two FGDs, a short FGD guide (appendix 2) followed, which was developed from the original discussion but was specific to issues that had fewer contributions from students and interns. All FGDs were audio recorded and then transcribed by the MF and CF and cross-reviewed by both. Mediator notes for each FGD were taken into consideration, in terms of how to conduct the next FGD or analysis. All FGDs lasted for around two hours, except the fourth FGD, which lasted for two and a half hours. The saturation of the data was reached after the fifth FGD. However, the sixth FGD, for male students and interns, was conducted due to previous planning and confirmation of attendance by participants, and to check whether the male perspective differed from the females.

\section{Data Analysis}

All FGDs were conducted in Arabic and all discussion materials were manually analyzed by the MF and CF as follows: The manuscript and memos of the discussion were reviewed after each FGD by the MF and CF and discussed with the mediator. Initial codes were then abstracted from the data. All similar codes were summarized to represent focus codes, which then led to the development of theoretical codes (Table 1). A coding tree was created to illustrate the coding process and to enhance understanding of the data (Figure 2). All codes were supported by quotes from participants, without referring to them directly. Subsequently, each developed focus code was reported in the result section, along with its major related initial codes and quotes from participants. All discussion materials were then translated into English by the MF, reviewed by the CF, and evaluated by all the authors, as not all members understand Arabic. All the participants were Arabic native speakers and preferred the interviews to be conducted in the Arabic language, as they could express their thoughts better. Data analysis was done on the original Arabic transcript, since analyzing the English-translated transcript was not a recommended option because data would be susceptible to deterioration and loss of valuable information. In addition to this, there was no data analysis software that operates in the Arabic language, leaving the team with no option but to use a manual qualitative analysis approach.

\section{Ethical Approval}

All procedures performed in the present study were in accordance with the ethical standards of the institutional research committee and with the 1964 Helsinki declaration. Prior to conducting this study, ethical approval was acquired from Jazan University - 
Registry no. [CDREC-06], dated 21 December 2016. Two updates were submitted to the JDS ethical committee regarding sampling phases, which were explained in the original request due to the nature of the study. All participants were informed that the FGDs were being recorded and provided written consent prior to their participation, including on the publication of the findings. 


\section{Results}

The FGDs revealed five major themes representing the participants' ideas and thoughts on oral cancer and its causes. The first theme related to the severity and distribution of oral cancer in the Jazan region, possible factors concerning delays in diagnosis and was referred to as a public health issue. The second theme was behavioral and cultural-related risk factors linked to the consumption of tobacco products and other locally consumed crops, e.g. Ghat. These two themes reflected the acknowledgment of oral cancer and the seriousness of risk factors in the Jazan region. The third theme was curriculum influence, which indicated the impact of Jazan Dental School's curriculum on oral cancer's recent and future related medical practices in the region. The fourth theme was clinicians' behavior towards oral cancer, which reflected the clinicians' opinion on the factors that may contribute to their attitude towards oral cancer-related medical practices. Lastly, the fifth theme was about the challenges and barriers that participants faced through their clinical practice related to oral cancer in the Jazan region. 


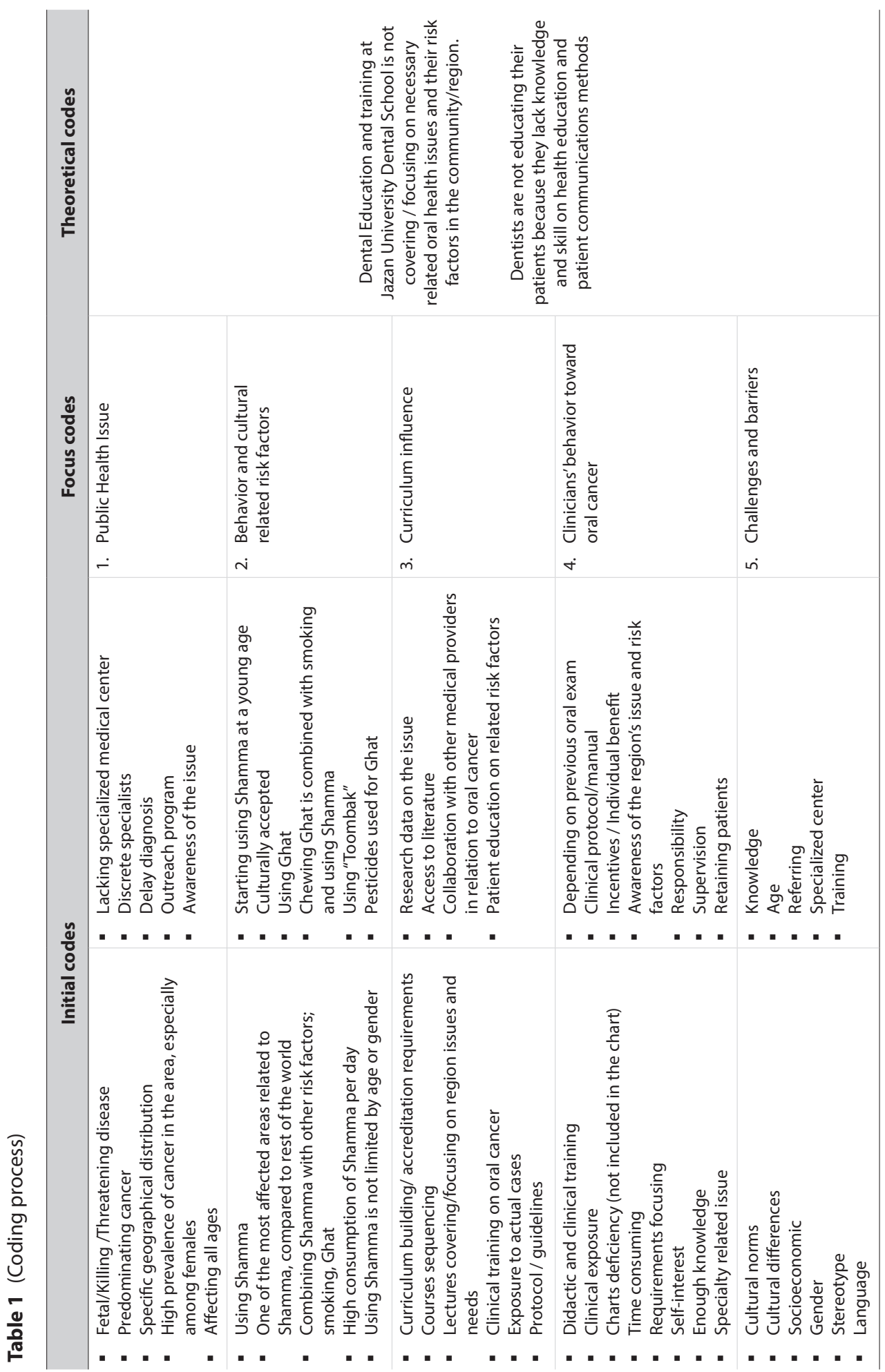


Figure 2

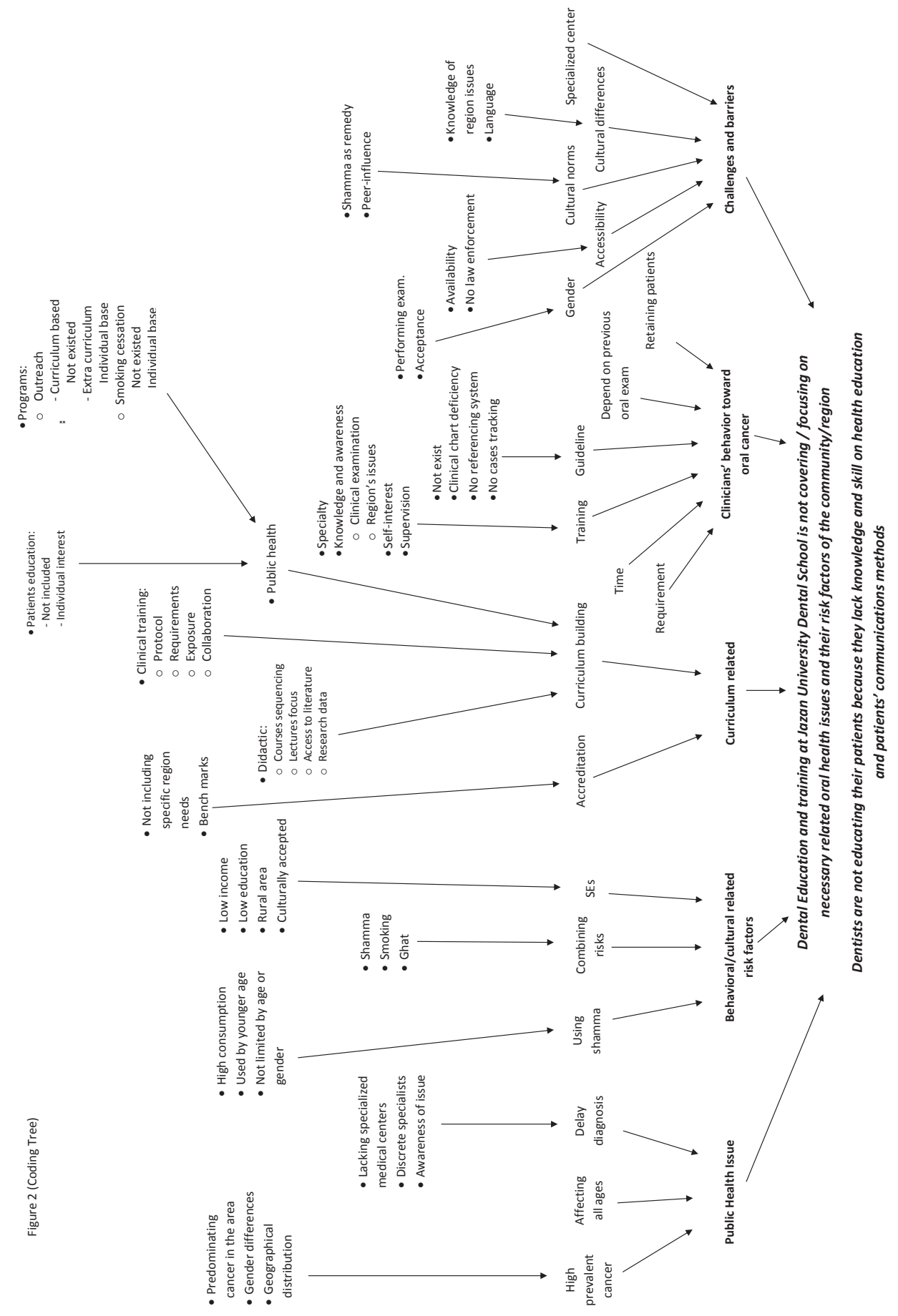




\section{Public health issue}

All participants acknowledged that oral cancer is a serious public health issue in the Jazan region, and one that has an effect on all ages: "I believe that oral cancer is a real problem in Jazan", "... not only for old people but for young too." They also mentioned that oral cancer has a high prevalence rate in the region, "According to the data available from Saudi records, this region has high rate of oral cancer patients." According to some participants, the prevalence of oral cancer might be related to gender and specific geographical locations in the region, "Oral cancer in Jazan has got specific geographical and sex distribution ... and affects women more than men."

Several participants stressed that the seriousness of oral cancer in the Jazan region is due to delayed diagnosis in such cases, "I think it's serious because people are going undetected for years ... and when they are finally diagnosed, it's so late and the condition is hopeless." A participant suggested multiple factors that might contribute to this delay in diagnosing oral cancer cases in the region. The first factor is the lack of specialized medical centers where oral cancer cases could be referred to for diagnosis and treatment: "... a center for consultation in which dentists can refer the suspicious cases should be present in Jazan." The second factor is the discrete number of specialized health care providers who are trained to deal with oral cancer cases: "to be honest, I've never seen any specialist in oral medicine conduct diagnosis of difficult cases during my years of education." The third factor a participant mentioned was the awareness among dental patients of oral cancer and its risk factors in the Jazan population: "... on a community level, I think the low awareness regarding risk factors is the main reason for high rates of oral cancer."

\section{Behavior and cultural related risk factors}

The majority of participants thought that tobacco is a major risk factor. It is available in the region and can be obtained easily by individuals of any age or gender: "... and some of them are of a young age", "females use Shammah and have more access to it in Jazan than males". Furthermore, several participants thought that use of tobacco products is culturally accepted: "...using Hookah between young females is quietly common... and society may accept using Hookah among women".

It was mentioned by several participants that individuals with a low socioeconomic status might tend to use smokeless tobacco, which is highly associated with oral cancer: "It's a real problem that needs to be addressed, and it has a socioeconomic relationship that should be investigated more." Additionally, they thought that education level, working status and location of an individual may contribute to the use of the tobacco: "... using Shammah depends on education, and if ladies work or not ... the majority of them are coming from the rural areas and usually they are illiterates ... most oral cancer cases had used Shammah." 
According to several participants, another substance that is frequently used in the region is Ghat, which is always combined with tobacco products: ".. here, it's a common belief that those who are chewing Ghat are smoking too, at least Hookah or cigarettes. But I have another one related to Shammah; people who chew Ghat usually tend to use Shammah at the same time". They also believe that the consumption of tobacco could be more severe when it is combined with the use of Ghat: "...especially if he/she is chewing Ghat, he/she may use Shammah up to 20 times per day."

\section{Curriculum influence}

Almost all participants agreed that one of the most important factors affecting their dental care practices is their formal dental education and clinical training. Participants also agreed that the local oral health issues must be part of their education and clinical training. Therefore, participants emphasize the need to incorporate oral cancer as a subject in Jazan Dental School's curriculum, as they consider oral cancer a major oral health issue, and one that is more prevalent in Jazan compared to other regions in the country.

Some respondents pointed out that this may be because Jazan Dental School is one of the most recently established dental schools in the country (established in 2008). Also, its curriculum should be benchmarked against other national and international dental schools, which may not necessary have similar local health issues: "... with high confidence, I will say that in our current curriculum, we are not taking regional issues into consideration and this is happening for other Saudi dental schools as well; because we need national and international benchmarks. And we don't have a national one that represents the region".

In addition to the curriculum construction issue, respondents agreed that data related to oral health issues in the region is limited, and since most of the faculty members in the dental school are not from Saudi Arabia, they may not be well informed on the region's specific needs "... we need to change the curriculum, have sound studies and bring more studies and evidence so it can be included in curriculum ... lectures have to be updated according to the area's needs". The discussions also demonstrated the limited involvement of local oral health needs in the construction of the dental educational material and clinical training, which leads to dental students having limited exposure to the specific situation in the region: "...exposing the students during their studies is very weak. No exposure to cases or referring."

It was mentioned that the didactic education on oral cancer and its related risk factors must be supported by adequate clinical exposure. Participants believe that this kind of exposure could be better obtained in the more specialized hospitals and centers, where students could observe and participate in examining, diagnosing and treating oral cancer cases:"... we were not exposed to clinical training with oral cancer cases ... when I went to the 
ministry of health, we see patients almost every week ..."Therefore, participants thought that collaborations with such organizations should be established to facilitate a satisfactory training for the dental school students.

Prevention of oral diseases is an essential component of Jazan Dental School's mission, as was stressed by several participants. For that purpose, students and clinicians at the Jazan Dental School clinics are expected to have adequate knowledge and training on risk factors of the region's diseases. However, the methods, skills and practices of educating patients on issues related to oral cancer and its risk factors are not part of Jazan Dental School's curriculum, "... I'm sure that no student has been exposed or taught about how to help oral cancer patients". Additionally, dental students should be trained to accurately communicate health advice to their patients: "... I was facing problems in how to make sure that a patient gets the message. How can I ensure that he understands what I want to tell him ... but I have no experience in communicating with patients".

In addition to patient education relating to oral cancer and its risk factors, respondents agreed that dental schools should carry the responsibility of raising the local population's awareness of regional oral diseases and risk factors. However, they mentioned that this was not the case at Jazan Dental School "... this was not the case at Jazan Dental School until very recently; we didn't go out or do a program for the community". Participants also indicated that the only oral health education program was initiated by the dental students themselves, with only limited involvement from Jazan Dental School "... people don't know the threats of Shammah and there are no official campaigns or anything educating the community by the dental school, besides some student efforts".

\section{Clinicians' behavior toward oral cancer}

The discussions revealed two major agreements among all participants toward practicing oral cancer screening and educating patients on its risk factors. First, practicing or not practicing oral cancer examinations and educating on its risk factors in their clinics was perceived as a behavioral issue rather than being limited to a lack of knowledge "... the problem is behavior-based but not knowledge". Secondly, the reason for not screening for oral cancer is due to not considering the consequences of their professional behavior: "... they are not taking it seriously".

Furthermore, several antecedent factors were referred to as influencing their behavior. Among those are three main enabling factors: no clinical examination protocol, and absence of referring and tracking systems. Lacking such a protocol and system that guides clinicians through their clinical practice in the dental school may contribute to this kind of behavior: "... there are no clinical guidelines or manuals to follow in college". Therefore, participants stressed the need to create a protocol that takes into account the Jazan 
region's oral health issues, such as oral cancer, which will ensure optimal clinical practice. Participants stressed that this protocol should include possible referring and tracking methods and pathways: "... I think we should have our own protocol in our college, where there is a system that tells us how to deal with such cases, where to refer to and how to track these cases".

In addition to the enabling factors, the participants discussed predisposing factors that might influence their behavior toward their oral cancer practices. First, most of the participants revealed that they usually depend on previous dental examinations and focus only on the patients' main complains: "... we are confident that our diagnostic clinic here does that for us". Based on the interns' and students' discussions, the majority of the participants agreed that they mainly focus on the required dental procedures to pass their courses "... because of the stress of requirements and other related things, only the teeth appear visible for us while the rest of the mouth unintentionally disappears from our sight".

Other reinforcing factors were mentioned that influence the students' behavior toward oral cancer examinations and patient education on its related risk factors. For instance, students might skip some clinical examination steps because of the limited time in their clinics "... in oral diagnoses, there is not enough time for students to make a diagnosis". Another factor was the lack of specialized supervision in the comprehensive clinic, where students are individually required to fully rehabilitate completed dental cases. Because there is no such supervision, students tend to neglect examining the full mouth and focus only on teeth-related issues: "... in a comprehensive course, no one cares about the soft tissue ... in a comprehensive team, there is no supervisor from oral medicine".

\section{Challenges and barriers in clinical practice}

Participants addressed different kinds of challenges that may impact their practice regarding oral cancer examination and patient education on its related risk factors. For example, Saudi participants agreed that performing oral cancer examinations on the opposite gender is uncomfortable and affects their ability to conduct a satisfying clinical examination: "... I find it very difficult for me to do the oral cancer screening on a female patient ..." On the other hand, among non-Saudi participants, gender did not have a noticeable effect on the way they performed their clinical examinations. However, language did, if Arabic was not their mother tongue.

Other challenges were related to the cultural acceptance of the main oral cancer risk factors. For instance, some patients use Shammah as a type of remedy: "... there was one female patient who had an ulcer in her tongue. Her neighbor advised her to put Shammah on the ulcer so it heals fast. She showed up with a white lesion because of that advice". Another harmful behavior is smoking Shisha/Hooka/Moasil, which is popular among youths, 
including young females: "... using Hookah among young females is quite common and they won't feel any embarrassment if you ask them". Although most of the participants indicated that they have knowledge about the spread of such risk factors, the majority of them felt unequipped to deal with these kinds of behavior-related problems: "... we don't know the clear steps for changing his/her behavior." 


\section{Discussion}

Dentists' formal education and training influences their practice in terms of oral cancer examinations and educating on oral cancer risk factors. Knowledge contributes to the behavior of dentists through different mediators, such as attitude, subjective norms and perceived control. Similar to a previous study, the present study indicates that dentists' knowledge of the topic is necessary for performing oral cancer examinations and educating on oral cancer risk factors $[17,18,31]$. Therefore, future dentists may lack the required competencies for effective oral cancer practices, as a consequence of insufficient attention being paid to local oral health issues within their education and training [32]. Likewise, dentists' attitudes and skills regarding oral cancer practices are crucial in their engaging in such behaviors $[20,33,34]$. Results of the present study are in line with previously-published findings in relation to dentists' limited performance of full clinical oral cancer examinations and educating patients on risk factors relating to oral cancer [19, $20,35]$. If the faculty members do not perform full clinical oral cancer examinations and educate patients about its related risk factors, these kinds of behavior can be transmitted to their dental students [36]. The dental students could be influenced by their peers' beliefs and behavior towards performing oral cancer examinations or educating patients about oral cancer risk factors. Moreover, the perceived school support for the practice, and the degree of dental students' motivation to comply with their fellow students' and supervisors' beliefs and behavior may influence dental students, as well [36, 37].

In addition, the present study findings revealed that the clinical courses' requirements for dental students may influence students' behavior toward oral cancer examination and patient education, as this may consume more time and perhaps have an effect on retaining patients. Previous studies were limited to investigating this in regard to academic performance and stress $[38,39]$. Hence, the findings of this present study are novel and need further investigation because it may require an adjustment to the clinical courses' requirements and support for the communication skills of dental students with their patients. Furthermore, perceived behavioral control toward conducting oral cancer examinations and patient education constitutes an important determinant for succeeding in these tasks [36]. Lacking the related necessary skills to perform oral cancer examinations and patient education of its risk factors contribute to not practicing the examination of oral cancer at all [40]. On the other hand, cultural aspects, such as reluctance of dentists or their patients toward oral cancer examinations performed by the opposite gender, or different cultural backgrounds or non-Arabic speaking dentists, may contribute to dentists not fully practicing oral cancer examinations or not educating patients on their behavior [41]. In the present study, several participants mentioned that they encounter difficulties examining the opposite gender, particularly local dental students and dentists with local 
patients. On the other hand, language and knowledge of local risk factors were barriers for faculty members who were not local to the region.

A limitation of this study was that the participants were limited to the JDS faculty members, interns and students, which may restrict the generalizability of the findings. However, some faculty members who had extensive previous experience in other health sectors also participated in the FGDs. Additionally, limited participation of female faculty members was due to their limited numbers at JDS. Nevertheless, a relatively equal participation of male and female interns and students was achieved. The interns and dental students provided insights regarding the effect of the clinical course requirements on their practice of oral cancer examinations and educating patients on oral cancer risk factors. Also, they provided insights into the aforementioned cultural barriers.

Further studies will need to investigate the possible effect of the dental school curriculum and its clinical training requirements on dental students and dentists' future oral cancer examinations and educating patients. A quantitative assessment of the relationship between the cognitions of dentists and their behavior is required, as well. For instance, there should be investigations into clinicians' knowledge, attitude, subjective norms and self-efficacy regarding oral cancer examinations and educating patients on oral cancer risk factors. Indeed, observing the actual practice of oral cancer and patient education in the JDS clinics is an essential step towards developing appropriate interventions. 


\section{Conclusions}

Broadly stated, our findings indicate that dental education and training at Jazan University Dental School has not been covering or focusing on the necessary related oral health issues and their risk factors in the community/region. Additionally, it casts a new light on the fact that dentists are not educating their patients because they themselves lack knowledge and skill in terms of health education and patient communication methods.

\section{Practice Implication}

Dental schools should empower their graduates through education and support to be able to contribute to reducing local oral health issues. In order for dental students to be competent in practicing oral cancer screening, the educational curriculum must emphasize the need to provide effective and necessary information and skills to perform oral cancer examinations and patient education, as well as to boost dental students' capabilities through authentic and vicarious experiences by incorporating the knowledge and skills training needed for oral cancer examinations and patient education throughout all clinical academic years. This study also adds to the technical ability of dental researchers to undertake a different scientific approach. For example, one way could be to utilize grounded theory to investigate the possible determinants and influences on dentists' behavior and to develop a theory that could explain such behaviors. In addition to this, this work will support the development of further studies and targeted interventions in Jazan Dental School and other dental schools in areas with similar levels of oral cancer, with high usage rates of smokeless tobacco, for example in Sudan [42]. 


\section{References}

1. Petersen PE. The World Oral Health Report 2003: continuous improvement of oral health in the 21 st century - the approach of the WHO Global Oral Health Programme. Community Dent Oral Epidemiol. 2003;31:3-24.

2. Saudi Cancer Registry. Saudi Arabia cancer incidence report 2010 [document on the Internet]. Riyadh, Saudi Arabia: Saudi Cancer Registry; 2014 [cited 2018 Apr 1]. Available from: http:// ghdx.healthdata.org/organizations/saudi-cancer-registry

3. Zhou J, Michaud DS, Langevin SM, McClean MD, Eliot M, Kelsey KT. Smokeless tobacco and risk of head and neck cancer: evidence from a case-control study in New England. Int J Cancer. 2013;132(8):1911-7.

4. Rodu B, Jansson C. Smokeless tobacco and oral cancer: A review of the risks and determinants. Crit Rev Oral Biol Med. 2004;15(5):252-63.

5. Allard WF, DeVol EB, Te OB. Smokeless tobacco (Shamma) and oral cancer in Saudi Arabia. Community Dent Oral Epidemiol. 1999;27(6):398-405.

6. Zhang X, Schmitz W, Gelderblom HR, Reichart PA. Shammah-induced oral leukoplakia-like lesions. Oral oncol. 2001;37(7):609-12.

7. Castellsague X, Quintana MJ, Martinez MC, Nieto A, Sanchez MJ, Juan A, et al. The role of type of tobacco and type of alcoholic beverage in oral carcinogenesis. Int J Cancer. 2004;108(5):741-9.

8. Blot WJ, McLaughlin JK, Winn DM, Austin DF, Greenberg RS, Preston-Martin S, et al. Smoking and drinking in relation to oral and pharyngeal cancer. Cancer Res. 1988; 48(11):3282-7.

9. Brown LM, Check DP, Devesa SS. Oral cavity and pharynx cancer incidence trends by subsite in the United States: Changing gender patterns. J Oncol. 2012;2012:649498.

10. Al Agili DE, Park HK. The prevalence and determinants of tobacco use among adolescents in Saudi Arabia. J Sch Health. 2012;82(3):131-8.

11. Ansari K, Farooqi FA. Comparison and prevalence of smoking among Saudi females from different departments of the College of Applied Medical Sciences in Dammam. Int J Health Sci. 2017; 11(5):56-62.

12. Fida HR, Abdelmoneim I. Prevalence of smoking among male secondary school students in Jeddah, Saudi Arabia. J Family Community Med. 2013;20(3):168-72.

13. Seoane J, Alvarez-Novoa P, Gomez I, Takkouche B, Diz P, Warnakulasiruya S, et al. Early oral cancer diagnosis: The Aarhus statement perspective. A systematic review and meta-analysis. Head Neck. 2016;38 Suppl 1:E2182-9. doi: 10.1002/hed.24050.

14. Rodrigues PC, Miguel MC, Bagordakis E, Fonseca FP, de Aquino SN, Santos-Silva AR, et al. Clinicopathological prognostic factors of oral tongue squamous cell carcinoma: a retrospective study of 202 cases. Int J Oral Maxillofac Surg. 2014;43(7):795-801.

15. Rikardsen OG, Bjerkli IH, Uhlin-Hansen L, Hadler-Olsen E, Steigen SE. Clinicopathological characteristics of oral squamous cell carcinoma in Northern Norway: a retrospective study. BMC Oral Health. 2014;14:103. 
16. Guggenheimer J, Verbin RS, Johnson JT, Horkowitz CA, Myers EN. Factors delaying the diagnosis of oral and oropharyngeal carcinomas. Cancer. 1989;64(4):932-5.

17. Awan KH, Khang TW, Yee TK, Zain RB. Assessing oral cancer knowledge and awareness among Malaysian dental and medical students. J Cancer Res Ther. 2014;10(4):903-7.

18. Burzynski NJ, Rankin KV, Silverman S, Jr., Scheetz JP, Jones DL. Graduating dental students' perceptions of oral cancer education: results of an exit survey of seven dental schools. J Cancer Educ. 2002;17(2):83-4. doi: 10.1080/08858190209528804.

19. Allison $P$, Franco $E$, Feine J. Predictors of professional diagnostic delays for upper aerodigestive tract carcinoma. Oral Oncol. 1998;34(2):127-32.

20. Warnakulasuriya KA, Johnson NW. Dentists and oral cancer prevention in the UK: opinions, attitudes and practices to screening for mucosal lesions and to counselling patients on tobacco and alcohol use: baseline data from 1991. Oral Dis. 1999;5(1):10-4.

21. Brouha XD, Tromp DM, Hordijk GJ, Winnubst JA, de Leeuw JR. Oral and pharyngeal cancer: analysis of patient delay at different tumor stages. Head Neck. 2005;27(11):939-45.

22. Andersen BL, Cacioppo JT. Delay in seeking a cancer diagnosis: delay stages and psychophysiological comparison processes. Br J Soc Psychol. 1995;34 ( Pt 1):33-52.

23. Grant E, Silver K, Bauld L, Day R, Warnakulasuriya S. The experiences of young oral cancer patients in Scotland: symptom recognition and delays in seeking professional help. Bdj. 2010;208:465. doi: 10.1038/sj.bdj.2010.450.

24. Subramanian S, Sankaranarayanan R, Bapat B, Somanathan T, Thomas G, Mathew B, et al. Costeffectiveness of oral cancer screening: results from a cluster randomized controlled trial in India. Bull World Health Organ. 2009;87(3):200-6.

25. Bala MM, Strzeszynski L, Topor-Madry R, Cahill K. Mass media interventions for smoking cessation in adults. Cochrane Database Syst Rev. 2013(6):Cd004704.

26. Jha P, MacLennan M, Chaloupka FJ, Yurekli A, Ramasundarahettige $C$, Palipudi K, et al. Global hazards of tobacco and the benefits of smoking cessation and tobacco taxes. In: Gelband $\mathrm{H}$, Jha P, Sankaranarayanan R, Horton S, editors. Cancer: Disease Control Priorities [Internet]. 3rd ed (Volume 3). Washington (DC): The International Bank for Reconstruction and Development/ The World Bank; 2015 [cited 2019 Apr 1]. Available from: https://www.ncbi.nlm.nih.gov/books/ NBK343639/

27. Jan JC, Hsu WH, Liu SA, Wong YK, Poon CK, Jiang RS, et al. Prognostic factors in patients with buccal squamous cell carcinoma: 10-year experience. J Oral Maxillofac Surg. 2011;69(2):396-404.

28. Ling W, Mijiti A, Moming A. Survival pattern and prognostic factors of patients with squamous cell carcinoma of the tongue: a retrospective analysis of 210 cases. J Oral Maxillofac Surg. 2013;71(4):775-85.

29. Services UDoHaH. Healthy People 2010. 2nd ed Washington, DC: US Government Printing Office. 2000; November(2).

30. Tong A, Sainsbury P, Craig J. Consolidated criteria for reporting qualitative research (COREQ): a 32-item checklist for interviews and focus groups. Int J Qual Health Care. 2007;19(6):349-57. 
31. Clovis JB, Horowitz AM, Poel DH. Oral and pharyngeal cancer: practices and opinions of dentists in British Columbia and Nova Scotia. J Can Dent Assoc. 2002;68(7):421-5.

32. Kujan O, Alzoghaibi I, Azzeghaiby S, Altamimi MA, Tarakji B, Hanouneh S, et al. Knowledge and attitudes of Saudi dental undergraduates on oral cancer. J Cancer Educ. 2014;29(4):735-8.

33. Maybury C, Horowitz AM, Goodman HS. Outcomes of oral cancer early detection and prevention statewide model in Maryland. J Public Health Dent. 2012;72 Suppl 1:S34-8.

34. Decuseara G, MacCarthy D, Menezes G. Oral cancer: knowledge, practices and opinions of dentists in Ireland. J Ir Dent Assoc. 2011;57(4):209-14.

35. Haresaku S, Makino M, Sugiyama S, Naito T, Marino RJ. Comparison of practices, knowledge, confidence, and attitude toward oral cancer among oral health professionals between Japan and Australia. J Cancer Educ. 2018;33(2):429-35.

36. Ajzen I. The theory of planned behavior. Organ Behav Hum Decis Process. 1991;50(2):179-211.

37. Hedayati $\mathrm{H}$, Marjadi $\mathrm{B}$, Askarian M. Barriers to standard precautions adherence in a dental school in Iran: a qualitative study. Am J Infect Control. 2014;42(7):750-4.

38. Sanders AE, Lushington $\mathrm{K}$. Effect of perceived stress on student performance in dental school. J Dent Educ. 2002;66(1):75-81.

39. Elani HW, Allison PJ, Kumar RA, Mancini L, Lambrou A, Bedos C. A systematic review of stress in dental students. J Dent Educ. 2014;78(2):226-42.

40. Fishbein M, Ajzen I. Predicting and changing Behavior: The Reasoned Action Approach. New York: Psychology Press; 2011.

41. Almutairi KM. Culture and language differences as a barrier to provision of quality care by the health workforce in Saudi Arabia. Saudi Med J. 2015;36(4):425-31.

42. Warnakulasuriya S. Global epidemiology of oral and oropharyngeal cancer. Oral Oncol. 2009;45(4-5):309-16. 


\section{Appendix 1}

Clinicians' Focus Group Guide (English translation)

\section{Questions:}

1) Do you think that oral cancer is an issue in Jazan?

- If yes, how /why? How serious is the problem?

- If no: why?

2) What do you think about oral cancer examination/screening?

- In your opinion, do you think it is useful?

- If yes, how /why?

- If no: why?

3) What do you see as advantages of performing an oral cancer examination/ screening?

4) What do you see as barriers for performing an oral cancer examination/ screening?

- Do you think you can do anything about it?

5) Do you think that there are clear guidelines/regulations in Jazan Dental School clinics for oral cancer examination/screening?

- If yes: do you think it is followed? If not: why?

- If no: why?

6) What do you feel toward performing an oral cancer examination/screening for your patients in the dental clinic?

- Do you think that you are comfortable doing an oral cancer clinical examination/screening?

- If not: why?

7) In your opinion, what do you think about oral cancer training in your education?

- How do you feel about the theoretical part of your education?

- How do you feel about the practical/clinical part of your education?

- What do you think should be done to improve/strengthen the curriculum?

- How could you contribute to improving/strengthening the overall experience of oral cancer clinical examination/screening?

8) In your opinion, what do you think of dentists educating their patients about oral cancers and their risk factors in clinics?

- In your opinion, do you think it is useful?

- If yes, how /why?

- If no: why? 
9) In your opinion, certain risk factors for oral cancer, such as alcohol and oral sex, could be discussed with the patient.

- If yes: is there any male/female differences and how you deal with it?

- If no: why?

10) Do you have anything that you would like to add? 


\section{Appendix 2}

Dental Students and Interns Focus Group Guide (English translation)

\section{Questions:}

1) What do you feel about performing an oral cancer examination/screening for your patients in the dental clinic?

- Do you think that you are comfortable doing an oral cancer clinical examination/screening?

- If not: why?

2) In your opinion, what do you think about oral cancer training in your education?

- How do you feel about the theoretical part of your education?

- How do you feel about the practical/clinical part of your education?

- What do you think should be done to improve/strengthen the curriculum?

- How could you contribute to improve/strengthen the overall experience of oral cancer clinical examinations/screening?

3) Do you think that there are clear guidelines/regulations in Jazan Dental School clinics for oral cancer examinations/screening?

- If yes: do you think it is followed? If not: why?

- If no: why? In your opinion, certain risk factors of oral cancer such as alcohol and oral sex could be discussed with the patient.

- If yes: is there any male/female differences and how do you deal with it?

- If no: why?

4) What do you see as barriers for performing an oral cancer examination/ screening?

- Do you think you can do anything about it?

5) In your opinion, what do you think of dentists educating their patients about oral cancers and their risk factors in clinics?

- In your opinion, do you think it is useful?

- If yes, how /why?

6) Do you have anything that you would like to add? 
CHAPTER 4 


\section{Dentists Behavioral Factors Influencing Early Detection of Oral Cancer: Direct Clinical Observational Study}




\section{Abstract}

\section{Background}

Oral cancer is a fatal disease that is usually detected in its late stage. Dentist could help in the early detection of oral cancer by performing full clinical examinations, including oral cancer screening for patients. This study aimed to investigate the possible factors affecting dentists' behavior relating to performing oral cancer examinations as part of routine clinical examination.

\section{Methods}

A total of 95 direct clinical observation sessions - utilizing an instrument consisting of 19 evidence-based observational-criteria for oral cancer examinations - were observed by four calibrated dentists. Thirty-two final year students, 32 interns, and 31 faculty members of Jazan Dental School were examined in the study. A descriptive analysis was conducted to investigate the frequencies/percentages of the performed observing-criteria by all examiners. ANOVA and Tukey tests were carried out to investigate the difference between the examiner groups.

\section{Results}

A total number of 32 patients participated in the study, whereby each patient was examined by three different examiners from each group, as well as by the attending observer/s. Fewer than $50 \%$ of the examiners performed the clinical steps necessary for an oral cancer examination - for example, taking into account past medical history, as well as extra and intra oral examinations. More than $90 \%$ of the examiners examined hard tissue, whereas fewer than $30 \%$ of them educated their patients about possible risk factors. A significant difference between examiner groups was found in favor of faculty members.

\section{Conclusion}

A gap between knowledge and actual practice of oral cancer examinations was evident: the majority of participants failed to perform the necessary steps for an oral cancer examination. Previous experience and confidence in performing oral cancer examination are possible explanations for the dentist's behavior towards oral cancer examination.

\section{Keywords:}

Early Detection; Oral Cavity Cancer; Oral Health; Behavior; Clinical Practice; Determinants; Preventive Dentistry 


\section{Introduction}

Global incidences of oral cancer are still rising, with South Asian countries having the highest incidence rates [1]. In Saudi Arabia, oral cancer - mainly squamous cell carcinoma - is among the most frequently occurring cancers in terms of incidence rates. Most reported cases came from the Jazan region of Saudi Arabia [2, 3]. Several possible factors could put people at a significantly higher risk of contracting oral cancer: using tobacco, in particular the smokeless form of it, and heavy alcohol usage [4-7]. Evidence on systematic disease association with oral cancer is not yet conclusive, except for diabetes, autoimmune diseases and a few separate syndromes. [8-10]. Moreover, infectious disease association with oral cancer is a foregone conclusion [11-16]. Evidence showed a weak association between dermatological conditions and oral cancer; nevertheless, it commonly manifests itself among patients with dermatological diseases [17]. Furthermore, the risk of oral cancer increases tremendously when a first-degree relative has a history of oral cancer $[18,19]$.

Most oral cancer cases are detected at a late stage when the tumor has already metastasized to another location in the body [20]. Several studies endorse the fact that the early detection of oral cancer leads to a better prognosis for the disease and better survival rates, and this can be achieved through routine dental clinical examinations [21-24]. An insufficient examination contributes to a delay in the detection of oral cancer, which hampers the prognosis of the disease and greatly affects the five-year survival rate of oral cancer patients [25]. Factors that might influence dentists' behavior in terms of practicing routine oral cancer examinations are not fully understood [26]. Possible determinants of the dentists' behavior can be abstracted individually from previous published work for example: dentists' knowledge [27], awareness [28], perceptions [29], experience [27], limited clinical examination time [30], and focusing on previously examined conditions [31]. Moreover, some dentists reported that they did not perform oral cancer examinations because they were worried about their patients' reaction toward oral cancer examinations [32]. Therefore, the present study investigates possible explanations for dentists' behavior by directly observing routine clinical dental examination sessions. 


\section{Methods}

The reporting of this present study followed the SRTOBE Statement for reporting crosssectional studies [33].

\section{Participants and procedure}

The aim is to investigate possible explanations for dentists' behavior in terms of performing oral cancer examinations as part of routine clinical dental examination sessions, as well as to investigate the current practice of oral cancer screening in Jazan University Dental School (JDS) clinics. The present study utilized a descriptive cross-sectional study design, in which direct clinical observation was carried out among final year dental students, interns and faculty members between April 9, 2017 and May 4, 2017. The main targets of this study were the dental interns who are the first line of treatment in JDS clinics and who oversee the completion of the primary dental charts of all new patients. The total number of interns was 40 at the time of planning this study. A personal invitation was sent to all the interns and an explanation of the study process was delivered to them in the form of two discussion sessions by the principle investigator (PI). To minimize effects on the behavior of clinicians under observation in dental examination sessions, the study and its process were explained to the participants without mentioning that the study would focus on the dental examinations and, in particular, oral cancer screening performance and the required related steps as a follow-up. We aimed to reduce the Hawthorne effect [34] (i.e., when the observer influences the examiners' behavior) by notifying the observers to remain unreactive while observing the sessions and to remain passive. All 32 interns who accepted the invitation to participate were informed later of their scheduled appointment to examine a patient in a designated clinic that was booked for the study. Afterwards, finalyear dental students, and Arabic-speaking faculty members were invited to participate in the study, and later those who accepted received an explanation of the study and related aspects in the same aforementioned process for interns. Four faculty members (dentists) from JDS were the observers in the dental examination sessions; three of whom are also authors of this study, with one acting as the main observer. The rule for the observer was to observe the examiner's practice and to subsequently mark the performed action in regard to the checklist items.

To ensure the study was conducted as a form of routine dental examination at JDS clinics, it was decided that all the study's clinical examinations would be conducted on new dental patients from the waiting list of JDS clinics. To compare between the three different groups of clinicians, dental-students, interns and faculty members, it was decided that each patient would be examined by a dental student, intern and a faculty member, as well as observer. Therefore, to reach the target number of 32 new patients who are willing to participate and be examined by three clinicians and available observer/s, around 93 patients were contacted and invited over the phone by the principal investigator from the 
JDS clinics' patient relation office. This process was repeated later to invite nine more new patients to replace the five patients who did not show up to their appointment and four patients who refused to be examined by all three examiners.

\section{Measurement and pretesting}

An instrument for the observation of oral cancer screening practice in form of checklist was developed and was based on the current available evidence relating to the recommended practice of oral cancer screening. The observation instrument included the most appropriate clinical steps to be taken during comprehensive clinical examinations of dental patients [35, 36], as well as the risk factors of oral cancer [37-39]. At first, the instrument consisted of 32 items in the form of a checklist, with two labeled boxes for the options 'done' and 'not done'. However, 15 items [11 to 25] were condensed to 6 items [11 to 16] after reaching a consensus from four oral cancer consultants, who evaluated the proposed observational instrument, to be able to fully reflect on the examiners performance of the targeted screening steps. Both checklists are available at $<$ https://osf. io/4v9gr/>. Therefore, the utilized observational instrument in the present study finally consisted of a 19-item checklist, with the first 17 items relating to the essential steps of routine oral cancer screening, and the last two items were for when further diagnostic/ evaluation step(s) were required. Items 1-10 related to reporting the patient's general health, family history of cancer, habits and diet. Items 11-16 related to the performance by the examiner of different steps for the head, neck and oral examination. Item 17 was for obtaining a plan radiograph, and items 18 and 19 were for conditions when further evaluation was necessary to diagnose potential positive oral cancer cases. Each item was given a weight of one, two or three, based on the degree of significance and relevance as supported by current evidence [4-19, 39-60], with one standing for items of the least significance and three for items of the most significance. Please see table 1 for more detailed information on each of the items with the designated weight and supportive evidence. The sum of the performed item weights from the checklist was used as the main outcome of the study. 


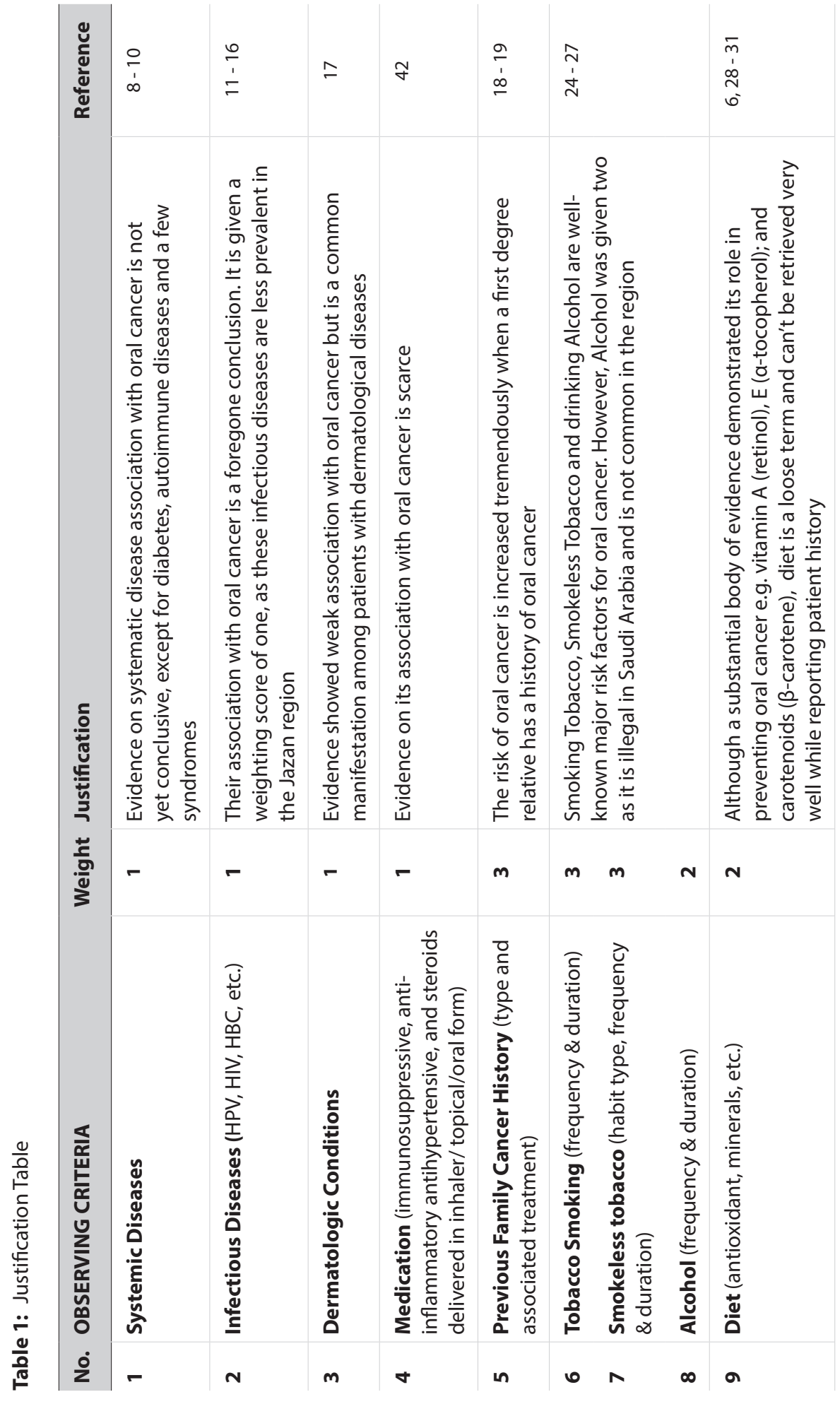




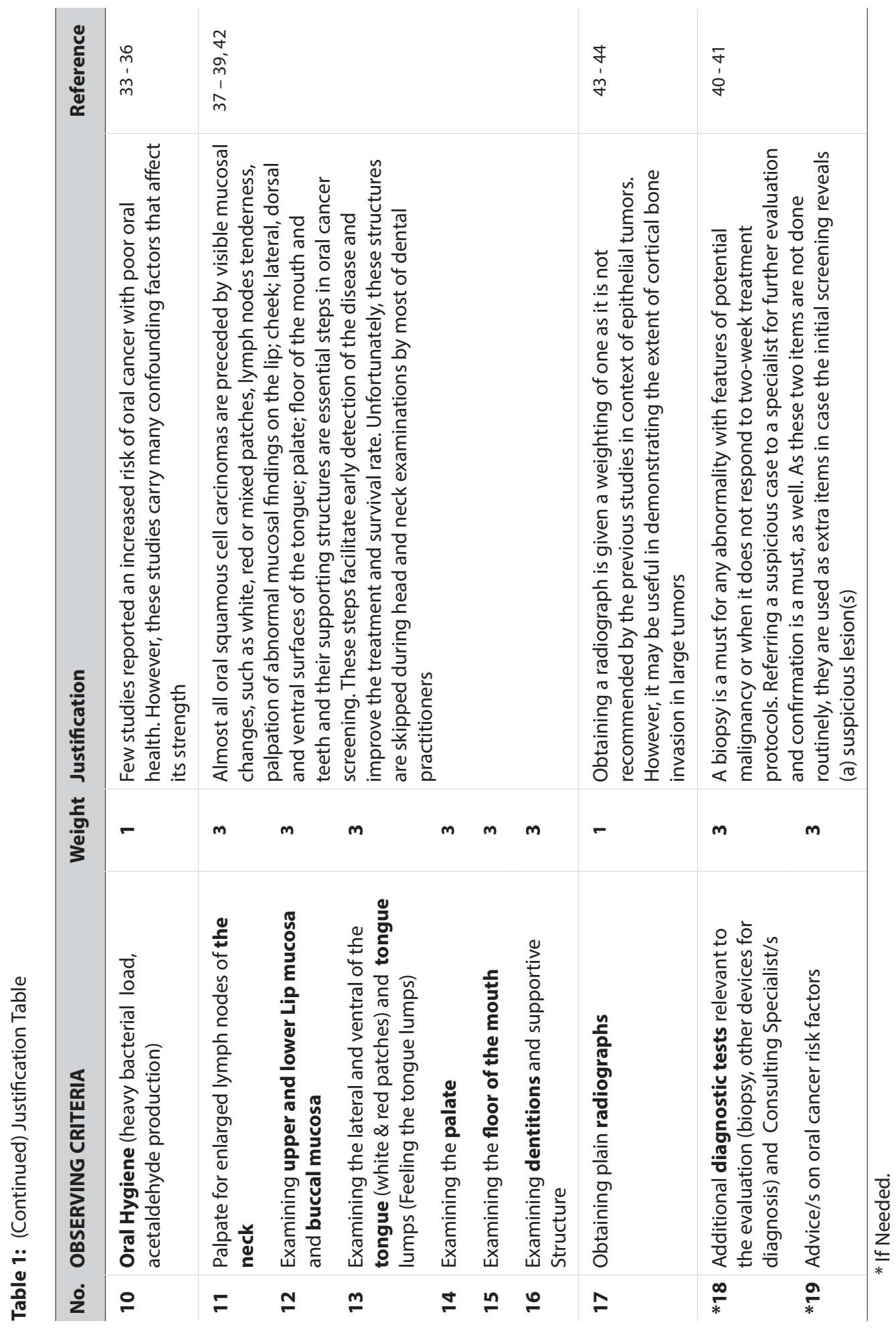




\section{Data Collection}

Prior to the initiation of the present study, a thorough discussion session including observers and the PI was conducted to acquaint all with the observational instrument and the logistics of the study. Afterwards, two hands-on clinical training sessions were provided with two volunteers, who acted as the patient and the examiner to facilitate the training sessions. This was also to provide the observers with experience in handling the checklist while also carefully observing the examiner performing the clinical examination as well as patients' responses. A feedback discussion session for observers, which included the PI, was conducted after the two training sessions to reflect on the experience, as well as to discuss and reach a consensus regarding the appropriate approach for handling the observational sessions and checklist. Then, for the internal validity testing of the observational instrument, eight dental examination sessions - which included eight volunteer patients and eight volunteer dentists - were overseen by all observers, whereby interrater reliability was investigated using an interclass correlation coefficient test that showed significant consistency; $\mathrm{p}<.000$. Prior to the present study's dental examination sessions, each participating patient was first examined by the observer/s who then observed the clinicians' dental examination sessions. All 95 dental examination sessions were observed by the main observer and mentored by the PI. In addition, 18 of these sessions were observed by all the observers, while others were overseen by two or three observers; see table 4.

\section{Data Analysis}

Descriptive analyses were run to investigate the participants' demographics, as well as the frequency of the individual performance items in the observational checklist by the main observer. Furthermore, paired t-tests and correlation tests were run to investigate any relationships between the main observer's findings and other observers' findings. Later, using total score by the main observer and mean total score by all observers, independent t-tests were run to investigate any differences between examiners' genders as well as patients' gender. Similarly, ANOVA were run to investigate any differences between examiners' occupations (final-year dental students, interns and faculty members) with Tukey's HDS comparison between each occupation category. Additionally, Pearson's correlations were run to investigate any correlation between patient age and total score by the main observer and mean total score by all observers.

\section{Ethical Approval}

The present study was performed according to the ethical standards of the institutional research committee, as well as the 1964 Helsinki Declaration. It received ethical approval from Jazan University; Registry no. [CDREC-06], dated 21 December 2016. All participants have consented prior to their participation, including with regard to the publication of the findings. 


\section{Result}

The total number of participating examiners was 95, with almost equal distribution of gender and occupation (final-year dental students, interns and faculty members). The total number of participating patients was 32, with an ages ranging between 19 and 70 years old and with $62.5 \%$ males; see table 2 .

Table 2: Demographics of Participants

\begin{tabular}{|c|c|c|c|c|c|}
\hline & $* \mathbf{n}$ & Frequency & $\%$ & M & SD \\
\hline Examiner & 95 & & & & \\
\hline \multicolumn{6}{|l|}{ Sex } \\
\hline Male & & 48 & 50.5 & & \\
\hline Student & & 16 & 33.3 & & \\
\hline Intern & & 16 & 33.3 & & \\
\hline Faculty member & & 16 & 33.3 & & \\
\hline Female & & 47 & 49.5 & & \\
\hline Student & & 16 & 34 & & \\
\hline Intern & & 16 & 34 & & \\
\hline Faculty member & & 15 & 31.9 & & \\
\hline Patients & $* * 32$ & & & & \\
\hline Age & & & & $\begin{array}{c}38.6 \\
\text { (Range: } 19-70)\end{array}$ & 14.4 \\
\hline \multicolumn{6}{|l|}{ Sex } \\
\hline Male & & 20 & 62.5 & & \\
\hline Female & & 12 & 37.5 & & \\
\hline
\end{tabular}

Table 3 shows the frequency of the observed items by the main observer; $70 \%$ of examiners investigated the systemic diseases of their patients, while fewer than $30 \%$ of examiners investigated their patients' tobacco use and their oral hygiene practices. Moreover, $90 \%$ of the examiners checked their patients' dentations, while fewer than $50 \%$ of them examined their patients for enlarged lymph nodes of the neck, lip, check, tongue, palate and floor of the mouth. Furthermore, among the participating patients, three had suspected lesions that required further investigation, and 14 required advice regarding oral cancer risk factors, according to the main observer. However, among participating examiners, only three female final-year dental students out of nine examiners had requested specialist consultations, as well as only 11 examiners out of 42 providing advice to the patients who needed it; see table 3. 


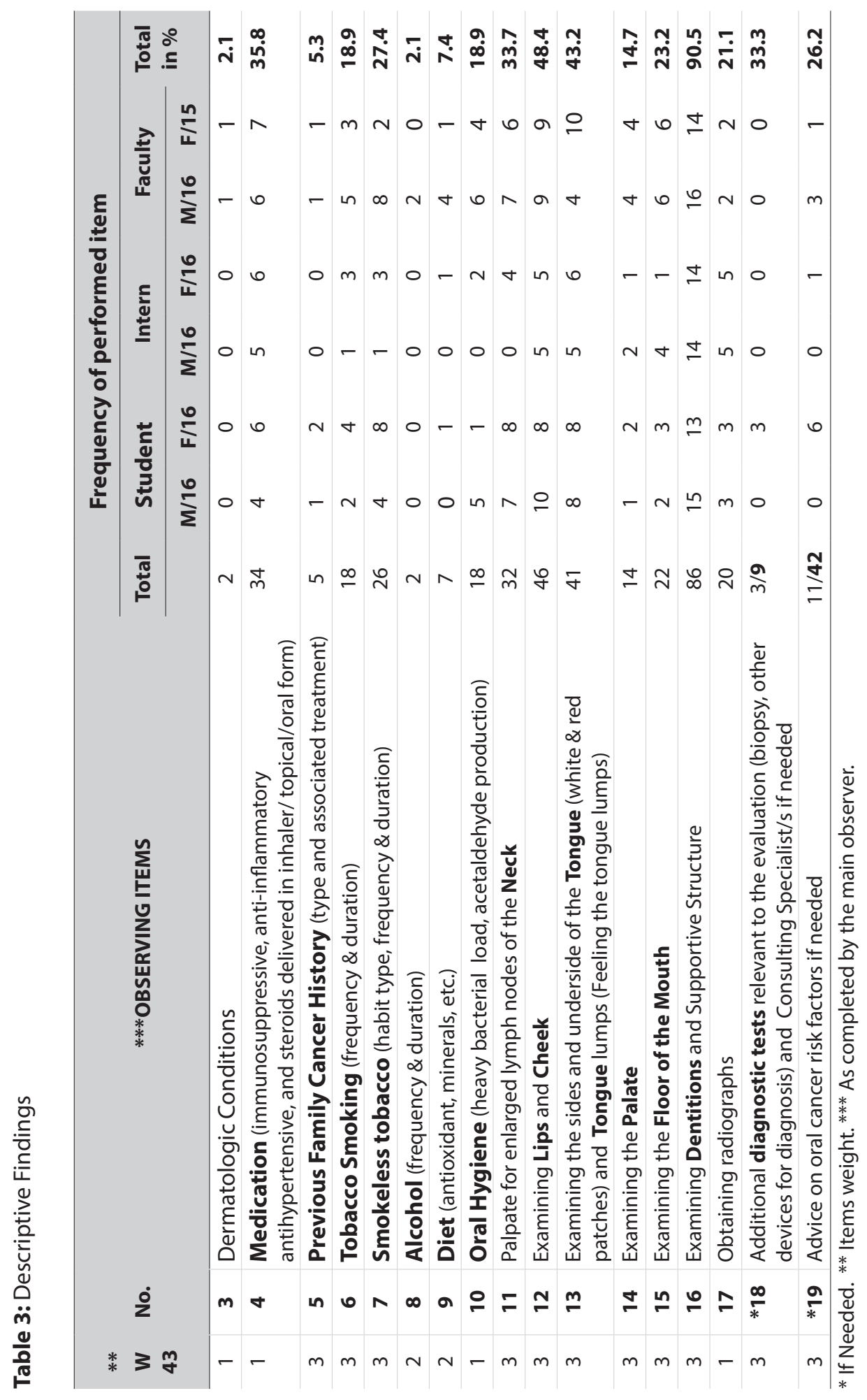


There were statistically significant correlations between the main observer and other observers, with the strongest correlation $(r=.804)$ between the main observer and the second observer; see table 4. Moreover, no statistically significant differences were found between the main observer and other observers (second observer $p=.561$ and fourth observer $p=.062)$, except for with the third observer $(p=.018)$; see table 4 . Furthermore, there were no statistically significant differences between all 95 examiners based on their sex. However, there were statistically significant differences based on the examiners based on occupation; see table 5. These statistically significant differences were found between faculty members and interns, using both total score by the main observer and total mean score by all observers ( $p=.007$ and $p=.030$, respectively), and between faculty members and students using the total mean score by all observers $(p=.049)$; see table 6 . On the other hand, there were no statistically significant differences found between examiners based on the patients' age or sex; see table 7.

Table 4: Paired t-tests and correlation tests between observers $\left(\mathrm{N}=95^{*}\right)$

$2^{\text {nd }}$ observer

Main observer

$1 \mathrm{M}=34.9, \mathrm{SD}=20.9$

$3 \mathrm{M}=36.3, \mathrm{SD}=20.9$

$M=-1.4, S D=12.9$

$95 \% \mathrm{Cl}$ for difference

$[-6.326-3.505]$

$\mathrm{t}(28)=-.588$

$\mathrm{p}=.561$

$d=0.067$

$r=.804$

$\mathrm{p}=.000$

\section{$3^{\text {rd }}$ observer}

$\mathrm{n}=38$

$1 \mathrm{M}=34.3, \mathrm{SD}=20.3$

$2 \mathrm{M}=28, \mathrm{SD}=15$

$M=6.3, S D=15.5$

95\% $\mathrm{Cl}$ for difference

[1.144-11.361]

$\mathrm{t}(37)=2.48$

$\mathrm{p}=.018$

$d=0.353$

$r=.649$

$\mathrm{p}=.000$

\section{$4^{\text {th }}$ observer}

$\mathrm{n}=18$

$1 \mathrm{M}=33.5, \mathrm{SD}=21.6$

$4 \mathrm{M}=25.2, \mathrm{SD}=13$

$M=8.2, S D=17.5$

95\% $\mathrm{Cl}$ for difference

[-.458 - 16.935]

$\mathrm{t}(17)=1.999$

$\mathrm{p}=.062$

$d=0.466$

$r=.588$

$\mathrm{p}=.010$

\footnotetext{
* number of clinical dental examination sessions, as observed by the main observer
} 
Table 5: Independent t-tests and ANOVA Tests for Examiners $\left(\mathrm{N}=95^{*}\right)$

\begin{tabular}{|c|c|c|c|c|}
\hline & * Sex & ${ }^{\circ}$ Sex & * Occupation & ${ }^{\circ}$ Occupation \\
\hline \multirow[t]{7}{*}{ Total Score } & ${ }^{2} \mathrm{M}=29.9, \mathrm{SD}=20.4$ & ${ }^{7} \mathrm{M}=28.3, \mathrm{SD}=17.3$ & $F=4.977$ & $F=4.145$ \\
\hline & $\phi M=30.2, S D=14.9$ & $+M=29.9, S D=14.0$ & $p=.009$ & $p=.019$ \\
\hline & $95 \% \mathrm{Cl}$ for difference & $95 \% \mathrm{Cl}$ for difference & $\eta_{p}^{2}=0.098$ & $\eta_{p}^{2}=0.083$ \\
\hline & {$[-7.602-6.987]$} & {$[-8.134-4.707]$} & & \\
\hline & $t(93)=-.084$ & $t(93)=-.531$ & & \\
\hline & $p=.933$ & $p=.597$ & & \\
\hline & $d=0.017$ & $d=0.102$ & & \\
\hline
\end{tabular}

* number of participated examiners as observed by the main observer

'using mean total scores by all observers

Table 6: ANOVA Comparisons of Examiners $\left(\mathrm{N}=95^{*}\right)$

\begin{tabular}{|c|c|c|c|c|c|}
\hline \multirow[b]{2}{*}{ Group } & & \multirow[b]{2}{*}{ Mean } & \multirow[b]{2}{*}{ SD } & \multicolumn{2}{|c|}{$\begin{array}{c}\text { Tukey's HSD } \\
\text { Comparisons ( } p \text {-values) }\end{array}$} \\
\hline & & & & Student & Inter \\
\hline \multirow[t]{2}{*}{ Intern } & Main observer & -8.68 & 4.27 & .111 & \\
\hline & All observers & -9.07 & 3.79 & .049 & \\
\hline \multirow[t]{2}{*}{ Faculty member } & Main observer & 4.69 & 4.31 & .522 & \\
\hline & All observers & .81 & 3.83 & .976 & \\
\hline \multirow[t]{2}{*}{ Faculty member } & Main observer & 13.37 & 4.31 & & .007 \\
\hline & All observers & 9.88 & 3.83 & & .030 \\
\hline
\end{tabular}

\#p-value

Table 7: Independent t-tests and Person correlation tests for Examiners based on Patients (P) (N=95*)

\begin{tabular}{|c|c|c|c|c|}
\hline & * P Sex & ${ }^{\circ}$ P Sex & * P Age & ${ }^{\circ}$ P Age \\
\hline \multirow[t]{7}{*}{ Total Score } & ${ }^{7} \mathrm{M}=31.6, \mathrm{SD}=17.9$ & ${ }^{2} \mathrm{M}=30.2, \mathrm{SD}=14.5$ & $r=.073$ & $r=.058$ \\
\hline & $\Phi \mathrm{M}=27.4, \mathrm{SD}=17.7$ & $+\mathrm{M}=27.3, \mathrm{SD}=17.6$ & $p=.482$ & $p=.577$ \\
\hline & 95\% Cl for difference & 95\% Cl for difference & & \\
\hline & {$[-3.312-11.631]$} & {$[-4.054-9.866]$} & & \\
\hline & $t(74.8)=1.109$ & $t(63.4)=-.834$ & & \\
\hline & $\mathrm{p}=.271$ & $p=.407$ & & \\
\hline & $d=0.236$ & $d=0.205$ & & \\
\hline
\end{tabular}

* the number of participating patients was 32; however, 95 was the total number of clinical dental examinations, as observed by the main observer

using mean total scores by all observers 


\section{Discussion}

The present study investigated possible explanations for dentists' behavior by means of direct observations of routine dental clinical examination sessions. In a previous study, oral cancer knowledge of the targeted population was found to be adequate [61]. In addition, favorable perceptions among dentists toward oral cancer practices was found regardless of the reaction of patients [32]. However, the experience and the confidence to perform oral cancer examinations and educate patients on risk factors was found to be limited to dentists specialized in fields related to oral cancer [32]. The factors relating to time constraints and previously-examined conditions were controlled for in this study, as no time restriction was placed on dental examination sessions and all were carried on new patients.

The overall findings of the study indicated that the examiners performed the clinical steps with which they had more experience and higher confidence, in terms of performing and understanding the potential treatment modalities and outcomes. The majority of them examined the dentations of their patients and asked for patients' systemic diseases, which could be necessary for their usual practice. However, fewer than half of the examiners performed other extra- and intra-oral examination steps and less than one third of them investigated their patients' potential risk factors for oral cancer. This is also supported by the statistically significant difference favoring the faculty members' group, as they have a higher level of experience and are confident in performing oral cancer examinations.

The knowledge of oral cancer among dentists has been investigated thoroughly in previous studies and postulated to be related to dentists' practice of oral cancer examinations [2729, 62]. However, knowledge (or lack thereof) alone is not enough to explain, for example, why dentists are not performing oral cancer examinations in their routine practice. According to behavior-change theories, such as the Reasoned Action Approach, the Social Cognitive Theory and the I-Change Model, knowledge only has a distal influence on the individual's behavior and its effect is often limited when trying to explain complex behaviors; such as in our case: dentists' practice of oral cancer examinations [63-65]. This is in line with the findings of this study, as most participants failed to perform oral cancer examinations even though they had adequate knowledge of oral cancer $[61,66,67]$. This observation has highlighted the important role of dentists having actual control over their practice of oral cancer examination.

Dentists have actual control over their practice of oral cancer examinations when they demonstrate their ability to perform the following essential sub-behaviors: extra- and intra-oral screening skills, obtaining radiographs, taking a biopsy, writing referral reports, specialist consultations, communicating with or counselling patients (e.g., smokeless 
tobacco users), specifying an oral cancer provisional treatment plan (treatment modalities, outcome), as well as referring suspicious cases to specialized centers (Table 1). Additionally, the lack of these basic sub-behaviors can adversely affect dentists' practice of oral cancer examination, either directly or indirectly via self-efficacy. As described in the Social Cognitive Theory by Albert Bandura, an individual's confidence in his capability to produce the desired effect through his actions constitutes a core belief that operates via its impacts on various processes - both cognitive and affective [64]. Among the four main sources that enhance self-efficacy, the individual's experience (mastery and vicarious/modeling) is recognized as creating and strengthening a stronger sense of self-efficacy. This suggests that a dentist's efficacy can be influenced by his own experience in practicing oral cancer examinations. In addition, observing other dentists succeeding at practicing oral cancer examinations is able to reinforce the observing dentist's belief in his own capability to master comparable actions required to succeed. Hence, dentists' practice of oral cancer examinations could be greatly influenced by their previous experience and confidence in their ability to perform oral cancer examinations $[63,64]$.

Direct clinical observation methods strengthen this study by capturing the clinical steps that dentists may or may not have performed, which leads to a better understanding of the behavior's potential causes. Due to the cross-sectional nature of this study, the findings need to be tested through an experimental study design, in order to measure the effect of experience, skills, and self-efficacy on dentists' behavior. Furthermore, having a main observer present, who observed all dental clinical examination sessions, added to the reliability of the comparison between different examiners. Similarly, having four observers to compare findings with added to the internal validity of this study. Moreover, the observational instrument that was developed for the study had not been tested in previous independent work. However, the findings of this study indicated that the developed instrument had the capacity to investigate oral cancer examinations as part of routine dental clinical examinations. All observers had strong statistical correlations, with no statistical difference being found between the three of them.

In conclusion, the behavior of dentists in regard to performing oral cancer examinations and educating patients, as part of their routine clinical dental sessions, is influenced by several factors. These factors could be of internal or external sources and should be made clear to dentists and dental educational organizations. The present study has shed light on the gap that existed between knowledge and actual practice of oral cancer examinations by dentists. The fact that the majority of study's participants failed to perform oral cancer examinations is alarming and requires immediate attention, as this behavior might negatively influence the early detection of oral cancer in a region identified as having a high level of oral cancer incidence. 


\section{Implications for practice}

The existing gap between knowledge and practice of oral cancer examinations was observed among the participants. Experience and confidence are essential determinants for performing oral cancer examinations and educating patients on the risks. Future interventions that intend to improve the practice of oral cancer examinations as part of routine dental clinical examination sessions should stress these determinants.

The practice of oral cancer examinations is a complex behavior that is influenced by multiple factors: oral cancer knowledge, perceptions, experience, self-efficacy, actual control, and other external factors such as the afforded clinic time per patient. Therefore, dental schools and decision-makers should be made aware of the influence these factors can exert on the practice of dentists in regard to oral cancer examinations. 


\section{References}

1. Warnakulasuriya S. Global epidemiology of oral and oropharyngeal cancer. Oral Oncol. 2009;45(4-5):309-16. doi: 10.1016/j.oraloncology.2008.06.002.

2. Saudi Cancer Registry. Saudi Arabia cancer incidence report 2012 [document on the Internet]. Riyadh, Saudi Arabia: Saudi Cancer Registry; 2015 [cited 2018 Apr 1]. Available from: http:// ghdx.healthdata.org/organizations/saudi-cancer-registry

3. Allard WF, DeVol EB, Te OB. Smokeless tobacco (Shamma) and oral cancer in Saudi Arabia. Community Dent Oral Epidemiol. 1999;27(6):398-405.

4. Madani AH, Dikshit M, Bhaduri D, Aghamolaei T, Moosavy SH, Azarpaykan A. Interaction of alcohol use and specific types of smoking on the development of oral cancer. Int J High Risk Behav Addict. 2014;3(1):e12120-e.

5. Petti S, Masood M, Scully C. The magnitude of tobacco smoking-betel quid chewing-alcohol drinking interaction effect on oral cancer in South-East Asia. A meta-analysis of observational studies. PloS one. 2013;8(11):e78999-e.

6. Ferreira Antunes JL, Toporcov TN, Biazevic MG, Boing AF, Scully C, Petti S. Joint and independent effects of alcohol drinking and tobacco smoking on oral cancer: a large case-control study. PLoS One. 2013;8(7):e68132.

7. Radoi L, Paget-Bailly S, Cyr D, Papadopoulos A, Guida F, Schmaus A, et al. Tobacco smoking, alcohol drinking and risk of oral cavity cancer by subsite: results of a French population-based case-control study, the ICARE study. Eur J Cancer Prev. 2013;22(3):268-76.

8. Gong Y, Wei B, Yu L, Pan W. Type 2 diabetes mellitus and risk of oral cancer and precancerous lesions: a meta-analysis of observational studies. Oral Oncol. 2015;51(4):332-40.

9. Goutzanis L, Vairaktaris E, Yapijakis C, Kavantzas N, Nkenke E, Derka S, et al. Diabetes may increase risk for oral cancer through the insulin receptor substrate-1 and focal adhesion kinase pathway. Oral Oncol. 2007;43(2):165-73.

10. Tseng CH. Oral cancer in Taiwan: is diabetes a risk factor? Clin Oral Investig. 2013;17(5):1357-64.

11. Burbelo PD, Kovacs JA, Wagner J, Bayat A, Rhodes CS, De Souza Y, et al. The Cancer-Associated Virus Landscape in HIV Patients with Oral Hairy Leukoplakia, Kaposi's Sarcoma, and NonHodgkin Lymphoma. AIDS Res Treat. 2012;2012:10.

12. Mohammed S, Sinha M, Chavan P, Premalata C, Shivaprakash M, Chakrabarti A, et al. Oral histoplasmosis masquerading as oral cancer in HIV-infected patient: A case report. Med Mycol Case Rep. 2012;1(1):85-7.

13. Silverman S, Jr. Oral cancer education and HIV-associated malignancies. J Cancer Educ. 1994;9(3):152-4.

14. Nohata N, Abba MC, Gutkind JS. Unraveling the oral cancer IncRNAome: Identification of novel IncRNAs associated with malignant progression and HPV infection. Oral Oncol. 2016;59:58-66.

15. Tsao AS, Papadimitrakopoulou V, Lin H, Guo M, Lee JJ, Holsinger FC, et al. Concordance of oral HPV prevalence between patients with oropharyngeal cancer and their partners. Infect Agent Cancer. 2016;11:21. 
16. Dediol E, Sabol I, Virag M, Grce M, Muller D, Manojlovic S. HPV prevalence and p16INKa overexpression in non-smoking non-drinking oral cavity cancer patients. Oral Dis. 2016;22(6):517-22.

17. Babu RA, Chandrashekar P, Kumar KK, Reddy GS, Chandra KL, Rao V, et al. A study on oral mucosal lesions in 3500 patients with dermatological diseases in South India. Ann Med Health Sci Res. 2014;4(Suppl 2):S84-93.

18. Radoï L, Paget-Bailly S, Guida F, Cyr D, Menvielle G, Schmaus A, et al. Family history of cancer, personal history of medical conditions and risk of oral cavity cancer in France: the ICARE study. BMC Cancer. 2013;13(1):560.

19. Garavello W, Foschi R, Talamini R, La Vecchia C, Rossi M, Dal Maso L, et al. Family history and the risk of oral and pharyngeal cancer. Int J Cancer. 2008;122(8):1827-31.

20. Mashberg A, Samit A. Early diagnosis of asymptomatic oral and oropharyngeal squamous cancers. CA. 1995;45(6):328-51.

21. Epstein JB, Huber MA. The benefit and risk of screening for oral potentially malignant epithelial lesions and squamous cell carcinoma. Oral Surg Oral Med Oral Pathol Oral Radiol. 2015;120(5):537-40.

22. Monteiro LS, Amaral JB, Vizcaino JR, Lopes CA, Torres FO. A clinical-pathological and survival study of oral squamous cell carcinomas from a population of the North of Portugal. Med Oral Patol Oral Cir Bucal. 2014;19(2):e120-6.

23. Ling W, Mijiti A, Moming A. Survival pattern and prognostic factors of patients with squamous cell carcinoma of the tongue: a retrospective analysis of 210 cases. J Oral Maxillofac Surg. 2013;71(4):775-85.

24. Warnakulasuriya KA, Johnson NW. Dentists and oral cancer prevention in the UK: opinions, attitudes and practices to screening for mucosal lesions and to counselling patients on tobacco and alcohol use: baseline data from 1991. Oral Dis. 1999;5(1):10-4.

25. Morelatto RA, Herrera MC, Fernandez EN, Corball AG, Lopez de Blanc SA. Diagnostic delay of oral squamous cell carcinoma in two diagnosis centers in Cordoba Argentina. J Oral Pathol Med. 2007;36(7):405-8.

26. Service NRaL. Delayed Diagnosis of Cancer: Thematic Review. London: National Patient Safty Agency; 2010 March. Report No.: Ref: 0968 March 2010.

27. Guggenheimer J, Verbin RS, Johnson JT, Horkowitz CA, Myers EN. Factors delaying the diagnosis of oral and oropharyngeal carcinomas. Cancer. 1989;64(4):932-5.

28. Awan KH, Khang TW, Yee TK, Zain RB. Assessing oral cancer knowledge and awareness among Malaysian dental and medical students. J Cancer Res Ther. 2014;10(4):903-7.

29. Burzynski NJ, Rankin KV, Silverman S, Jr., Scheetz JP, Jones DL. Graduating dental students' perceptions of oral cancer education: results of an exit survey of seven dental schools. J Cancer Educ. 2002;17(2):83-4. doi: 10.1080/08858190209528804.

30. Laronde DM, Bottorff JL, Hislop TG, Poh CY, Currie B, Williams PM, et al. Voices from the community--experiences from the dental office: initiating oral cancer screening. J Can Dent Assoc. 2008;74(3):239-41. 
31. Allison P, Franco E, Feine J. Predictors of professional diagnostic delays for upper aerodigestive tract carcinoma. Oral Oncol. 1998;34(2):127-32.

32. Jafer M, Crutzen R, Moafa I, Van Den Borne B. What do dentists and dental-students think of oral cancer and its control and prevention strategies? A qualitative study in Jazan Dental School. Forthcoming 2019.

33. Von Elm E, Altman DG, Egger M, Pocock SJ, Gotzsche PC, Vandenbroucke JP. Strengthening the reporting of observational studies in epidemiology (STROBE) statement: guidelines for reporting observational studies. Ann Intern Med. 2007;147(8):573-7.

34. McCambridge J, Witton J, Elbourne DR. Systematic review of the Hawthorne effect: new concepts are needed to study research participation effects. J Clin Epidemiol. 2014;67(3):26777.

35. Clarke AK, Kobagi N, Yoon MN. Oral cancer screening practices of Canadian dental hygienists. Int J Dent Hyg. 2018;16(2):e38-e45.

36. Tax CL, Haslam SK, Brillant M, Doucette HJ, Cameron JE, Wade SE. Oral cancer screening: knowledge is not enough. Int J Dent Hyg. 2017;15(3):179-86.

37. Nowosielska-Grygiel J, Owczarek K, Bielinska M, Waclawek M, Olszewski J. Analysis of risk factors for oral cavity and oropharynx cancer in the authors' own material. Otolaryngol Pol. 2017;71(2):23-8.

38. Yakin M, Gavidi RO, Cox B, Rich A. Oral cancer risk factors in New Zealand. N Z Med J. 2017;130(1451):30-8.

39. Kumar M, Nanavati R, Modi TG, Dobariya C. Oral cancer: Etiology and risk factors: A review. J Cancer Res Ther. 2016;12(2):458-63.

40. Kulkarni DP, Wadia PP, Pradhan TN, Pathak AK, Chiplunkar SV. Mechanisms involved in the down-regulation of TCR zeta chain in tumor versus peripheral blood of oral cancer patients. Int J Cancer. 2009;124(7):1605-13.

41. Kim KH, Kim MC, Jung GJ. Gastric cancer occurring in a patient with Plummer-Vinson syndrome: a case report. World J Gastroenterol. 2005;11(44):7048-50.

42. Larsson LG, Sandstrom A, Westling P. Relationship of Plummer-Vinson disease to cancer of the upper alimentary tract in Sweden. Cancer Res.1975;35(11 Pt. 2):3308-16.

43. Velleuer E, Dietrich R, Frohnmayer A, Pomjanski N, E Hays L, Biesterfeld S. Prevalence and clinical significance of visible oral lesions in patients with Fanconi Anemia at risk for head and neck cancer. Curr Drug Targets. 2017.

44. Cannon TL, Lai DW, Hirsch D, Delacure M, Downey A, Kerr AR, et al. Squamous cell carcinoma of the oral cavity in nonsmoking women: a new and unusual complication of chemotherapy for recurrent ovarian cancer? Oncologist. 2012;17(12):1541-6.

45. Filomeno M, Bosetti C, Garavello W, Levi F, Galeone C, Negri E, et al. The role of a Mediterranean diet on the risk of oral and pharyngeal cancer. Br J Cancer. 2014;111(5):981-6.

46. Garavello W, Giordano L, Bosetti C, Talamini R, Negri E, Tavani A, et al. Diet diversity and the risk of oral and pharyngeal cancer. Eur J Clin Nutr. 2008;47(5):280-4. 
47. Tavani A, Gallus S, La Vecchia C, Talamini R, Barbone F, Herrero R, et al. Diet and risk of oral and pharyngeal cancer. An Italian case-control study. Eur J Cancer Prev. 2001;10(2):191-5.

48. Macfarlane GJ, Zheng T, Marshall JR, Boffetta P, Niu S, Brasure J, et al. Alcohol, tobacco, diet and the risk of oral cancer: a pooled analysis of three case-control studies. Eur J Cancer B Oral Oncol. 1995;31b(3):181-7.

49. Chen F, He BC, Yan LJ, Qiu Y, Lin LS, Cai L. Influence of oral hygiene and its interaction with standard of education on the risk of oral cancer in women who neither smoked nor drank alcohol: a hospital-based, case-control study. Br J Oral Maxillofac Surg. 2017;55(3):260-5.

50. Tsai ST, Wong TY, Ou CY, Fang SY, Chen KC, Hsiao JR, et al. The interplay between alcohol consumption, oral hygiene, $\mathrm{ALDH} 2$ and $\mathrm{ADH} 1 \mathrm{~B}$ in the risk of head and neck cancer. Int J Cancer. 2014;135(10):2424-36.

51. Talamini R, Vaccarella S, Barbone F, Tavani A, La Vecchia C, Herrero R, et al. Oral hygiene, dentition, sexual habits and risk of oral cancer. Br J Cancer. 2000;83(9):1238-42.

52. Zheng TZ, Boyle P, Hu HF, Duan J, Jian PJ, Ma DQ, et al. Dentition, oral hygiene, and risk of oral cancer: a case-control study in Beijing, People's Republic of China. Cancer Causes Control. 1990;1(3):235-41.

53. Yang KY, Jiang RS, Shiao JY, Wang CC, Wang CP, Liang KL, et al. Visual screening of oral cavity cancer: The role of otolaryngologists. Laryngoscope. 2007;117(1):92-5.

54. Mignogna MD, Fedele S. Oral cancer screening: 5 minutes to save a life. Lancet. 2005;365(9475):1905-6.

55. Patton LL. The effectiveness of community-based visual screening and utility of adjunctive diagnostic aids in the early detection of oral cancer. Oral Oncol. 2003;39(7):708-23.

56. Richards D. Clinical recommendations for oral cancer screening. Evid Based Dent. 2010;11(4):1012.

57. Seoane J, Corral-Lizana C, Gonzalez-Mosquera A, Cerero R, Esparza G, Sanz-Cuesta T, et al. The use of clinical guidelines for referral of patients with lesions suspicious for oral cancer may ease early diagnosis and improve education of healthcare professionals. Med Oral Patol Oral Cir Bucal. 2011;16(7):e864-9.

58. Mignogna MD, Fedele S, Lo Russo L. The world cancer report and the burden of oral cancer. Eur J Cancer Prev. 2004;13(2):139-42.

59. Rumboldt Z, Day TA, Michel M. Imaging of oral cavity cancer. Oral Oncol. 2006;42(9):854-65.

60. Aulino JM, Strother MK, Shipman JL. Imaging of oral cavity squamous cell carcinoma. Oral Maxillofac Surg Clin North Am. 2006;18(4):445-63.

61. Jafer M, Crutzen R, Jafer A, Van Den Borne B. What do dental college clinicians know about oral cancer and its risk factors? An assessment among final year students, interns and faculty members in saudi arabia. J Clin Exp Dent. 2018;10(9):e908-13. doi: 10.4317/jced.55168.

62. McGurk M, Chan C, Jones J, O'Regan E, Sherriff M. Delay in diagnosis and its effect on outcome in head and neck cancer. Br J Oral Maxillofac Surg. 2005;43(4):281-4.

63. Fishbein M, Ajzen I. Predicting and changing Behavior: The Reasoned Action Approach. New York: Psychology Press; 2011 
64. Bandura A. Self-efficacy : the exercise of control. New York: Freeman; 1997.

65. De Vries H. An integrated approach for understanding health behavior; the I-Change Model as an example. Psychol Behav Sci Int J. 2017; 2(2). doi:10.19080/PBSIJ.2017.02.555585.

66. Haresaku S, Makino M, Sugiyama S, Naito T, Marino RJ. Comparison of Practices, Knowledge, Confidence, and Attitude toward Oral Cancer among Oral Health Professionals between Japan and Australia. J Cancer Educ. 2018;33(2):429-35.

67. Shimpi N, Bharatkumar A, Jethwani M, Chyou PH, Glurich I, Blamer J, et al. Knowledgeability, attitude and behavior of primary care providers towards oral cancer: a pilot study. J Cancer Educ. 2018;33(2):359-64. 

CHAPTER 5 


\section{Dental Patients' Views and Need for Oral Cancer Examination, Preventive Measures and Information in the Jazan Region of Saudi Arabia: A Mixed Methods Qualitative and Quantitative Study}




\section{Abstract}

\section{Objectives}

To investigate dental patients' thoughts, opinions and needs for oral cancer information and dentists' behavior regarding prevention and examination of oral cancer, as well as the patient's own behavior regarding oral cancer.

\section{Methods}

A qualitative investigation followed by a quantitative study were conducted in Jazan Dental School clinics. Firstly, semi-structured interviews with mainly open-ended questions were conducted with forty dental patients of both sexes. Notes and audio recordings were taken for the interviews. Subsequently, based on the qualitative analysis, a structured questionnaire was developed and distributed, and data was analyzed for 315 dental patients to quantify their thoughts, opinions, needs, their own behavior and behavior expected from dentists regarding oral cancer.

\section{Results}

Different aspects of knowledge about oral cancer, and the needs and expectations of dental patients regarding the dentist's behavior, as well as the patient's own behavior were identified in the qualitative study. The quantitative study revealed that patients' knowledge levels on oral cancer were fairly adequate, but the majority reported that their dentist had never examined them for oral cancer. Additionally, they had never performed selfexaminations for oral cancer, nor were they aware of the possibility to do so. Participants showed a preference for being examined and educated by their dentist about oral cancer and believed it would help in terms of the early detection of the disease.

\section{Conclusion}

Jazan Dental School clinic patients are aware of oral cancer and its risk factors. However, the practice of oral cancer examinations and patient education of its risk factors by dental practitioners is limited. Patients feel a need for more attention to be paid to oral cancer examinations, preventive measures and targeted information on oral cancer risk factors.

\section{Practical implication}

Oral cancer examinations and patient education at Jazan Dental School clinics need to be implemented in order to aid in the early detection of oral cancer. 


\section{Introduction}

Oral cancer is one of the most prevalent cancers in the world [1]. In Saudi Arabia, oral cancer, together with head and neck cancer, is the most prevalent form of the disease, according to the latest Saudi Cancer Registry [2]. In particular, the Jazan region of Saudi Arabia has the highest rate of oral cancer, as indicated by registrations since 1999 [2-4]. Oral cancer is one of the most aggressive forms of cancer and it has a low survival rate $[5,6]$. The survival rate of oral cancer is negatively affected by its tendency towards a late first diagnosis time [5-9]. Tobacco is a major risk factor for oral cancer, particularly with the use of smokeless forms of the substance [10]. Smokeless tobacco (ST) is frequently mixed with other substances, and is either inhaled by sniffing, chewed, or placed in the mouth against the mucosa sites [11]. The use of ST is prevalent at a global level, with many different recipes found worldwide [12-14]. In Saudi Arabia, the main ST product used is Shammah, which was found to be the major independent risk factor for oral cancer in the Jazan region [15]. Data on the extent of Shammah use in Saudi Arabia is absent. However, most diagnosed oral cancer patients are from the Jazan region of Saudi Arabia and have reported using Shammah [15]. Awareness of this link between oral cancer and its risk factors is essential [16], and therefore, the public's lack of awareness is a possible contributor towards the use of Shammah in the Jazan region.

A lack of public awareness about oral cancer signs and symptoms, as well as about oral cancer self-examination, also influence the odds of being diagnosed [17, 18]. The fact that early stages of oral cancer are usually asymptomatic could affect patients' ability to recognize symptoms and lead to a delay in oral cancer diagnosis [9]. Moreover, the signs and symptoms of oral cancer, if noticed, are usually misattributed to other manifestations of dental diseases, such as a standard infection [19]. In addition to the silent nature of oral cancer, the routine practice of oral cancer examinations, which is associated with a better prognosis of the disease [20], is usually not practiced by dentists [21]. This was found to be true among dentists in the Jazan region of Saudi Arabia $[22,23]$. The objectives of the present study were: to investigate the dental patients' - who are visiting Jazan Dental School (JDS) - thoughts, opinions and needs for oral cancer information and dentists' behavior regarding prevention and examination of oral cancer, as well as the patient's own behavior regarding oral cancer. Then, to assess the obtained ideas and thoughts of participants among a larger sample of the same population for generalizability with a quantitative approach. 


\section{The qualitative study: Design, materials, procedures, and data analysis}

In the qualitative study, semi-structured interviews with mainly open-ended questions were conducted with dental patients of both sexes in a one-on-one interview. The interview guide contains 14 open-ended questions (available in both languages at: $<$ https://osf.io/nhryx/>) and was created by the authors. The questions focused on patients' knowledge on oral cancer, perceived risks and the seriousness of oral cancer, as well as patients' experiences and perceptions of the feasibility of oral cancer examinations. It also looked into preferences for oral cancer examinations, education about oral cancer and its risk factors in the dental clinic, and patients' self-examination of oral cancer. Prior to use, the interview guide was evaluated by two experts in the field of health promotion and oral cancer from JDS. The interview guide was pre-tested with four volunteers' patients of different educational levels from JDS clinics, to evaluate the appropriateness of the language level and of guiding questions. The reporting of the qualitative study was in line with the Consolidated Criteria for Reporting Qualitative research (COREQ) checklist [24]. All of the interviews were conducted by a male and a female dental public health specialist from JDS, Saudi Arabia. To ensure a good quality for the interviews, both interviewers conducted three mock-interviews with individuals of the same sex from the targeted group, under direct supervision from a Professor of Health Promotion from Jazan University.

\section{Participant Selection}

All patients visiting JDS male and female clinics from March 1 to April 19, 2017 were invited for an interview and were informed about its purpose. Male and female patients, who were willing to participate, were interviewed by an interviewer of the same sex. A maximum of three individual interviews per day were carried out by an interviewer. The participants $(\mathrm{N}=40)$ were made up of 21 females and 19 males, ranging in age from 23 to 60 years old, with most of the female participants being older than age 30 . Moreover, participants had different educational backgrounds, with the majority holding secondary school-level education. Almost all the participants were Saudi nationals $(n=35)$, with four non-Saudi female participants and one non-Saudi male participant.

\section{Data Collection procedure}

The interviews took place in designated rooms at the male and the female branches of JDS. All interviews were conducted in the Arabic language. Each interview lasted about 60 minutes. Notes were taken by interviewers for all male and female interviews; however, only male interviews were audio recorded, as female participants denied being recorded due to personal preferences. 


\section{Data Analysis}

In the analysis of the qualitative data, a grounded theory methodology [25] was utilized to discover the emerging patterns in the thoughts, opinions and expectations of the JDS clinic patients in regard to oral cancer and its related aspects. After each interview, the notes were reviewed with the participant to check if they represented his or her thoughts and opinions. For example, some participants mentioned that their dentist had examined them for oral cancer; however, they later indicated that they were not informed on oral cancer examinations. Moreover, all interview notes and audio recordings were reviewed by both interviewers together on the same day of the interview. To avoid distortions in the data, verbatim transcriptions and analyses were carried out in the Arabic language. The analysis was conducted manually, as there was no software program available that supported the Arabic language. Without referring to any participants, responses from all one-on-one interviews were grouped and all similar responses were coded. Subsequently, focus codes were developed from the codes, which were later developed into theoretical codes (coding process table). The codes were reviewed and then translated to English by the third author, who is fluent in both languages. The English translations of the codes were reviewed and approved by both interviewers. Consequently, all codes were reported in the result section, along with the related participants' responses. The quotations in the result section were mainly obtained from the male audio recordings; however, when looking at the notes, both the males' and females' interview notes were comparable.

\section{Ethical Approval}

Written consent from all individuals, for participation and publication of the findings, was obtained before the study was conducted. The interviewers explained the interview process to the patients and how data would be abstracted from their opinions and experiences. This study was approved by Jazan University, Saudi Arabia, under the ethical registration number [CDREC-06], dated December 21, 2016, prior to conducting it.

\section{Qualitative Study: Results}

The analysis of the one-on-one interviews in the present study showed three major themes that represent the participants' thoughts, opinions, and behavior regarding oral cancer and its related aspects. The first major theme was the knowledge of the participants regarding oral cancer and its related aspects. The second major theme was related to the perception of the participants towards oral cancer and its related aspects. The third major theme concerned the behavior (practice) of the participants and their dentists regarding oral cancer self-examination and clinical procedures. 


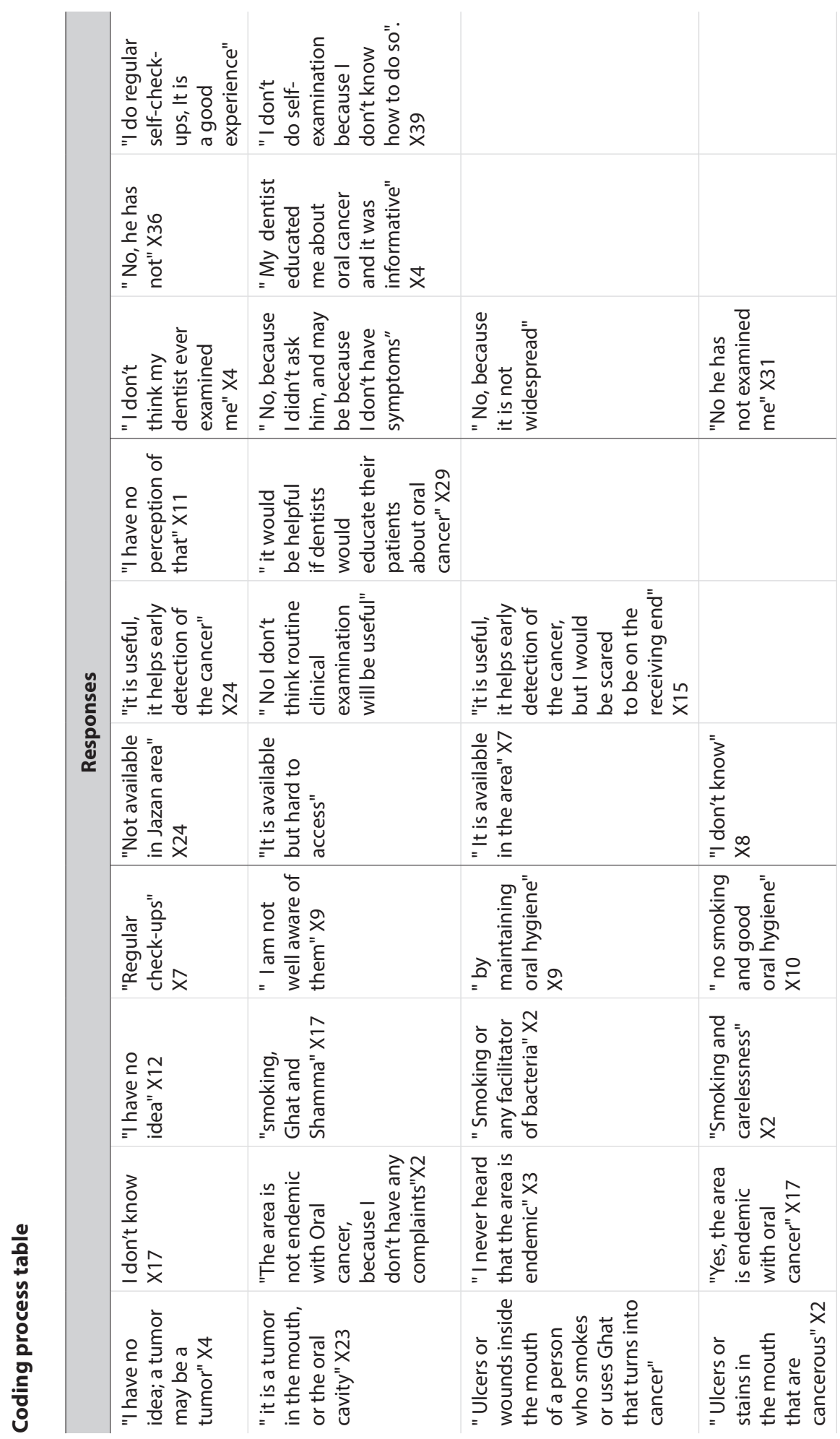




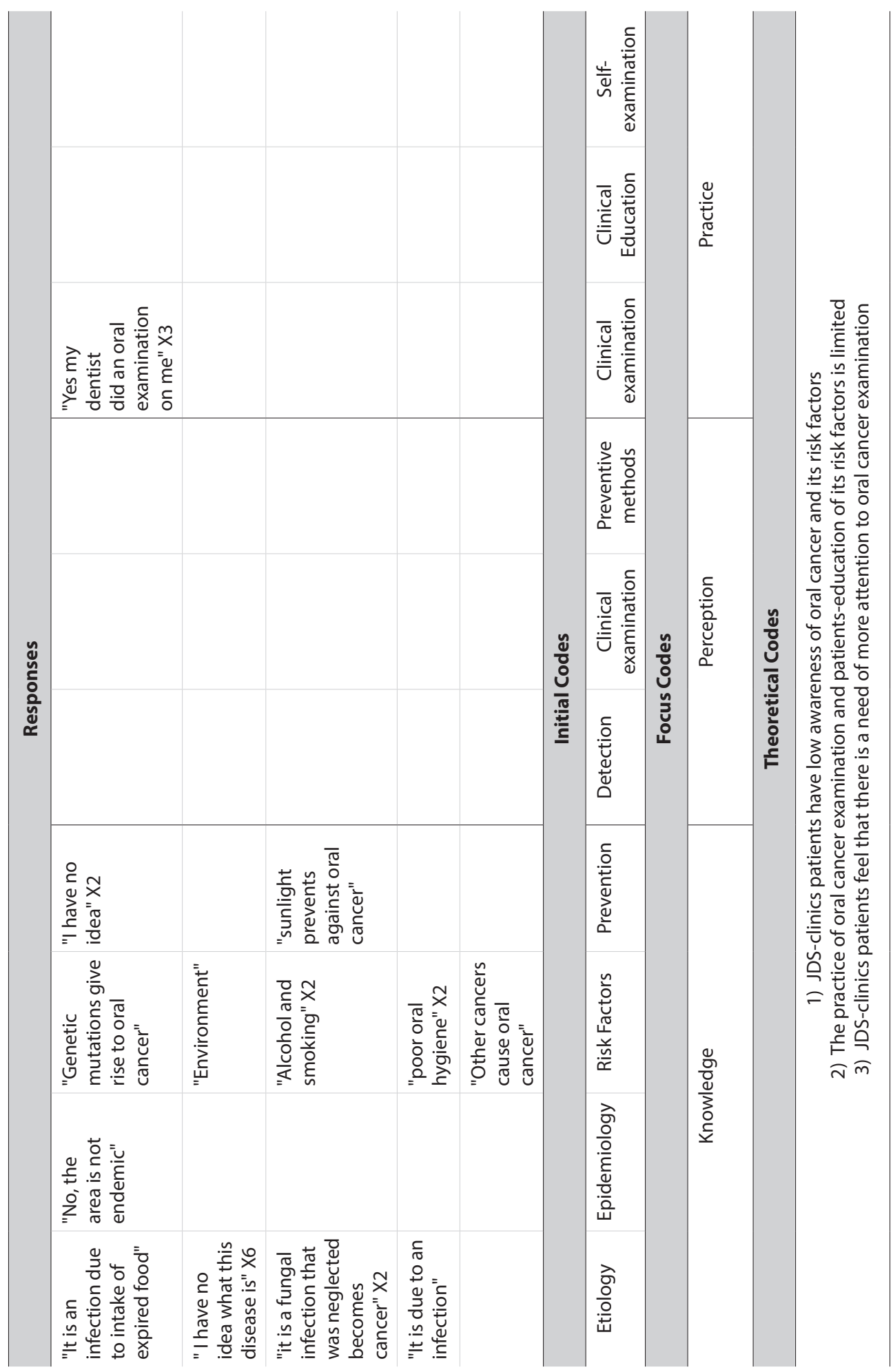




\section{Knowledge}

The knowledge of the participants regarding oral cancer and its related aspects was one of the major themes that emerged from the analysis of the present study's data. It was developed out of four subthemes: etiology, epidemiology, risk factors and prevention. Participants refer to oral cancer as the cancer of the mouth but did not know about its etiology. Several participants indicated that they had no idea of what oral cancer could mean, "I have never heard of cancer in the mouth". Other participants thought that oral cancer could be the result of some type of bacterial or fungal infection, "my grandmother had an infection in her mouth that she neglected, and it became cancer ... she died of it".

Regarding the high prevalence of oral cancer in the Jazan region, almost half of the participants confirmed that the Jazan region has a high prevalence of oral cancer: "I have read in the media, that the highest number of oral cancer patients was from the Jazan region". However, many participants mentioned that they were not aware of an epidemic: "I work in the health sector and had never heard of such a claim". Other participants even argued that oral cancer is not prevalent in the region of Jazan, "I do not have oral cancer, nor does anyone of my family or my friends or their family".

Most of the participants indicated that they did not know what the risk factors of oral cancer could be. Though many thought that it could be related to smoking, Ghat chewing and Shamma use, "I heard that one lady in the neighboring village died of cancer because she used Shamma". Several other participants mentioned that smoking could be a risk factor; however, in combination with other factors such as bacteria, alcohol, carelessness of the individual or poor oral hygiene. They thought that a local factor would have to be involved for smoking to cause harm in the mouth, "I do not believe that smoking alone can cause a cancer in the mouth, maybe patients were using something else with it, like Ghat". Other participants believed that it related to the individuals' genetics or their environment, "my dad used to smoke and chew Ghat for more than forty years and did not have cancer", "the environment is the reason of all cancer". Another participant mentioned that it could be because an individual had another type of cancer somewhere else in his or her body, "my friend had cancer in his leg bone but then it spread to all of his body and finally reached his mouth".

Regarding the prevention of oral cancer, several participants were not aware of the preventive measures they could take to avoid oral cancer. Other participants thought that oral cancer could be prevented by regular dental check-ups, "my dentist will let me know if he notices any issues in my mouth and will help me to solve it", "if my dentist tells me there is a problem in my mouth that could become cancer, I will stop smoking". Others mentioned that by maintaining good oral hygiene, an individual can prevent oral cancer, "I believe maintaining good oral hygiene is the key to preventing all oral health issues". On the other 
hand, to prevent oral cancer, several participants thought that, in addition to good oral hygiene, an individual must not smoke, "I believe to prevent any cancer, I must not smoke".

\section{Perception}

Several participants had negative perceptions towards oral cancer facilities and accessibility in the Jazan region, whereby several participants indicated that there is no facility in the Jazan region to detect oral cancer. Other participants mentioned that they were not aware of any facility in the Jazan region that could help in detecting oral cancer, "I am from Jazan and if God wills that I have oral cancer, I do not know any facility in Jazan that could help me in detecting or later treating my problem". However, other participants stated that oral cancer can be detected in the Jazan region, "in Jazan, we have several dental clinics and a hospital that can detect oral cancer". Moreover, a participant declared that it is possible to have oral cancer detected in the Jazan region in several facilities but that it would be difficult to access them, "I believe that oral cancer could be diagnosed in some specialized hospital in Jazan, but the issue is the difficulties individuals may face getting to those hospitals".

Regarding the benefits of having a routine clinical oral cancer examination, many participants thought it would be useful and that it would help in the early detection of oral cancer. However, several participants stated that, even though clinical examinations of oral cancer would help towards early detection of the disease, it would cause fear to be on the receiving end, "I believe oral cancer screening by a dentist will be very helpful but scary at the same time", "I will be scared if my dentist tells me he will examine me for oral cancer, even though I think it is good for me". Similarly, many participants indicated that it would be helpful if dentists educated their patients about oral cancer.

\section{Practice}

Many participants believed that their dentists did not examine them for oral cancer, "I am absolutely sure that no dentists I have ever visited examined me for oral cancer, they only look for what I was complaining of". Moreover, several others thought that they were not examined for oral cancer by their dentists, "I am a heavy smoker, and I do not think any dentists examined me for oral cancer; they have not told me anything". However, some participants thought that their dentist had not examined them for oral cancer because there would be no need for an oral cancer examination, "my dentist did not examine me for oral cancer because I did not ask him, and maybe because I do not have oral cancer symptoms", "no dentist examined me for oral cancer and maybe because oral cancer is not widespread in Jazan". Similarly, many participants indicated that they have not received any health education regarding oral cancer from their dentists, "my dentist knew I am a heavy smoker and I chew Ghat, but he never educated me of oral cancer and its risk factors". 
Regarding self-examination for oral cancer, only one participant mentioned that she performs a regular self-check-up. Furthermore, many participants indicated that they did not practice oral cancer self-examination because they did not know how to do so, "I have not heard of this oral cancer self-examination before today", "I do not know what oral cancer self-examination is, and if I knew I would have done it", "I have several problems with my teeth and my mouth and I usually look at my mouth but I did not know that I could examine myself for oral cancer".

\section{The quantitative study: Design, participants and procedures, measurement instrument, and data analysis}

\section{Design}

Following the qualitative study, a descriptive quantitative cross-sectional study was conducted to investigate and quantify oral cancer-related aspects among a larger sample of dental patients. Data was collected using a structured questionnaire from patients.

\section{Participants and procedure}

The study was conducted in two branches of JDS clinics, both for males and females, of Jazan University in Saudi Arabia. All regular dental patients that attended JDS clinics in the period between September 25 and December 31, 2017 and who had at least one previous visit for a dental check-up were invited by the clinics receptionists to participate in this study.

The annual number of regular patients attending JDS clinics is around 700, with the majority visiting in the first academic semester that started on September 17 in the year 2017. The working schedule of JDS clinics operates in line with the academic year schedule of Jazan University. All regular dental patients must visit the clinic receptions prior to their appointments. The targeted sample for this study were all regular patients in the first academic semester. Among all regular patients who agreed to participate, 336 consented and returned the data collection forms to the JDS clinic receptions. All participation was voluntarily and no incentive was provided. At the end of each day, a designated receptionist collected all of the questionnaire forms from both JDS branches and stored them in a closed locker at the clinic Director's office. The Principal Investigator collected all of the filled-in forms on January 3, 2018. Of those 336 participants, 21 did not complete the data collection forms and were not included in the analysis of the data, resulting in a final sample of 315 participants. 


\section{Measurement instrument and pretesting}

A questionnaire was developed based on findings from the prior qualitative study, which explored the view of dental patients from JDS clinics, regarding oral cancer and its related aspects. The questionnaire consisted of 55 items that incorporated the three main themes that arose out of the previous qualitative study. Those themes were focused on knowledge, perception and practice. The first part of the questionnaire assessed the participants'knowledge of oral cancer etiology, oral cancer local epidemiology, oral cancer risk factors and oral cancer prevention. The second part investigated the perceptions of the participants regarding oral cancer detection, oral cancer clinical examinations, oral cancer self-examination, oral cancer preventive methods and perceived dentist roles regarding patient education and tobacco cessation. The final part evaluated the participants' clinical experiences of oral cancer examination with their dentists, as well as dentists' practice of oral cancer patient education and participants' oral cancer selfexamination. The questionnaire was developed in English and translated into Arabic by an Arabic and English-speaking dental public health specialist and reviewed and evaluated using cross-translation by the Principal Investigator.

The questionnaire was pre-tested among 15 males and 11 females, who were returning JSD dental patients, initially using a thinking-aloud method. This led to a substantial revision in order to improve the participants' understanding of several questions. Therefore, a re-evaluation of the modified questionnaire, using the thinking-aloud method, was carried out among 12 males and 13 females, who were regular patients at JSD clinics. The questionnaire was then sent to an Arabic-speaking dental public health specialist and two Arabic-speaking health promotion specialists for an overall evaluation. They had no further concerns regarding the questionnaire. The full questionnaire is available in both languages at: < https://osf.io/nhryx/>.

\section{Data Analysis}

The mean, standard deviation, mode and range were calculated for the age of participants. Frequency and percentages were obtained for all other demographics, as well as all individual items of the questionnaire; see tables 1-4. Furthermore, cumulative percentages of dental patients' perceptions toward oral cancer examinations were calculated for items number 22, 23, 33, 34 and 35. Other cumulative percentages were obtained for dental patients' clinical experiences, included in items 45, 51 and 52, which considered if the participants were examined for oral cancer, informed of oral cancer examinations and if they were educated about oral cancer and its risk factors. Figure 1 illustrates the dental patients' perceptions and their clinical experiences of oral cancer examination at JDS clinics. 


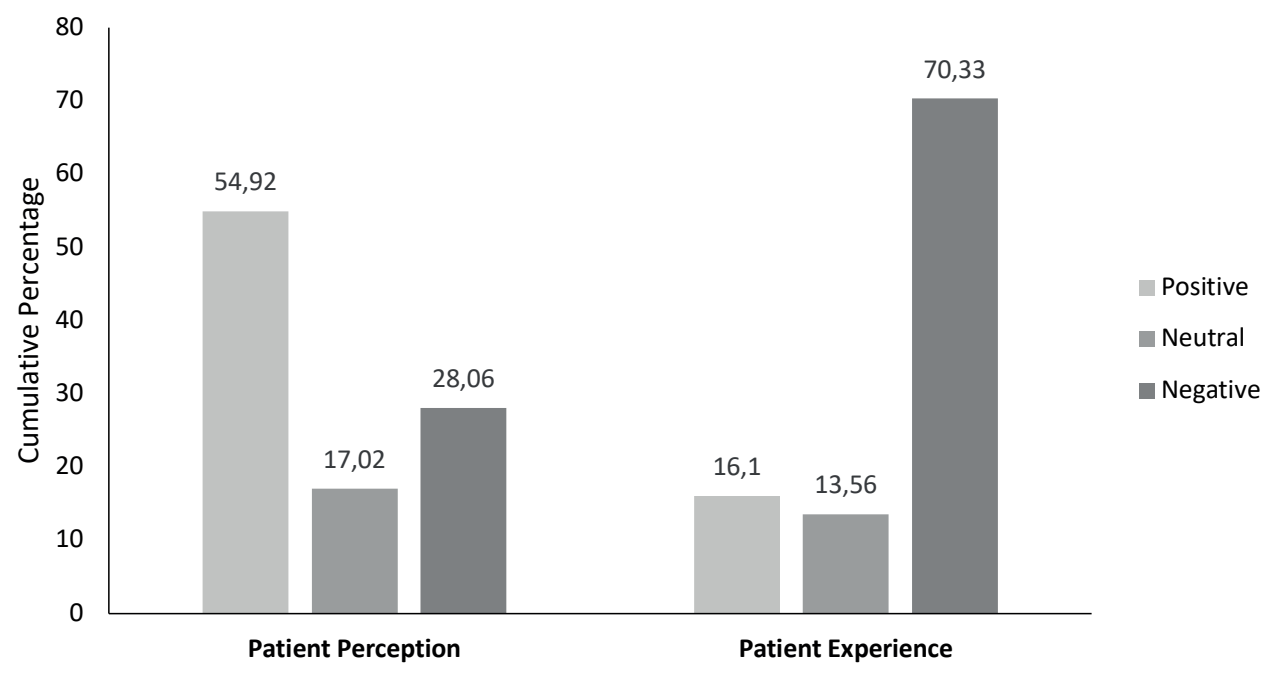

Figure 1: A cumulative percentage comparing dental patients' perception toward oral cancer examination included items number 22, 23, 33, 34 and 35 and dental patients' clinical experiences included the items number 45, 51 and 52

\section{Ethical approval}

Jazan University granted ethical approval, with registry no. [CDREC-06], dated 21 December 2016, prior to conducting the present study. All participants consented for participation and publication of the findings. 


\section{Results}

The total number of participants who completed the questionnaires and consented for participation was 315. Of those, 290 participants reported their ages. The mean participant age was $31 \pm 11$ years (range of 12-70), with a mode of 25 years. Among the 313 participants who reported their sex, $41.2 \%$ were males and $58.8 \%$ were females. The majority of participants who reported their nationality were Saudis (85.9\%). Participants have reported their levels of education as following: $4.4 \%$ were uneducated, $7.9 \%$ had primary education, $15.6 \%$ had intermediate education, $24.1 \%$ had secondary education, and $47.2 \%$ had university education - as shown in Table 1.

Table 1: (Demographics)

\begin{tabular}{|c|c|c|c|c|c|}
\hline & $N=315$ & Mean & SD & Frequency & Percentage \\
\hline Age (years) & 290 & *31.0 & 11.1 & & \\
\hline Sex & 313 & & & & \\
\hline Male & & & & 129 & 41.2 \\
\hline Female & & & & 184 & 58.8 \\
\hline Nationality & 249 & & & & \\
\hline Saudi & & & & 214 & 85.9 \\
\hline Not Saudi & & & & 35 & 14.1 \\
\hline Education Level & 315 & & & & \\
\hline Uneducated & & & & 14 & 4.4 \\
\hline Primary & & & & 25 & 7.9 \\
\hline Intermediate & & & & 49 & 15.6 \\
\hline Secondary/High school & & & & 76 & 24.1 \\
\hline University & & & & 144 & 45.7 \\
\hline Higher education & & & & 7 & 2.2 \\
\hline
\end{tabular}

${ }^{*}$ Mode $=25$, range $=(12,70)$

The first part of the questionnaire assessed the participants' knowledge of oral cancer etiology, oral cancer local epidemiology, oral cancer risk factors and oral cancer prevention; see table 2. The majority of the participants gave correct responses to the knowledge items relating to the nature of the disease (items 1,2 and 3). In addition, most participants provided correct answers to the questions relating to signs of oral cancer (items 4, 7 and 8 ), although many did not know that swellings and lumps anywhere in or around the mouth can be signs of oral cancer (items 5 and 6) (table 2.1.). Around $70 \%$ of the participants were 
aware of the prevalence of oral cancer in Saudi Arabia (item 9). However, most participants were not aware of the relatively high prevalence of oral cancer in the Jazan region (items 10 and 11), (table 2.2.). Between 60 and 82 percent of participants knew about the main risk factors for oral cancer (table 2.3.). Moreover, the majority of participants had correct knowledge of preventative measures for oral cancer, except for knowledge about the effects of physical activity (item 18) (table 2.4.).

Table 2: (Knowledge)

\begin{tabular}{|c|c|c|c|c|}
\hline 2.1. Etiology & $\mathbf{N}=315$ & Correct & Correct & Not \\
\hline 1. Oral cancer affects the oral cavity & 309 & 57 & 176 & 133 \\
\hline 2. Oral cancer is a malignant disease & 312 & 81.7 & 255 & 57 \\
\hline $\begin{array}{l}\text { 3. Oral cancer may metastasize to the rest of the } \\
\text { body }\end{array}$ & 293 & 59 & 173 & 120 \\
\hline $\begin{array}{l}\text { 4. Sores anywhere in or around your mouth are } \\
\text { signs of oral cancer }\end{array}$ & 306 & 64.1 & 196 & 110 \\
\hline $\begin{array}{l}\text { 5. Swellings anywhere in or around your mouth are } \\
\text { signs of oral cancer }\end{array}$ & 305 & 33.4 & 102 & 203 \\
\hline $\begin{array}{l}\text { 6. Lumps anywhere in or around your mouth are } \\
\text { signs of oral cancer }\end{array}$ & 309 & 38.8 & 120 & 189 \\
\hline $\begin{array}{l}\text { 7. Thick patches anywhere in or around your mouth } \\
\text { are signs of oral cancer }\end{array}$ & 312 & 76.3 & 238 & 74 \\
\hline $\begin{array}{l}\text { 8. Loose teeth without apparent dental cause is a } \\
\text { sign of oral cancer }\end{array}$ & 302 & 52 & 157 & 145 \\
\hline
\end{tabular}

\subsection{Epidemiology}

9. Oral cancer is prevalent in Saudi Arabia

$\begin{array}{lllc}311 & 68.8 & 214 & 97 \\ 310 & 34.8 & 108 & 202\end{array}$

10. Jazan area has the highest prevalence of oral cancer in comparison with other areas in Saudi Arabia

11. Oral cancer in Jazan is more prevalent among 306 22.2 68 238 females than males

\subsection{Risk factors}

12. Genes play a role in the pathogenesis of oral 303 79.2

240
63 cancer

13. Smoking is a causing factor of oral cancer 306

82

251

14. Using Ghat is not a causing factor of oral cancer 308

60.1 185 123

15. Using Shamma is a causing factor of oral cancer

313

$77.6 \quad 243$


Table 2: (Continued) (Knowledge)

\subsection{Preventive measures}

\begin{tabular}{lllllc}
\hline 16. Avoiding smoking /Shamma prevents oral cancer & 308 & 80.2 & 247 & 61 \\
\hline 17. Stopping smoking /Shamma prevent oral cancer & 306 & 76.8 & 235 & 71 \\
\hline 18. Sports prevent oral cancer & 309 & 40.1 & 124 & 185 \\
\hline 19. Eating vegetables prevent oral cancer & 314 & 83.8 & 263 & 51 \\
\hline
\end{tabular}

The second part of the questionnaire investigated the participants' perceptions regarding oral cancer detection, oral cancer clinical examinations and oral cancer preventative measures; see table 3. The majority of participants responded favorably towards oral cancer detection (table 3.1.). Furthermore, the majority of participants believed that oral cancer examination should be a routine practice in dental clinics (table 3.2.). Slightly more than half of the participants believed that dentists often skip oral cancer examination because they only focus on patients' dental complaints (item 26). In addition, the majority of participants said that the clinics (dental clinic or hospital), where the dentist meets the patient, impact the likelihood of dentists performing oral cancer examinations (item 32). Almost half of the participants mentioned that they would feel uncomfortable and uncertain when being examined for oral cancer (items 33 and 35). Nevertheless, slightly more than half of the participants expressed positive feelings (would feel comfortable) about being examined for oral cancer (item 34). The majority of participants had favorable attitudes toward different oral cancer preventative measures, such as health education, community lectures and symposiums, and distributions of written educational material about oral cancer (items 36, 37, 38, 39). Around three-quarters of the participants were in favor of banning Ghat, Shamma and tobacco as a way of preventing oral cancer in the community (item 40; table 3.3.). 


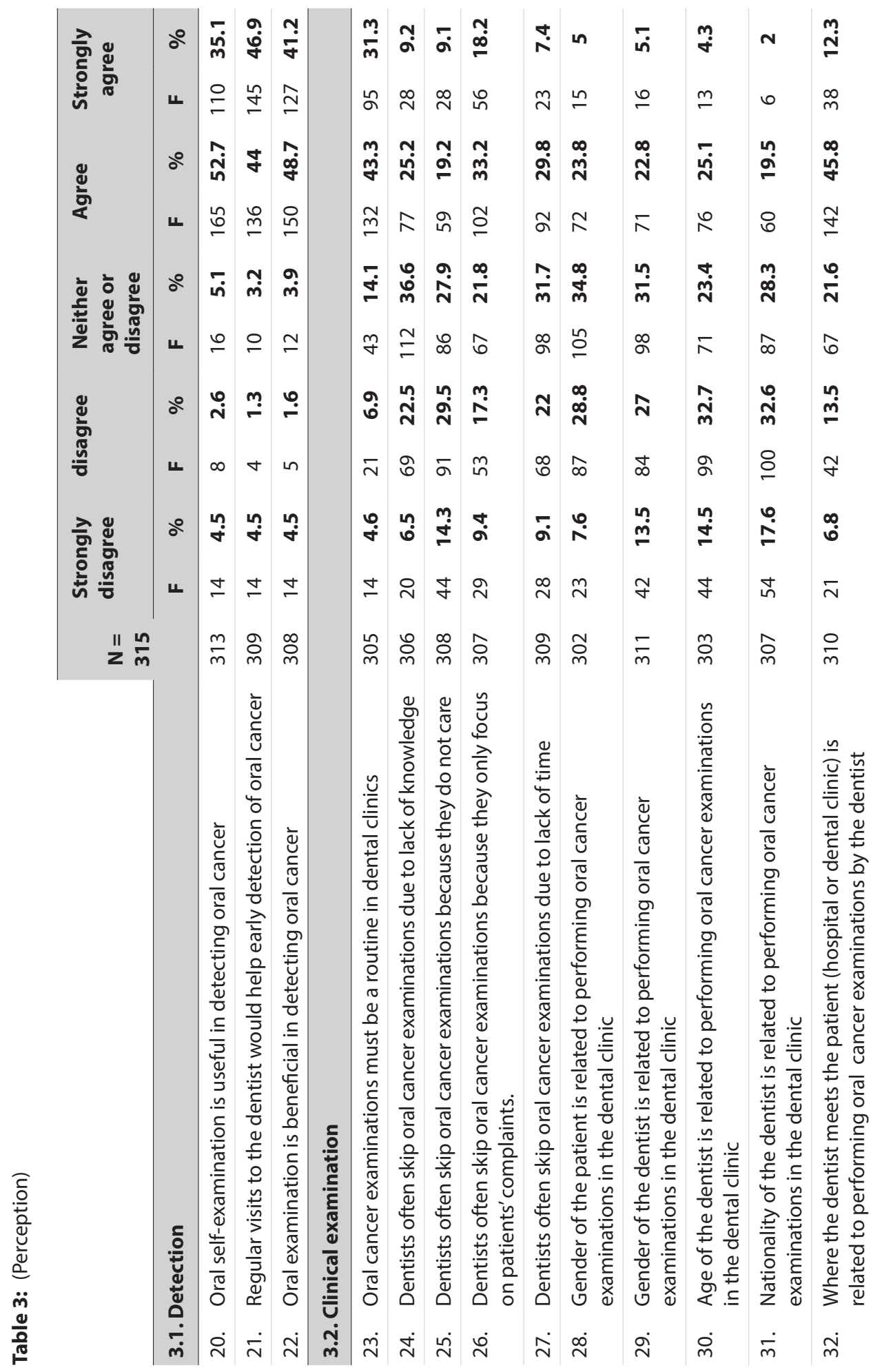




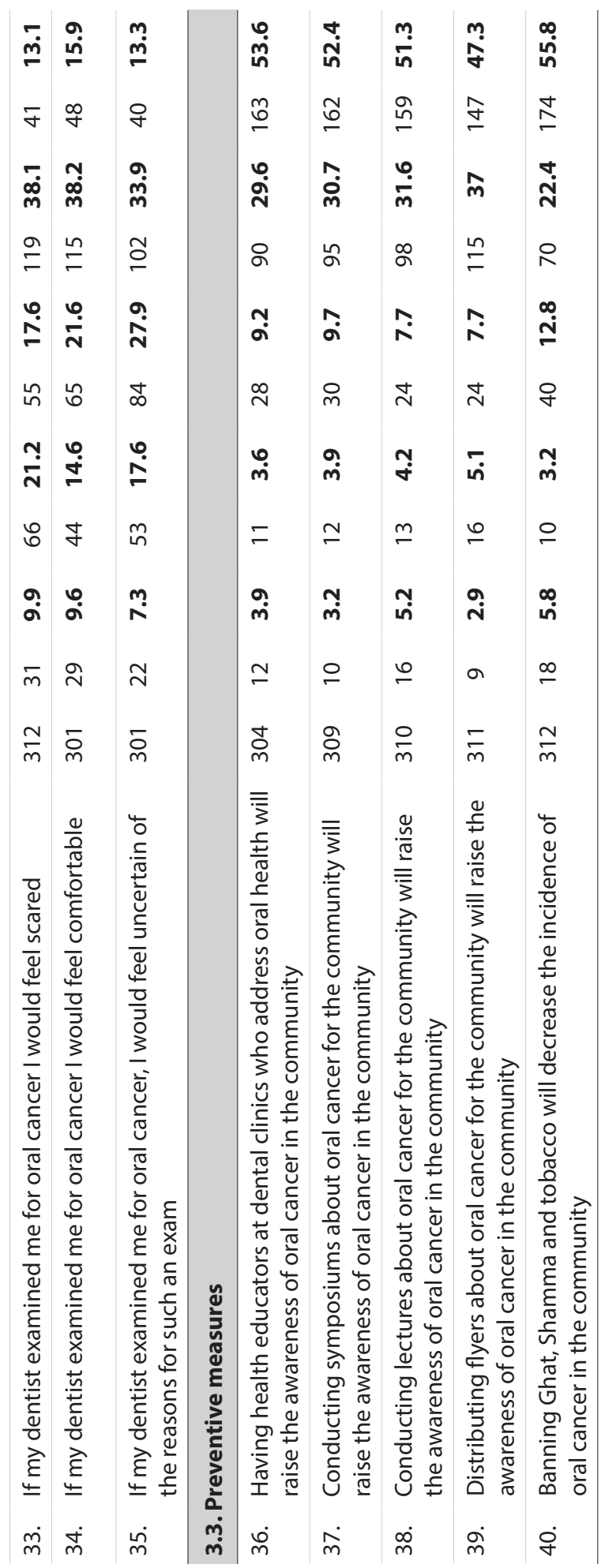


The final part of the questionnaire assessed oral cancer practices in relation to oral cancer detection, oral cancer clinical examination by dentists, oral cancer clinical education, oral cancer self-examination and the perceived role of dentists (see table 4). A wide majority of the participants reported that their dentist never $(62.3 \%)$ or rarely $(14.1 \%)$ examined them for oral cancer (Table 4.2). The reasons participants mentioned for not being examined for oral cancer by their dentist were because they said they did not have any signs or symptoms of oral cancer and because they had visited the dentist for a specific dental issue (items 41 and 43; table 4.1.). Also, the majority of the participants showed a positive intention toward visiting the dentist when noticing changes that might indicate signs of oral cancer (table 4.2.). The majority of participants also reported that their dentist had not educated them about oral cancer and its risk factors (table 4.3.). Furthermore, the majority of participants reported that they do not perform oral cancer self-examinations (table 4.4.). Finally, a large majority of participants favored dentists having a role in terms of patient education about oral cancer and referrals for tobacco cessation programs, if needed (table 4.5.).

Despite the fact that dentists' examinations for oral cancer caused fear and uncertainty among dental patients (items 33 through 35), a high percentage of dental patients are in favor of routine oral cancer examinations by dental clinic health workers (items 22 and 23). 


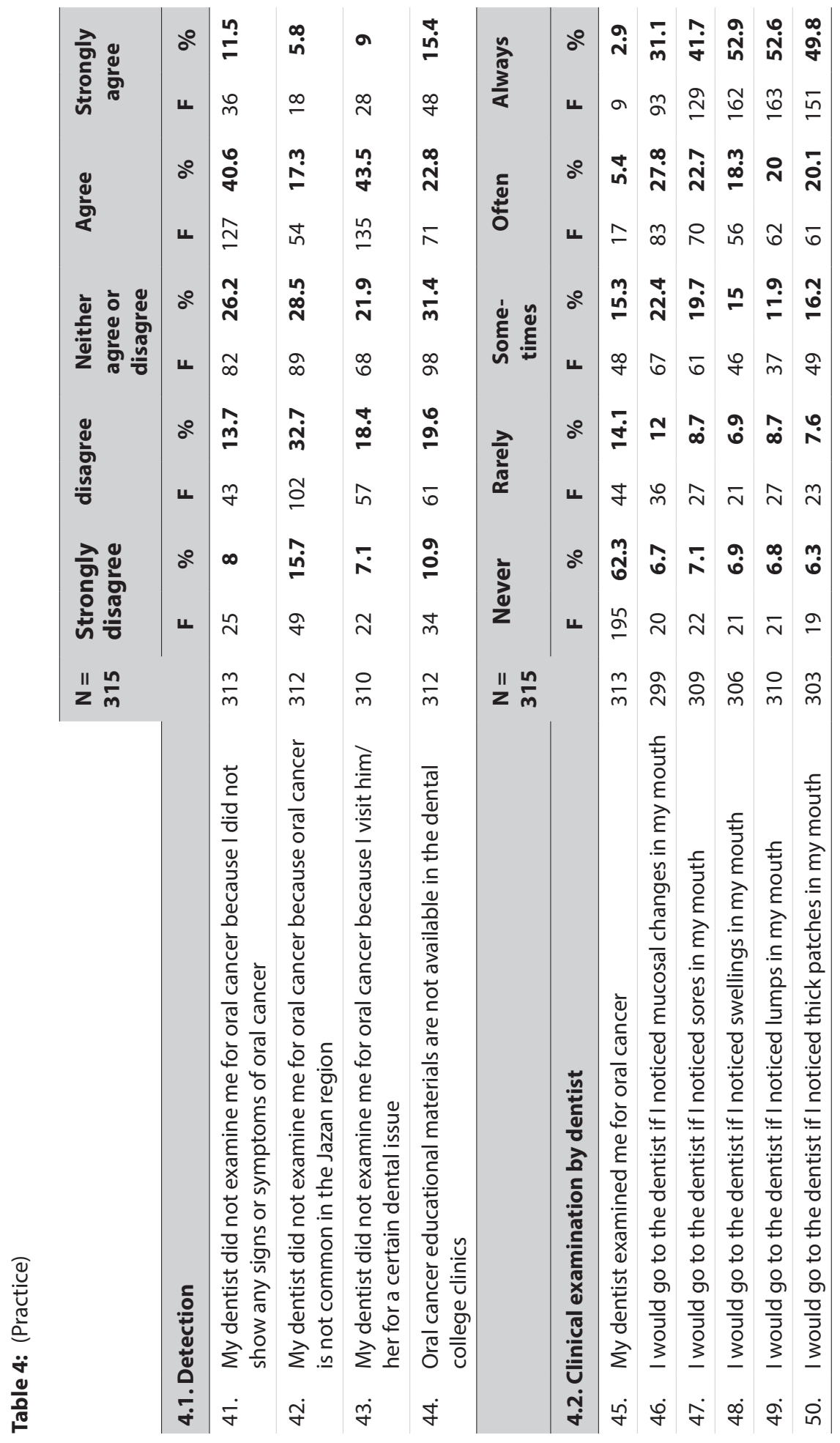




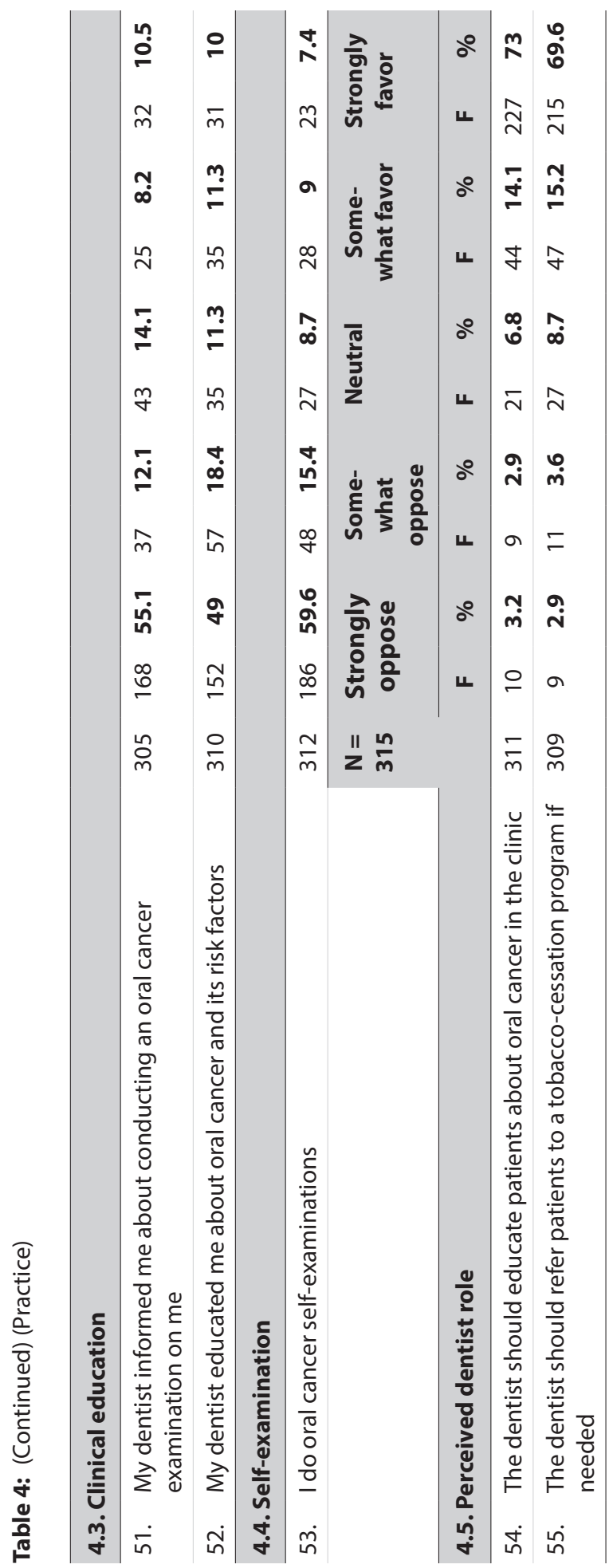




\section{Discussion}

The first study explored aspects possibly related to oral cancer, as perceived by dental patients who visit JDS clinics. Three major themes resulted from the participants'narratives: oral cancer knowledge, perceptions of oral cancer examination, and the practice of oral cancer examination. Delays in oral cancer detection would contribute to a reduction in the oral cancer five-year survival rate [5]. At an advanced stage of oral cancer, the tumor will have metastasized to local lymph nodes and, hence, will necessitate an invasive procedure that is usually extensive, and will more than likely result in disfigurement [26]. Individuals having a low level of health literacy regarding essential information related to oral cancer, as was found in this study, could lead to misinterpretations of early signs and symptoms of the disease. This misinterpretation could contribute to a delay in seeking a dentist's advice, which may in turn lead to oral cancer only being detected at a more advanced stage. This effect of lacking oral cancer knowledge has also been reported in previous studies $[17,27]$. Therefore, knowledge of oral cancer was recognized as a modifiable determinant that aids in the early detection of oral cancer and thus may reduce oral cancer morbidity and mortality [28]. Our quantitative study revealed a substantial level of knowledge among the patient population. This could be attributed to the relatively high level of education of the participants in our quantitative study, as almost half of them had a university-level education. Despite the adequate knowledge of participants regarding oral cancer etiology, their knowledge of the local prevalence of oral cancer and its sex distribution was low. Around $35 \%$ of participants knew that Jazan had a high prevalence of oral cancer and only $22 \%$ were aware of the sex distribution of the disease; although the majority (around 70\%) of the participants were aware that oral cancer is prevalent in Saudi Arabia more generally.

Another determinant that may contribute to early detection of oral cancer is the individual's perception on the availability and accessibility of health care facilities. A negative perception of dental patients towards accessing a healthcare facility and the ability of health care workers to detect and treat oral cancer would adversely affect seeking a dentist's advice, and would eventually lead to diagnosis at a later stage of the disease. The individual help-seeking behavior for oral cancer was also found to be influenced by the access to healthcare, costs and competing responsibilities, as well as work commitments, childcare, holidays and others [29]. The prevailing perception of the participants toward the availability and accessibility of health care facilities was negative.

Key-findings from the present study are that more than three-quarters of the participants (both males and females) would prefer to receive oral cancer examinations in routine dental screening, as well as education about oral cancer from their dentist. This is even though examination for oral cancer causes feelings of fear and uncertainty among a 
substantial number of the surveyed patients. This can be considered a positive reflection of the participants' caring about their health and their interest in increasing their awareness of oral cancer. A similar finding was also evident in a previous study, in which patients also favored being examined for oral cancer; although, in that study, dentists were concerned that their patients would be anxious because of the oral cancer examination [30]. In the present study, participants were not aware as to whether their dentists had examined them for oral cancer or not. Participants also mentioned that their dentists had not educated them about oral cancer. Moreover, participants declared their lack of knowledge and ability to perform oral cancer self-examinations.

A limitation of the present study was that all participants were from JDS clinics. A relatively high percentage of the clinics' visitors have a higher or university education. This likely limits the generalizability of our findings. However, JDS clinics are the major dental clinics in the Jazan region of Saudi Arabia, receiving all patients with no restrictions on age, gender or nationality, while providing all types of dental treatment free of cost. The quantitative study's data collection was planned to be completed before an international oral cancer conference in the Jazan region, which was advanced in schedule from December 27, 2017 to November 14, 2017, and the media attention regarding the conference may have had an external influence on the oral cancer awareness level of participants in the second study. 


\section{Conclusion}

JDS clinic patients have an adequate awareness of oral cancer and its risk factors. The practice of oral cancer examination and patient education of its risk factors is, however, limited. JDS clinic patients feel a need for oral cancer examinations to be embedded in routine dental practice.

\section{Practice Implications}

The findings of both studies shed light on the existing gap in the dental practice of oral cancer examination and patient education. This may reflect the missed opportunities of detecting oral cancer at its earlier stages and dentists raising patients' awareness of oral cancer. An effective tool to raise patients' awareness and ability to detect oral cancer signs is self-examinations for oral cancer [31]. For this, dentists can utilize regular dental appointments to educate and train their patients on oral cancer and its self-examination, which will, most likely, aid in increasing the early detection of oral cancer among highrisk individuals. In future research, a quantitative assessment could help to assess the relevance of socio-cognitive determinants associated with oral cancer prevention [32]. 


\section{References}

1. Warnakulasuriya S. Global epidemiology of oral and oropharyngeal cancer. Oral Oncol. 2009;45(4-5):309-16. doi: 10.1016/j.oraloncology.2008.06.002.

2. Saudi Cancer Registry. Saudi Arabia cancer incidence report 2012 [document on the Internet]. Riyadh, Saudi Arabia: National Cancer Registry; 2015 [cited 2018 Apr 1]. Available from: http:// ghdx.healthdata.org/organizations/saudi-cancer-registry

3. Saudi Cancer Registry. Saudi Arabia Cancer Incidence Report 1999-2000 [document on the Internet]. Riyadh, Saudi Arabia: National Cancer Registry; 2004 [cited 2018 Apr 1]. Available from: http://ghdx.healthdata.org/organizations/saudi-cancer-registry

4. Saudi Cancer Registry. Saudi Arabia Cancer Incidence Report 2008 [document on the Internet]. Riyadh, Saudi Arabia: National Cancer Registry. Available from: http://ghdx.healthdata.org/ organizations/saudi-cancer-registry

5. Mashberg A, Samit A. Early diagnosis of asymptomatic oral and oropharyngeal squamous cancers. CA. 1995;45(6):328-51.

6. Jan JC, Hsu WH, Liu SA, Wong YK, Poon CK, Jiang RS, et al. Prognostic factors in patients with buccal squamous cell carcinoma: 10-year experience. J Oral Maxillofac Surg. 2011;69(2):396-404.

7. Kreppel M, Eich HT, Kubler A, Zoller JE, Scheer M. Prognostic value of the sixth edition of the UICC's TNM classification and stage grouping for oral cancer. J Surg Oncol. 2010;102(5):443-9.

8. Dissanayaka WL, Pitiyage G, Kumarasiri PV, Liyanage RL, Dias KD, Tilakaratne WM. Clinical and histopathologic parameters in survival of oral squamous cell carcinoma. Oral Surg Oral Med Oral Pathol Oral Radiol 2012;113(4):518-25..

9. Gomez I, Seoane J, Varela-Centelles P, Diz P, Takkouche B. Is diagnostic delay related to advancedstage oral cancer? A meta-analysis. Eur J Oral Sci. 2009;117(5):541-6.

10. Asthana S, Labani S, Kailash U, Sinha DN, Mehrotra R. Association of smokeless tobacco use and oral cancer: a systematic global review and meta-analysis. Nicotine Tob Res. 2018:nty074-nty.

11. Warnakulasuriya S. Smokeless tobacco and oral cancer. Oral Dis. 2004;10(1):1-4.

12. Chang MC, Lin LD, Wu HL, Ho YS, Hsien HC, Wang TM, et al. Areca nut-induced buccal mucosa fibroblast contraction and its signaling: a potential role in oral submucous fibrosis-a precancer condition. Carcinogenesis. 2013;34(5):1096-104. doi: 10.1093/carcin/bgt012

13. Idris AM, Nair J, Friesen M, Ohshima H, Brouet I, Faustman EM, et al. Carcinogenic tobaccospecific nitrosamines are present at unusually high levels in the saliva of oral snuff users in Sudan. Carcinogenesis. 1992;13(6):1001-5.

14. Zhang X, Schmitz W, Gelderblom HR, Reichart PA. Shammah-induced oral leukoplakia-like lesions. Oral Oncol. 2001;37(7):609-12

15. Allard WF, DeVol EB, Te OB. Smokeless tobacco (Shamma) and oral cancer in Saudi Arabia. Community Dent Oral Epidemiol. 1999;27(6):398-405.

16. De Vries H. An integrated approach for understanding health behavior; the I-Change Model as an example. Psychol Behav Sci Int J. 2017; 2(2). doi:10.19080/PBSIJ.2017.02.555585. 
17. Warnakulasuriya KA, Harris CK, Scarrott DM, Watt R, Gelbier S, Peters TJ, et al. An alarming lack of public awareness towards oral cancer. Br Dent J. 1999;187(6):319-22.

18. Grant E, Silver K, Bauld L, Day R, Warnakulasuriya S. The experiences of young oral cancer patients in Scotland: symptom recognition and delays in seeking professional help. Br Dent J. 2010;208(10):465-71.

19. Andersen BL, Cacioppo JT. Delay in seeking a cancer diagnosis: delay stages and psychophysiological comparison processes. Br J Soc Psychol. 1995;34 ( Pt 1):33-52.

20. Mitchell E, Macdonald S, Campbell NC, Weller D, Macleod U. Influences on pre-hospital delay in the diagnosis of colorectal cancer: a systematic review. Br J Cancer. 2008;98(1):60-70.

21. Warnakulasuriya KA, Johnson NW. Dentists and oral cancer prevention in the UK: opinions, attitudes and practices to screening for mucosal lesions and to counselling patients on tobacco and alcohol use: baseline data from 1991. Oral Dis. 1999;5(1):10-4.

22. Jafer M, Crutzen R, Moafa I, Van Den Borne B. What do dentists and dental-students think of oral cancer and its control and prevention strategies? A qualitative study in Jazan Dental School. Forthcoming 2019.

23. Jafer M, Crutzen R, Halboub E, Moafa I, Van Den Borne B, Bajonaid A. Dentists behavioral factors influencing early detection of oral cancer: A direct clinical observational study. Forthcoming 2019.

24. Tong A, Sainsbury P, Craig J. Consolidated criteria for reporting qualitative research (COREQ): a 32-item checklist for interviews and focus groups. Int J Qual Health Care. 2007;19(6):349-57.

25. Chapman AL, Hadfield M, Chapman CJ. Qualitative research in healthcare: an introduction to grounded theory using thematic analysis. J R Coll Physicians Edinb. 2015;45(3):201-5.

26. Shimpi N, Jethwani M, Bharatkumar A, Chyou P-H, Glurich I, Acharya A. Patient awareness/ knowledge towards oral cancer: a cross-sectional survey. BMC Oral Health. 2018;18:86.

27. Horowitz AM, Nourjah P, Gift HC. U.S. adult knowledge of risk factors and signs of oral cancers: 1990. J Am Dent Assoc (1939). 1995;126(1):39-45.

28. Villa A, Kreimer AR, Pasi M, Polimeni A, Cicciu D, Strohmenger L, et al. Oral cancer knowledge: a survey administered to patients in dental departments at large Italian hospitals. J Cancer Educ. 2011;26(3):505-9.

29. Scott SE, Grunfeld EA, Auyeung V, McGurk M. Barriers and triggers to seeking help for potentially malignant oral symptoms: implications for interventions. J Public Health Dent. 2009;69(1):34-40.

30. Choi Y, Dodd V, Watson J, Tomar SL, Logan HL, Edwards H. Perspectives of African Americans and dentists concerning dentist-patient communication on oral cancer screening. Patient Educ Couns. 2008;71(1):41-51.

31. Elango KJ, Anandkrishnan N, Suresh A, lyer SK, Ramaiyer SK, Kuriakose MA. Mouth selfexamination to improve oral cancer awareness and early detection in a high-risk population. Oral Oncol. 2011;47(7):620-4.

32. Crutzen R, Peters GY, Noijen J. Using confidence interval-based estimation of relevance to select social-cognitive determinants for behavior change interventions. Front Public Health. 2017;5:165. 
CHAPTER 6 


\section{Introducing ISAC for Oral Cancer Comprehensive Dental Practice}




\section{Abstract}

\section{Background}

Jazan has the highest rate of oral cancer in Saudi Arabia, with more than 35\% of total cases being registered in the region. In the Jazan region, dentists' engagement in oral cancer screening and patient education is limited. The objective of this paper was to describe the development of a comprehensive approach to oral cancer practice (ISAC), using the Intervention Mapping approach.

\section{Methods}

ISAC was developed using the Intervention Mapping approach and was informed by thorough needs assessments, which involved reviewing the relevant existing literature and was followed by focus group discussions, observations, one-on-one interviews and questionnaires to investigate oral cancer practice and its related aspects in Jazan Dental School clinics. This included key stakeholders, such as dental practitioners and patients. The effect of ISAC will be measured with a four-year longitudinal study among dental interns.

\section{Results}

ISAC is a comprehensive oral cancer dental practice that comprises: Informing dental patients about performing routine oral cancer screenings, Screenings for oral cancer according to the clinical guidelines, Advising patients who are at high risk, and Connecting patients to the required services if necessary. Practical applications of ISAC were clustered into two components: a) a didactical session covering aspects related to oral cancer practices, including local issues and introducing ISAC, b) a practical session that included a stepby-step modeling of the ISAC intervention.

\section{Conclusion}

The use of Intervention Mapping aided in systematically planning ISAC intervention and covered the main issues revealed by the needs assessments. Furthermore, upon assessing the contextual characteristics of the implementing organization, several factors were found to be positive toward the intervention's implementation, and these included the implementation climate and the type of leadership. 


\section{Introduction}

Oral cancer, and particularly squamous cell carcinoma, is one of the most prevalent cancers in Saudi Arabia [1]. In comparison to other regions of Saudi Arabia, the Jazan region carried the heaviest burden of the disease, as it had more than $35 \%$ of the registered diagnosed cases at an advanced stage, with a slightly increased rate in females (compared to men) [1]. A strong association was found between these diagnosed cases and the use of smokeless tobacco [2]. The form of smokeless tobacco that is commonly used in the Jazan region is known as Shammah. The use of Shammah is linked to various individual and environment-level factors, including the prevailing norm of using Shammah as a remedy for dental pain, presence of Shammah users in the family and close friend network, as well as its availability and accessibility [3].

Despite the disease being so prevalent in Saudi Arabia, and particularly in the Jazan region, there has been limited effort to prevent its risk factors or to screen for it in clinics [4]. Evidence had shown that oral cancer can be prevented by eliminating its risk factors [5]. Moreover, it was found that early detection of oral cancer can lead to a better prognosis for the disease [6]. Due to this, dentists screening oral cancer and educating patients on its risk factors is highly recommended [7]. However, these recommendations are not usually met by dentists [8]. Similarly, in the Jazan region, dentists' engagement in oral cancer screening and patient education has been found to be limited [4]. Several factors were suggested as contributing factors towards this kind of behavior by dentists - for example, limited exposure to oral cancer cases, a lack of oral cancer screening skills and a lack of skill in educating patients [4]. Therefore, it is essential there is an intervention that aims to improve oral cancer practices in the Jazan region. The objective of this paper was to describe the systematic development of a comprehensive approach for oral cancer practices (ISAC), using the Intervention Mapping approach. 


\section{Methods}

Intervention Mapping (IM) was the approach used for developing the current intervention [9]. IM is a systematic protocol that utilizes theory and evidence as foundations, while also considering the ecological perspective, in order to assess and develop effective interventions for behavior and environmental changes that are conducive to health. IM entails six steps and each of them involves several tasks in an iterative process. Moreover, IM is conducted in a cumulative process, with each step building on the ones prior. The six steps of IM, as well as its tasks for the current intervention, are described below:

\section{Step 1: Logic model of the problem}

The IM logic model of the problem is composed of four tasks. The first task was to define the health problem, which, in this case, is the high rate of oral cancer in the Jazan region of Saudi Arabia [2]. This problem was found to involve people of all ages and genders [4], with higher rates among smokeless tobacco (Shammah) [2] users. The second task was to establish the planning group, which included all authors and potential intervention implementers of essential value - including the Dean and the Head of the Community Dentistry Division (CDD) of Jazan Dental School (JDS) [10]. Moreover, a bottom-up community empowerment approach sought to include the target group: dentists, dental interns and dental patients of JDS (from both the male and female branches) were involved to create a compatible intervention that ensured dental best practices and patient quality of life $[9,11]$. The third task was to investigate the behavior and environmental factors related to the problem. For this, a thorough literature review was carried out as first step, followed by four formative studies investigating the practices relating to oral cancer, including dental students, dentists and dental patients. Data was collected through various means, such as: observing 95 dentists' practices [12], questionnaires measuring dentists' knowledge of oral cancer ( $\mathrm{N}=228$ ) [13], dentists' perspectives ( 6 focus group interviews) [4], patients' perspectives (40 one-on-one interviews) and patient questionnaires $(\mathrm{N}=300)$ to assess their knowledge and perception of oral cancer and its related aspects (including dentists practicing oral cancer screening and educating patients) [14]. After completion of task three, task four looked into identifying the determinants of the behavioral and the environmental conditions. This was achieved by means of group brainstorming sessions and an assessment of the literature and the findings on the newly-conducted studies (see figure 1).

\section{Step 2: Program Outcomes and Objectives and Logic model of change}

This step is composed of five tasks. The first was to identify the desired changes in behavior and the environment. The outcomes were formulated using SMART objectives, which stands for: Specific, Measurable, Achievable, Realistic and Time [15]. The second task was to specify the required performance objectives for the behavioral and the environmental 
outcomes. The performance objectives are the sub-behaviors or exact actions needed to be carried out by individuals to achieve the behavioral change outcome. In the third task, the most important and changeable determinants related to the behavioral and environmental outcomes were selected from the literature and findings of the conducted studies (table 3). The fourth task was concerned with formulating the matrices of change objectives. Change objectives symbolize the pathways for the most immediate changes in the targeted determinants, which influence the individual and environmental agent's behavior. The matrix of change objectives is formed by crossing the performance objectives with their determinants. The resulting specific change objectives will help to reach the desirable intervention outcomes. Finally, the logic model of change was constructed as the fifth task (Figure 2).

\section{Steps 3 and 4: Program Design and Program Production}

These steps involved seven tasks altogether, focusing on intervention conceptualization and design, as well as organizing intervention methods and their applications. In the first task, the intervention theme (general ideas that give a brand to the intervention), components, scope (the length and extent of the intervention) and sequence (the delivery order of intervention components/materials) were defined. The second task was to identify the behavioral change methods used to target determinants that concern the behavior of the target group and the environmental agents. Furthermore, practical applications based on the selected methods were also developed. The third task was to identify the essential considerations (i.e., parameters for use) for translating the selected behavior change methods adequately into practical applications. In the fourth task, an intervention plan that includes structure, organization and sequence were refined and presented in table 4. Aside from this, the intervention channel/vehicle, materials, length and producers were distinguished for each component. In the fifth task, a plan for intervention materials, feasibility, length, quality and resources will be prepared in collaboration with experts in oral cancer, digital design, health education and promotion. The last two tasks cover the intervention materials, protocol drafting and pretest plan.

\section{Step 5: Program Implementation Plan}

This step consisted of four tasks. In order to increase the likelihood that the intervention would be disseminated, implemented with high fidelity and completeness, and survive over time, it is essential that the potential implementers of the intervention are involved and target the determinants that influence the adoption, implementation and maintenance of the intervention. Therefore, the first task of this step was to identify the potential adopter and implementers of the intervention - including decision-makers, stakeholders, intermediaries - and set up a linkage system that aids in bridging the gap between the intervention development and implementation. The second task was to describe the outcome and performance objectives for the intervention implementers, 
followed in the third task by specifying the determinants and matrices of change. The fourth and final task was to design the implementation intervention by selecting methods and its practical applications, in order to achieve the change objectives for implementation and maintenance.

\section{Step 6: Evaluation Plan}

This step constitutes the final step in the systematic planning approach, and forms a guide for evaluation and it is composed of four tasks. Additionally, this step involved a prior identification of the evaluation stakeholders and of the extent and type of their involvement to ensure that the evaluation results would be used. The first task included writing evaluation questions (process/effect), which were derived from a review of the intervention logic models, goals, objectives and matrices. Effect evaluation investigates whether the behavior, environmental outcomes and objectives change because of the intervention $[9,16]$, while the process evaluation assesses the intervention implementation and delivery [9]. In other words, process evaluation helps to explain why and how the intervention was or was not successful, and with what level of fidelity the intervention components were implemented - instead of only its effect (effect evaluation). Aside from that, it allows us to deal with the threats to the intervention's external validity. The second task involved developing indicators and measures to assess the formulated questions on the effect and process evaluation; in which the measure is an instrument for quantifying an indicator [17]. In the third task, the methodological design for conducting process and effect evaluations was specified. The final task covered the evaluation plan's specification and completeness. 


\section{Result}

\section{Step 1: Logic model of the problem (Figure 1)}

The results of step 1 revealed the contributing behaviors and environmental factors related to oral cancer. Furthermore, the findings revealed the gap that exists between knowledge and the practice of oral cancer examination among JDS dentists $[4,12,14]$. The dentist-level behaviors included dentists not screening for oral cancer, not informing their patients of oral cancer screening, not advising patients at high risk of oral cancer, not connecting oral-cancer and high-risk patients to specialized clinics and counseling centers. The personal determinants that were found to be related to the previous contributing behaviors were: low awareness of the status of oral cancer in Jazan, dentists' lack of experience, skills and self-efficacy, as well as the negative descriptive norms regarding oral cancer practices in JDS [4, 12-14]. Other environmental factors contributing to the problem included dental clinics having no clinical oral cancer guidelines and that Clinical Directors were not including oral cancer centers in interns' training rotations. The determinants of the environmental behaviors were interns lacking exposure to oral cancer patients and having clinical guidelines that do not include oral cancer. 
Figure 1: Logic Model of the Problem

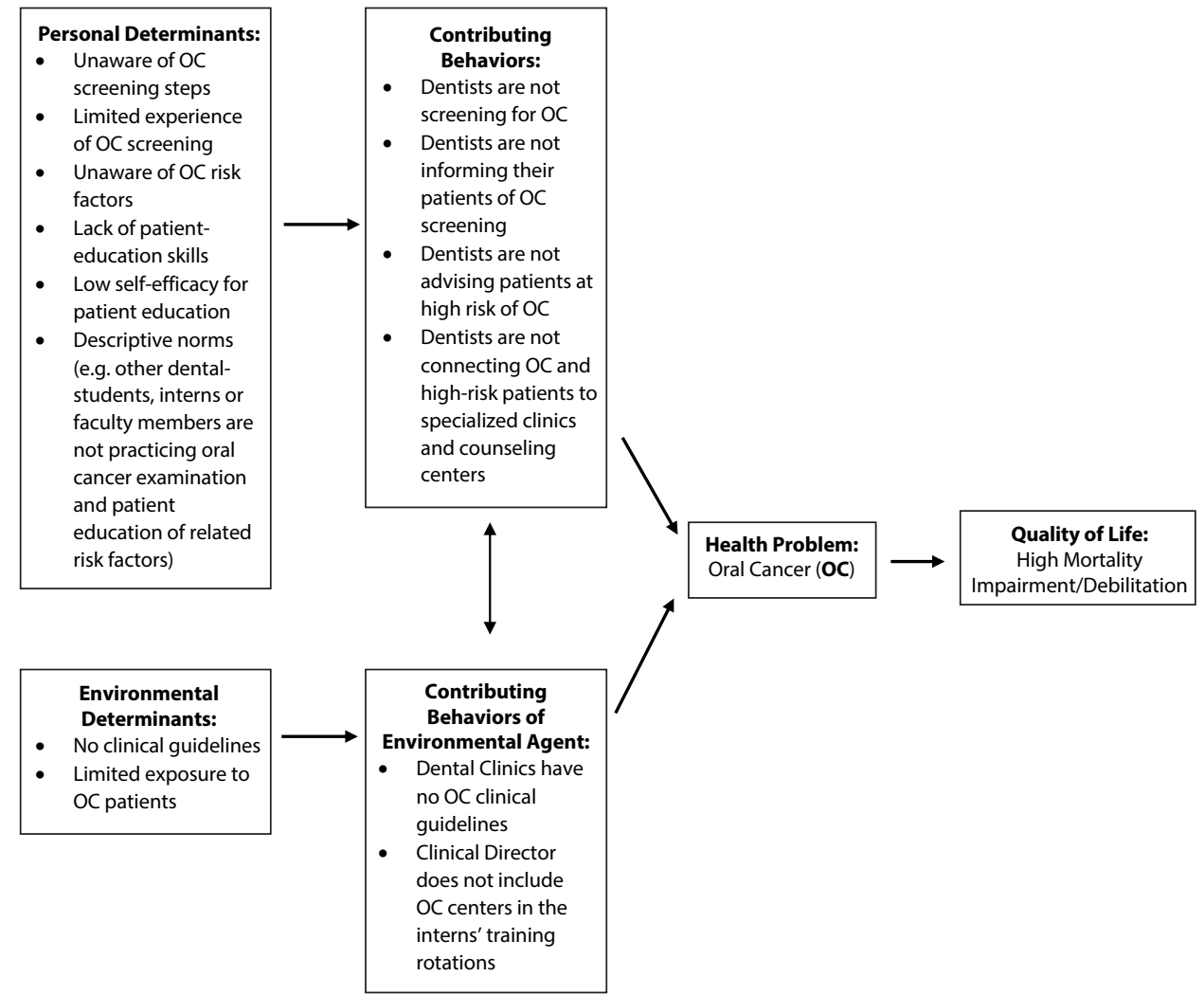

\section{Step 2: Program Outcomes and Objectives and Logic model of change (Figure 2)}

\section{(Tables 1, 2 and 3)}

The results of step 2 identified the behavioral outcome as all dental interns performing complete oral cancer practices (examination and patient education) at JDS clinics within 1 year of implementation. Dental interns at JDS clinics are the first to see patients. One year was decided due to the structure of JDS interns' rotations, as all interns must practice at JDS within their one-year internship. The performance objectives for dental interns to perform a complete oral cancer practice were as follows: 1 ) dentists inform their patients of oral cancer screening, 2) dentists perform a full oral cancer screening for their patients, 3) dentists advise patients who have oral cancer or are high-risk patients, 4) dentists connect their oral-cancer and high-risk patients with specialized clinics and counseling centers. It was found that dentists had not been carrying out these procedures [14]. The main behavioral determinants that need to be modified to achieve these performance objectives were: awareness, skills, self-efficacy and descriptive norms, which were 
evaluated according to their importance and changeability in the literature; see table 3, A. The change objectives for these performance objectives are listed in table 1.

Table 1: Matrices of Change Objectives for Interns

All dental interns perform complete oral cancer practice at JDS clinics within 1 year of implementation

\begin{tabular}{|c|c|c|c|c|}
\hline \multirow{2}{*}{$\begin{array}{l}\text { Performance } \\
\text { Objectives }\end{array}$} & \multicolumn{4}{|c|}{ Personal Determinants } \\
\hline & Awareness & Skills & Self-efficacy & $\begin{array}{l}\text { Descriptive } \\
\text { norms }\end{array}$ \\
\hline $\begin{array}{l}\text { 1. Dentists inform } \\
\text { their patients of oral } \\
\text { cancer screening }\end{array}$ & $\begin{array}{l}\text { Acknowledge } \\
\text { the importance } \\
\text { of patient } \\
\text { communication }\end{array}$ & $\begin{array}{l}\text { Demonstrate } \\
\text { ability in } \\
\text { informing their } \\
\text { patients of oral } \\
\text { cancer screening }\end{array}$ & $\begin{array}{l}\text { Express } \\
\text { confidence in } \\
\text { ability to inform } \\
\text { their patients } \\
\text { of oral cancer } \\
\text { screening }\end{array}$ & $\begin{array}{l}\text { Recognize that } \\
\text { other dentists } \\
\text { inform their } \\
\text { patients of oral } \\
\text { cancer }\end{array}$ \\
\hline $\begin{array}{l}\text { 2. Dentists perform } \\
\text { full oral cancer } \\
\text { screenings on their } \\
\text { patients }\end{array}$ & $\begin{array}{l}\text { Acknowledge } \\
\text { the importance } \\
\text { of full oral } \\
\text { cancer } \\
\text { screening }\end{array}$ & $\begin{array}{l}\text { Demonstrate } \\
\text { ability in } \\
\text { performing } \\
\text { full oral cancer } \\
\text { screenings }\end{array}$ & $\begin{array}{l}\text { Express } \\
\text { confidence in } \\
\text { ability to perform } \\
\text { full oral cancer } \\
\text { screenings }\end{array}$ & $\begin{array}{l}\text { Recognize that } \\
\text { other dentists } \\
\text { perform full } \\
\text { oral cancer } \\
\text { screenings on } \\
\text { their patients }\end{array}$ \\
\hline $\begin{array}{l}\text { 3. Dentists advising } \\
\text { their oral-cancer } \\
\text { and high-risk } \\
\text { patients }\end{array}$ & $\begin{array}{l}\text { Acknowledge } \\
\text { the importance } \\
\text { of advising } \\
\text { their patients }\end{array}$ & $\begin{array}{l}\text { Demonstrate } \\
\text { ability in advising } \\
\text { their patients } \\
\text { regarding their } \\
\text { oral cancer status } \\
\text { or regarding oral } \\
\text { cancer risk factors }\end{array}$ & $\begin{array}{l}\text { Express } \\
\text { confidence in } \\
\text { ability to advice } \\
\text { their patients } \\
\text { regarding their } \\
\text { oral cancer status } \\
\text { or regarding } \\
\text { oral cancer risk } \\
\text { factors }\end{array}$ & $\begin{array}{l}\text { Recognize } \\
\text { that other } \\
\text { dentists advise } \\
\text { their patients } \\
\text { regarding } \\
\text { their oral } \\
\text { cancer status } \\
\text { or regarding } \\
\text { oral cancer risk } \\
\text { factors }\end{array}$ \\
\hline $\begin{array}{l}\text { 4. Dentists connecting } \\
\text { their oral-cancer } \\
\text { and high-risk } \\
\text { patients with } \\
\text { specialized clinics } \\
\text { and counseling } \\
\text { centers }\end{array}$ & $\begin{array}{l}\text { List the } \\
\text { specialized } \\
\text { clinics and } \\
\text { counseling } \\
\text { services }\end{array}$ & $\begin{array}{l}\text { Demonstrate } \\
\text { ability in referring } \\
\text { oral cancer } \\
\text { patients }\end{array}$ & $\begin{array}{l}\text { Express } \\
\text { confidence in } \\
\text { their ability to } \\
\text { refer oral cancer } \\
\text { patients }\end{array}$ & $\begin{array}{l}\text { Recognize that } \\
\text { other dentists } \\
\text { connect their } \\
\text { patients to } \\
\text { tobacco- } \\
\text { quitting } \\
\text { services }\end{array}$ \\
\hline
\end{tabular}


The environmental outcome of the intervention was defined as Clinical Directors including the complete oral cancer practice in the clinical guidelines and adding oral cancer centers to the interns'training schedule at JDS clinics within 1 year of implementation. The Clinical Director is the main person in charge of internships in JDS. The performance objectives of the environmental outcome were: 1) the Clinical Director including the complete oral cancer practice in the clinical guidelines and 2) the Clinical Director increasing the interns' exposure to oral cancer patients by adding oral cancer centers to interns' training rotations. The findings of the conducted studies revealed that dental interns not performing oral cancer practices was influenced by their limited exposure to oral cancer cases and that oral cancer practice was not included in the clinical guidelines [4] which were evaluated according to their importance and changeability in the literature; see table 3 , B. The change objectives for the environmental outcome can be seen in table 2 . 
Figure 2: Logic Model of Change

\section{Personal Determinants:}

- Awareness of oral cancer (OC) screening steps

- Experience and skills of OC screening

- Awareness of OC risk factors

- Patient-education skills

- Self-efficacy for patient education

- Descriptive norms (e.g. other dentalstudents, interns or faculty members are practicing oral cancer examinations and patient education on related risk factors)

\section{Environmental Determinants:}

- OC clinical guidelines

- Exposure to OC patients
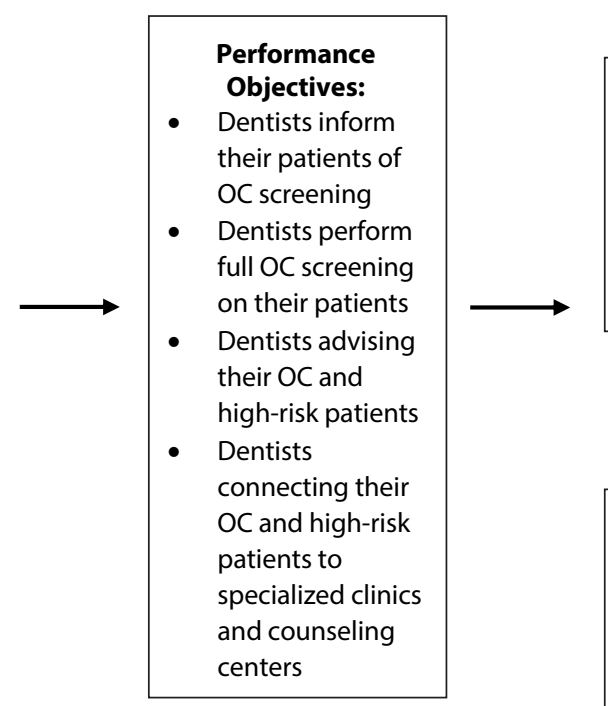

\section{Behavioral}

Outcome:

All dental

interns

perform

complete OC practice
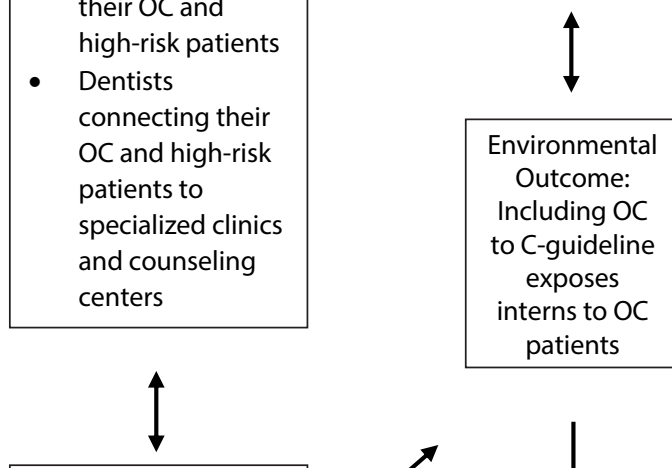

\section{Performance} Objectives of

Environmental Agent (Clinical Director):

- Clinical Director includes $\mathrm{OC}$ practice e.g. ISAC in the clinical guidelines

- Clinical Director increases interns' exposure to $\mathrm{OC}$ patients by adding $\mathrm{OC}$ centers to their

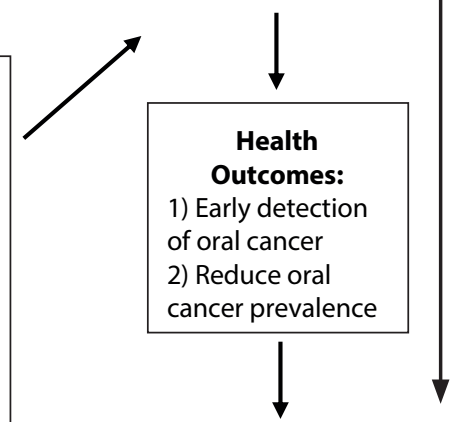

1) Early detection of oral cancer 2) Reduce oral cancer prevalence interns' training rotations
Quality of Life: Less

Mortality and Impairment/Debilitation 
Table 2: Matrices of Change Objectives for Clinical Director

The Clinical Director includes the complete oral cancer practice to the clinical guidelines and adds oral cancer centers to the interns' training at JDS clinics within 1 year of implementation

\begin{tabular}{lll} 
& \multicolumn{2}{c}{ Environmental Determinants } \\
\cline { 2 - 3 } Performance Objectives & $\begin{array}{c}\text { Exposure to oral cancer } \\
\text { patients }\end{array}$ & $\begin{array}{c}\text { Oral cancer clinical } \\
\text { guideline }\end{array}$ \\
\hline $\begin{array}{l}\text { 1. The Clinical Director } \\
\text { includes oral cancer } \\
\text { practices e.g. ISAC into the } \\
\text { clinical guidelines }\end{array}$ & \multicolumn{1}{c}{ n/a } & $\begin{array}{l}\text { The Clinical Director } \\
\text { acknowledges the } \\
\text { importance of including } \\
\text { oral cancer practices in the } \\
\text { clinical guidelines }\end{array}$ \\
\hline $\begin{array}{l}\text { 2. The Clinical Director } \\
\text { increases interns' exposure } \\
\text { to oral cancer patients by } \\
\text { adding oral cancer centers } \\
\text { to their interns' training } \\
\text { rotations }\end{array}$ & $\begin{array}{l}\text { The Clinical Director } \\
\text { acknowledges the importance } \\
\text { of exposing interns to oral } \\
\text { cancer patients }\end{array}$ \\
\hline
\end{tabular}

Table 3: Importance and changeability of determinants

\begin{tabular}{|c|c|c|c|c|}
\hline Outcome & Performance objectives & Determinant & Importance & Changeability \\
\hline \multirow{4}{*}{$\begin{array}{l}\text { A) Behavior: } \\
\text { All dental interns } \\
\text { perform the } \\
\text { complete oral } \\
\text { cancer practice } \\
\text { at JDS clinics } \\
\text { within } 1 \text { year of } \\
\text { implementation }\end{array}$} & $\begin{array}{l}\text { Dentists inform their } \\
\text { patients of oral cancer } \\
\text { screening }\end{array}$ & Awareness & + & ++ \\
\hline & $\begin{array}{l}\text { Dentists perform full oral } \\
\text { cancer screenings on their } \\
\text { patients }\end{array}$ & Skills & ++ & ++ \\
\hline & $\begin{array}{l}\text { Dentists advising their } \\
\text { oral-cancer and high-risk } \\
\text { patients }\end{array}$ & Self-efficacy & ++ & + \\
\hline & $\begin{array}{l}\text { Dentists connecting their } \\
\text { oral-cancer and high-risk } \\
\text { patients to specialized } \\
\text { clinics and counseling } \\
\text { centers }\end{array}$ & $\begin{array}{l}\text { Descriptive } \\
\text { norms }\end{array}$ & ++ & + \\
\hline
\end{tabular}


Table 3: (Continued) Importance and changeability of determinants

\begin{tabular}{|c|c|c|c|c|}
\hline Outcome & Performance objectives & Determinant & Importance & Changeability \\
\hline $\begin{array}{l}\text { B) Environmental } \\
\text { Agent (Adoption): } \\
\text { Clinical Director } \\
\text { includes complete } \\
\text { oral cancer practice }\end{array}$ & $\begin{array}{l}\text { The Clinical Director } \\
\text { includes oral cancer } \\
\text { practices, e.g. ISAC in the } \\
\text { clinical guideline }\end{array}$ & $\begin{array}{l}\text { Oral cancer } \\
\text { clinical } \\
\text { guideline }\end{array}$ & + & ++ \\
\hline $\begin{array}{l}\text { to the clinical } \\
\text { guideline and } \\
\text { adding oral cancer } \\
\text { centers to the } \\
\text { interns' training } \\
\text { at JDS clinics } \\
\text { within } 1 \text { year of } \\
\text { implementation. }\end{array}$ & $\begin{array}{l}\text { The Clinical Director } \\
\text { increases interns' exposure } \\
\text { to oral cancer patients by } \\
\text { adding oral cancer centers } \\
\text { to their interns' training } \\
\text { rotations }\end{array}$ & $\begin{array}{l}\text { Exposure to } \\
\text { oral cancer } \\
\text { patients }\end{array}$ & + & ++ \\
\hline \multirow{5}{*}{$\begin{array}{l}\text { C) Implementation: } \\
\text { All faculty } \\
\text { members in } \\
\text { the Community } \\
\text { Dentistry Division } \\
\text { of JDS will } \\
\text { implement ISAC } \\
\text { with high fidelity } \\
\text { and completeness } \\
\text { within one year }\end{array}$} & \multirow{3}{*}{$\begin{array}{l}\text { The Community Dentistry } \\
\text { faculty members learn } \\
\text { about ISAC content and } \\
\text { how to apply it }\end{array}$} & Knowledge & + & ++ \\
\hline & & Attitude & ++ & ++ \\
\hline & & Self-efficacy & ++ & + \\
\hline & \multirow{2}{*}{$\begin{array}{l}\text { The Community Dentistry } \\
\text { faculty members deliver } \\
\text { ISAC workshops in line with } \\
\text { the intervention plan }\end{array}$} & Skills & ++ & ++ \\
\hline & & Self-efficacy & ++ & + \\
\hline
\end{tabular}

Note: $+=$ not very important, not easy to change.

$++=$ important, changeable.

\section{Steps 3 and 4: Program Design and Program Production (Tables 4, 5, 6)}

ISAC was determined as the intervention theme. ISAC can be defined as an acronym for a new evidence-based approach for comprehensive oral cancer dental practices, which stands for: I = Inform (verbally and documentation): dental interns will inform their patients about performing oral cancer examinations as part of the routine dental examination practice, and include the action of informing of this in the clinical examination documentation. $\mathrm{S}=$ Screen, with two main parts: the first part is taking medical history, according to the clinical guidelines as well as including asking about the local risk factors, such as smokeless tobacco and water-pipe smoking. The second part is a clinical examination according to the clinical guidelines, which includes screening for oral cancer. $A$ = Advice: patients at high risk (e.g. users of smokeless tobacco), will be counseled to aid cessation, using clear and tailored language to deliver health messages [18]. C = Connect, with two dimensions: the first dimension is to connect the patient that has any suspicious lesions with specialized centers that are qualified in dealing with oral cancer cases, such as, for instance, Prince Mohammed Bin Nasser Hospital (PMBN) in the 
Jazan region. The second dimension is to connect tobacco users with a designated service to stop using tobacco products. For JDS, ISAC intervention will be delivered as a workshop that targets JDS dental interns and consists of didactic and practical components. The didactical section will be done in the form of presentations that cover the following aspects: general and local oral cancer epidemiology, general and local oral cancer risk factors and their effects, full oral cancer screening and referring oral cancer procedures (if needed), emphasis on patient education and practical examples, as well as introducing the ISAC method, and tobacco cessation services. The practical section emphasizes the following dimensions: modeling by the trainer (using ISAC), interns engaging in a roleplay where they apply ISAC on each other in two groups - the first group practices and the second group observes, and vice versa. This will be followed by providing feedback to each other, under the supervision of a trainer who will provide positive comments. At the end, recognition in the form of a certificate will be provided to all participants. The ISAC program schedule at JDS can be seen in the following Gantt chart.

Gantt chart: Program schedule

\section{ISAC (Inform, Screen, Advise and Connect) Program}

\begin{tabular}{|c|c|}
\hline \multicolumn{2}{|c|}{ Main Jazan Dental School Auditorium, Jazan University } \\
\hline Date: / / & \\
\hline 09:00 - 9:30 & Sign-In \\
\hline 09:30 - 10:00 & Introduction to ISAC \\
\hline $10: 00-10: 30$ & $\begin{array}{l}\text { General/local oral cancer epidemiology, general/local oral cancer risk factors } \\
\text { and their effects }\end{array}$ \\
\hline $10: 30-11: 00$ & Full screening protocol \\
\hline $11: 00-11: 30$ & The importance of patient education and its applications \\
\hline $11: 30-12: 00$ & $\begin{array}{l}\text { Introducing referring methods and centers } \\
\text { Introducing tobacco counseling and cessation services }\end{array}$ \\
\hline $12: 00-12: 30$ & Lunch break \\
\hline $12: 30-13: 00$ & Prayer break \\
\hline $13: 00-13: 30$ & ISAC Workshop Introduction \\
\hline $13: 30-14: 00$ & Modeling \\
\hline $14: 00-14: 55$ & First group practice and second group observe \\
\hline $14: 55-15: 05$ & Break \\
\hline $15: 05-16: 00$ & Second group practice and first group observe \\
\hline $16: 00-16: 45$ & Feedback Session \\
\hline $16: 45-17: 15$ & FAQ, Certificate distribution and closing \\
\hline
\end{tabular}


The selected theory and evidence-based behavior change methods for dental interns and the Clinical Director at JDS can be seen in tables 4 and 5. First, consciousness raising was selected as an evidence-based method to increase the awareness of dental interns about the importance of: patient communication, full oral cancer screening, advising patients, and about referring patients to specialized centers and counseling services. To increase the effectiveness of this method, it is essential that it is followed by increasing the capacity and self-efficacy of dental interns to perform ISAC, which will be done in the next component of the intervention. The trainer will give a lecture addressing: general/local oral cancer epidemiology, general/local oral cancer risk factors and their effects, full oral cancer screening, the importance of patient education and its applications, introducing the ISAC method and introducing tobacco-cessation services.

Second, guided practice was chosen as the evidence-based change method, and it aims to demonstrate subskills, as well as provide instructions and feedback that will develop dental interns' skills and raise their confidence in performing ISAC. The practical application of this method will be as follows: 1) dental interns will have a session with their trainer (MJ) who models ISAC practices; 2) interns will engage in a roleplay, where they apply ISAC in two groups, both practicing and observing; 3 ) dental interns will give feedback to each other under the supervision of $\mathrm{MJ}$ and will receive positive comments from the supervisors as well as each other; 4) a workshop certificate, signed by the JDS Dean, will be distributed to interns who successfully completed performing the ISAC method.

Third, information on the approval of others was specified as the change method to transform the descriptive norm of JDS interns (regarding ISAC practices) into a positive norm. To apply this method practically, dental interns will be shown through the lecture, group communication and mutual support that all JDS clinicians will be engaging in ISAC practices. Fourth, the selected evidence-based change method for the Clinical Director was persuasive communication. This method will be used to guide the Clinical Director towards the adoption of ISAC in the clinical guidelines as well as increasing dental interns' exposure to oral cancer patients. In order to increase the effectiveness of this method, the delivered messages will be relevant to the Clinical Director, framed in a way that fits his beliefs and will be further stimulated by surprising cases and supporting arguments, as follows: The trainer (MJ) will give a presentation introducing the ISAC method and discuss the importance of including oral cancer practices in the clinical guidelines, as well as the benefits of adding oral cancer centers to the interns' training rotations to expose them to oral cancer cases. The sequence of ISAC interventions can be seen in Gantt chart. ISAC intervention components and materials will be pre-tested using thinking-aloud, expert evaluation and questionnaire piloting, in order to optimize the content and execution. The objectives of the pre-test were based on the change method parameters (as illustrated in table 4 and 5), to test the concept (dental interns, the Community Dentistry Division), 
readability (dental interns), message execution (dental interns), and the implementation factors to determine the perceptions of the Clinical Director and the Community Dentistry Division of ISAC's complexity, trialability, relative advantage, and to predict possible problems with implementation (table 6) [9]. 


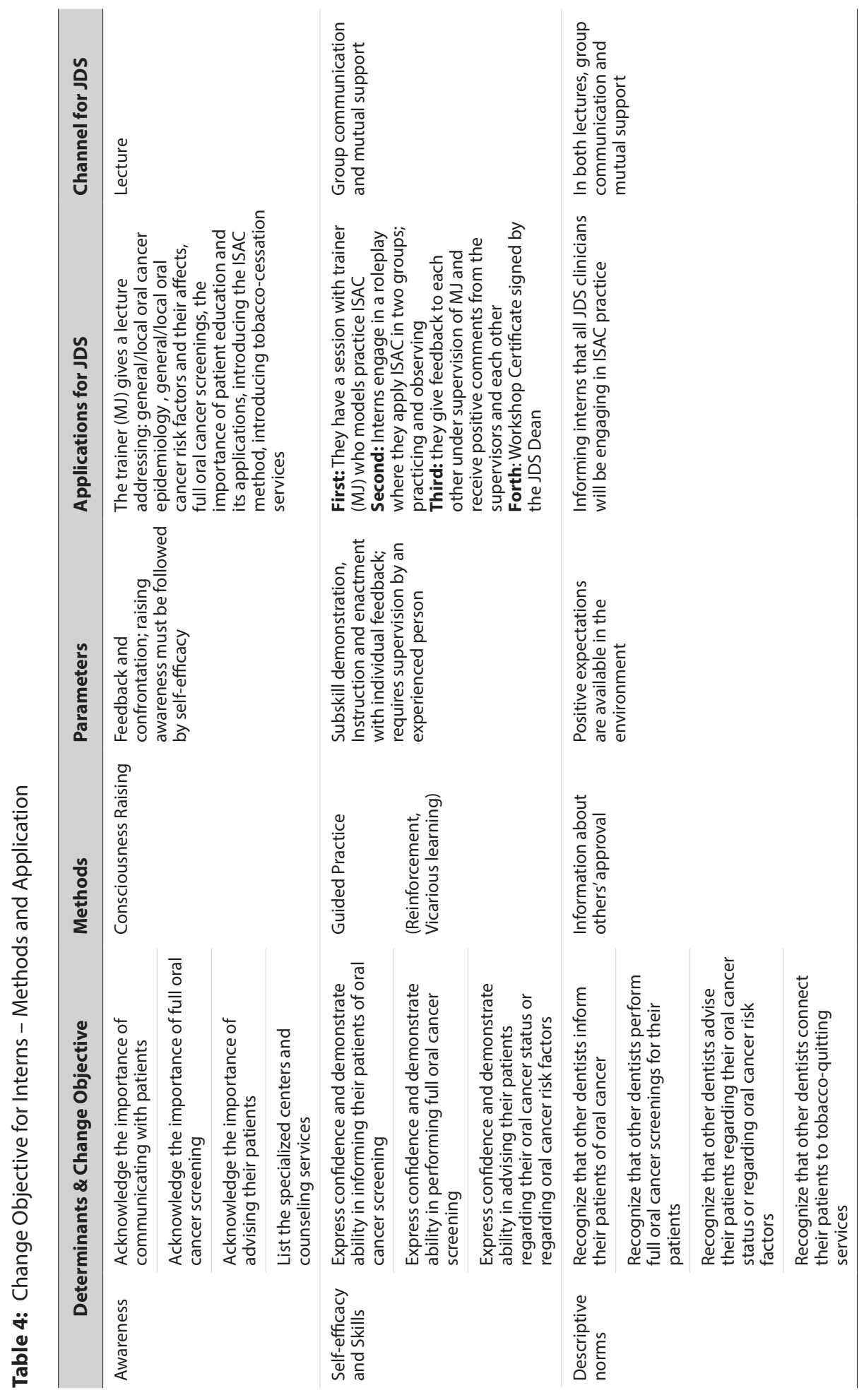




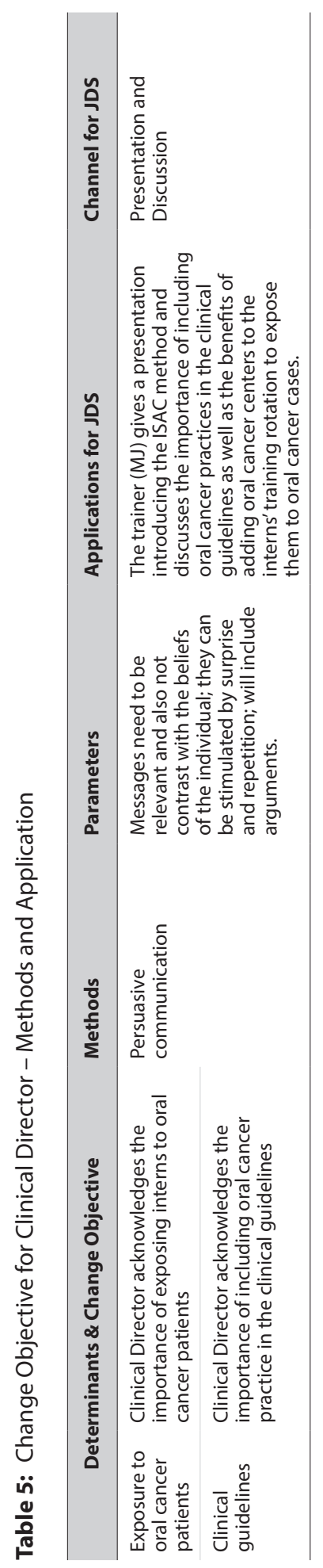


Table 6: Pre-test plan for program components

\begin{tabular}{|c|c|c|c|}
\hline $\begin{array}{l}\text { Program } \\
\text { components }\end{array}$ & Pre-test objectives & Pre-test population & Pre-test procedure \\
\hline \multirow[t]{2}{*}{ Presentation } & $\begin{array}{l}\text { Readability and clarity } \\
\text {. Are the messages } \\
\text { readable and } \\
\text { comprehendible? }\end{array}$ & Dental interns & \multirow{2}{*}{$\begin{array}{l}\text { Thinking-aloud: } \\
\text { The ISAC presentation is } \\
\text { delivered to the interns. } \\
\text { Then, interns are asked to } \\
\text { talk aloud and speak their } \\
\text { mind about the content } \\
\text { of the presentations; } \\
\text { clarity, relevance and } \\
\text { credibility }\end{array}$} \\
\hline & $\begin{array}{l}\text { Message execution } \\
\text { - Is the information } \\
\text { source perceived as } \\
\text { credible? } \\
\text { - Are the presented } \\
\text { images imaginable and } \\
\text { familiar? }\end{array}$ & Dental interns & \\
\hline Presentation & $\begin{array}{l}\text { Implementation } \\
\text { characteristics } \\
\text { · To determine the } \\
\text { perceptions of ISAC's } \\
\text { complexity, trialability, } \\
\text { relative advantage. } \\
\text {. To predict possible } \\
\text { problems with } \\
\text { implementation }\end{array}$ & $\begin{array}{l}\text { Clinical Director } \\
\text { Community Dentistry } \\
\text { Division }\end{array}$ & $\begin{array}{l}\text { Expert evaluation: } \\
\text { ISAC presentation of both } \\
\text { theoretical and workshop } \\
\text { parts are given to Clinical } \\
\text { Director and Community } \\
\text { Dentistry Division. Then, } \\
\text { they will be asked to } \\
\text { evaluate the complexity, } \\
\text { trialability, relative } \\
\text { advantage and possible } \\
\text { obstacles regarding the } \\
\text { implementation of ISAC }\end{array}$ \\
\hline Workshop & $\begin{array}{l}\text { Concept testing } \\
\text {. Is the workshop useful? } \\
\text {. Does it fit with the } \\
\text { needs of dental interns? }\end{array}$ & $\begin{array}{l}\text { Dental interns } \\
\text { Community Dentistry } \\
\text { Division }\end{array}$ & $\begin{array}{l}\text { Thinking-aloud: } \\
\text { Interns and Community } \\
\text { Dentistry faculty } \\
\text { members are asked to } \\
\text { talk aloud and speak } \\
\text { their mind about the } \\
\text { usefulness and if it fits } \\
\text { with their needs }\end{array}$ \\
\hline
\end{tabular}

\section{Step 5: Program Implementation plan}

The adopter of ISAC interventions in JDS is the same environmental agent (Clinical Director), therefore the change method and its practical application were already elaborated previously in steps 3 and 4 . In this situation, the implementers of ISAC in JDS will be the Community Dentistry Division. The outcome of the implementation plan is that all faculty members in the Community Dentistry Division at JDS will implement ISAC with high fidelity and completeness within one year. The performance objectives were as follows: 1) the Community Dentistry Division needs to learn about ISAC content and how to apply it; 2 ) the Community Dentistry faculty members deliver ISAC workshops 
in line with the intervention plan. In order to reach these performance objectives, certain determinants identified from the literature need to be considered for change [19-21]. These determinants include knowledge of ISAC intervention, attitude towards implementing ISAC, self-efficacy and skills to deliver ISAC sessions. Knowledge and attitude as determinants for the implementers of the innovation are considered among the 50 determinants, and this was reached by consensus in the published Delphi-study by Fleuren and his colleagues in 2004 [19]. Furthermore, the role of these determinants in influencing behavior change has been proven with supporting evidence [22, 23]. Additionally, prevention and educational researchers have recognized training of staff as an essential part of promoting the successful implementation of the intervention [21, 24]. Self-efficacy was also found to be strongly associated with the intention to implement interventions $[19,20]$. These determinants were evaluated according to their importance and changeability in the literature; see table 3, C. Matrices for change objectives for implementation can be seen in table 7. The selected theory and evidence-based change methods for implementers at JDS can be seen in table 8. Both the Clinical Director and the Community Dentistry Division were proposed as the potential linkage group participants and their role and responsibilities are listed in table 9.

Table 7: Matrices of Change Objectives for Implementation

Outcome: All faculties in the Community Dentistry Division of JDS will implement ISAC with high fidelity and completeness within one year

\begin{tabular}{|c|c|c|c|c|}
\hline Determinants: & Knowledge & Attitude & Self-efficacy & Skills \\
\hline $\begin{array}{l}\text { Community Dentistry faculty } \\
\text { members learn about ISAC } \\
\text { content and how to apply it }\end{array}$ & $\begin{array}{l}\text { Describe the } \\
\text { content of ISAC }\end{array}$ & $\begin{array}{l}\text { Express positive } \\
\text { feelings towards } \\
\text { learning about } \\
\text { the execution of } \\
\text { ISAC }\end{array}$ & $\begin{array}{l}\text { Demonstrate } \\
\text { confidence to } \\
\text { learn about ISAC } \\
\text { content and how } \\
\text { to apply it }\end{array}$ & $\mathrm{n} / \mathrm{a}$ \\
\hline $\begin{array}{l}\text { Community Dentistry faculty } \\
\text { members deliver ISAC workshop } \\
\text { in line with the intervention plan }\end{array}$ & $\mathrm{n} / \mathrm{a}$ & $\mathrm{n} / \mathrm{a}$ & $\begin{array}{l}\text { Demonstrate } \\
\text { confidence in } \\
\text { delivering ISAC }\end{array}$ & $\begin{array}{l}\text { Demonstrate } \\
\text { skills to deliver } \\
\text { ISAC in line } \\
\text { with the plan }\end{array}$ \\
\hline
\end{tabular}




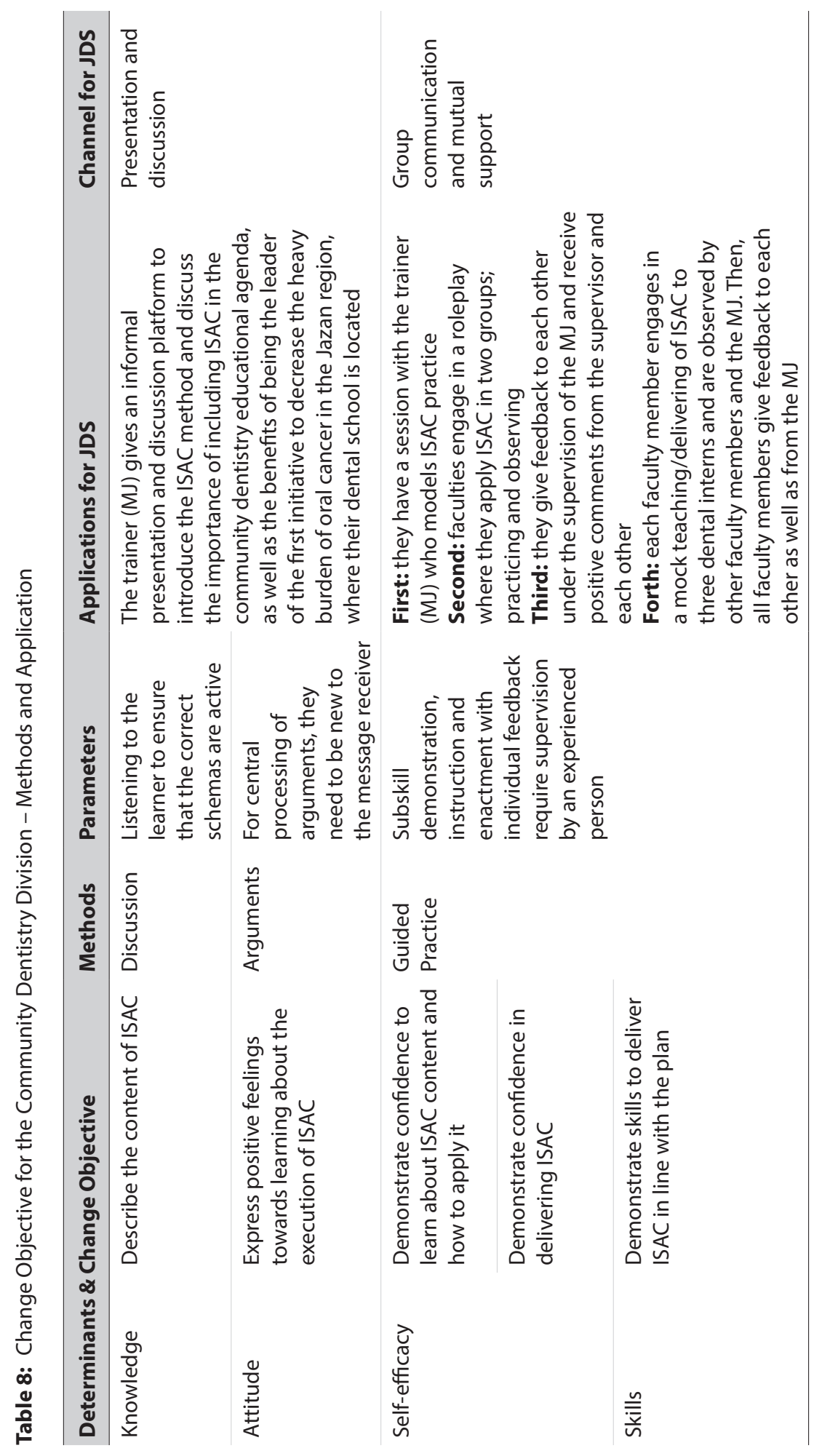


Table 9: Linkage Group Participants

\begin{tabular}{|c|c|c|}
\hline $\begin{array}{l}\text { Adopter, implementers and } \\
\text { maintainers }\end{array}$ & $\begin{array}{l}\text { Roles and responsibilities; } \\
\text { decision power }\end{array}$ & Collaboration in ISAC \\
\hline Clinical Director & $\begin{array}{l}\text { - Responsible for the interns' } \\
\text { training } \\
\text { - Decides on the } \\
\text { implementation of ISAC } \\
\text { - Decides on the maintenance of } \\
\text { ISAC }\end{array}$ & \multirow[t]{2}{*}{$\begin{array}{l}\text { Collaboration of } \\
\text { Clinical Director with } \\
\text { Community Dentistry } \\
\text { Division to implement } \\
\text { and maintain ISAC }\end{array}$} \\
\hline Community Dentistry Division & $\begin{array}{l}\text { Responsible for teaching } \\
\text { dental public health topics at } \\
\text { JDS } \\
\text {. Demonstration of ISAC } \\
\text {. Carries out the maintenance } \\
\text { of ISAC }\end{array}$ & \\
\hline
\end{tabular}

Moreover, in the research on implementation, the aforementioned determinants belong to the employee-readiness factor, which affects the implementation of the innovation in the organization $[23,25]$. Aside from this, other factors such as the implementation climate, leadership and resources were also considered as influencing factors. Implementation climate is a type of the strategic/focused organizational climate that concerns the shared perceptions of implementers (CDD) regarding the importance of implementing the intervention within JDS [26]. The emphasis on the implementation climate was because it provides a fertile context for bringing ISAC intervention into practice successfully [26]. When the Clinical Director and Head of CDD communicate the value of successfully implementing ISAC through their procedures - such as joining the implementer training sessions, emphasizing ISAC in their policies, recognizing the implementers' efforts and providing contingent rewards - the implementer will understand that the organization's leaders value the implementation of ISAC. This, in turn, will enable the implementer to focus their energy and motivation to achieve that goal. As a result, the implementation of ISAC will be highly likely to succeed. The leadership type in JDS could be referred to as transformational leadership [27]. This is associated with high performance and positive implementer attitudes in regard to the active implementation of the intervention, whereby the Clinical Director as well as the Head of CDD care about developing faculty staff to higher levels of potential, stimulating them intellectually to think innovatively about the issues, and recognizing their efforts and accomplishments. The resources are available for the implementation of ISAC; it is going to be part of the $30 \%$ working load of the CDD faculty members designated toward public health services and will not add an extra workload. Four members of CDD will engage in each of the ISAC workshop sessions, 
which is made up of around ten dental interns per one faculty member. Therefore, these factors provide supportive context for the active implementation of ISAC at JDS.

\section{Step 6: Evaluation Plan (Tables 10, 11 and 12)}

The results of step 6 identified the evaluation stakeholders, including the Clinical Director, dental interns, the Community Dentistry Division, the College Board and others, along with the degree and type of involvement of each of them; as can be seen in table 10. Initial questions for the process evaluations were developed according to Linnan and Steckler's [28] key process evaluation components, including: context, reach, dose delivered, dose received and fidelity; as seen in table 11.

Table 10: Evaluation Stakeholders for ISAC Intervention

\begin{tabular}{|c|c|c|}
\hline Stakeholder category & Evaluation stakeholder & Degree and type of involvement \\
\hline $\begin{array}{l}\text { Policymakers and decision- } \\
\text { makers }\end{array}$ & Dean and Clinical Director & $\begin{array}{l}\text { Responsible for deciding whether } \\
\text { ISAC intervention is started, } \\
\text { implemented, continued, } \\
\text { discontinued, restructured }\end{array}$ \\
\hline Target participants & Dental Interns & $\begin{array}{l}\text { Persons and other units that receive } \\
\text { ISAC }\end{array}$ \\
\hline Program staff & $\begin{array}{l}\text { Community Dentistry } \\
\text { Division }\end{array}$ & $\begin{array}{l}\text { Personnel responsible for delivering } \\
\text { ISAC }\end{array}$ \\
\hline Contextual stakeholders & $\begin{array}{l}\text { Preventive dentistry } \\
\text { department }\end{array}$ & $\begin{array}{l}\text { Groups and individuals in the } \\
\text { immediate environment of ISAC, with } \\
\text { interests in regard to what ISAC is } \\
\text { doing and what happens to it }\end{array}$ \\
\hline $\begin{array}{l}\text { Evaluation and research } \\
\text { community }\end{array}$ & $\begin{array}{l}\text { Preventive Dentistry } \\
\text { Department research unit }\end{array}$ & $\begin{array}{l}\text { Evaluation professionals who read } \\
\text { evaluations and pass judgement on } \\
\text { their technical quality and credibility, } \\
\text { and researchers who work in areas } \\
\text { related to ISAC }\end{array}$ \\
\hline
\end{tabular}


Table 11: Initial Process Evaluation Questions for ISAC intervention in JDS

\begin{tabular}{|c|c|c|c|}
\hline Components & Questions & Indicators & Method \\
\hline Context & $\begin{array}{l}\text { During intervention } \\
\text { implementation, has the } \\
\text { context changed for ISAC? } \\
\text { - What changes, if any, have } \\
\text { been made to the JDS } \\
\text { clinical guidelines? } \\
\text { - What changes, if any, have } \\
\text { been made in JDS's capacity } \\
\text { for ISAC? } \\
\text { - What oral cancer } \\
\text { interventions or messages } \\
\text { have JDS dental interns } \\
\text { been exposed to? }\end{array}$ & $\begin{array}{l}\text { JDS clinical guidelines. } \\
\text { Dental interns' eligibility for } \\
\text { and access to ISAC materials. } \\
\text {. JDS ISAC capacity. } \\
\text {. JDS capacity to integrate } \\
\text { new interventions. } \\
\text { - Dental interns' exposure to } \\
\text { other oral cancer screening } \\
\text { intervention efforts, other } \\
\text { than ISAC. }\end{array}$ & $\begin{array}{l}\text { - Tracking JDS clinical } \\
\text { guidelines and } \\
\text { access policies. } \\
\text { · Interviews with } \\
\text { dental interns. } \\
\text { - Communication } \\
\text { with the JDS } \\
\text { Clinical Director } \\
\text { and Community } \\
\text { Dentistry Division } \\
\text { staff }\end{array}$ \\
\hline Reach & $\begin{array}{l}\text { To what extent is ISAC } \\
\text { reaching the intended } \\
\text { participants? }\end{array}$ & $\begin{array}{l}\text { Number/percentage of } \\
\text { dental interns who practiced } \\
\text { ISAC. }\end{array}$ & $\begin{array}{l}\text { ISAC records during } \\
\text { the delivery time. }\end{array}$ \\
\hline Dose delivered & $\begin{array}{l}\text { How much of ISAC is being } \\
\text { delivered? } \\
\text { - What, if anything, is } \\
\text { being omitted/delivered } \\
\text { inconsistently? Why? }\end{array}$ & $\begin{array}{l}\text { Degree of completion } \\
\text { of each part of the ISAC } \\
\text { presentation and training } \\
\text { sessions: } \\
\text { o Attendance of } \\
\text { participants. } \\
\text { o Delivery of presentation } \\
\text { and workshop. } \\
\text { o Feedback by participants. }\end{array}$ & $\begin{array}{l}\text { ISAC records, } \\
\text { including workshop } \\
\text { implementing staff } \\
\text { checklists, dental } \\
\text { intern checklists and } \\
\text { patient checklists. }\end{array}$ \\
\hline Dose received & $\begin{array}{l}\text { What is the average dose } \\
\text { received by dental interns? } \\
\text { What parts of ISAC } \\
\text { intervention, if any, are not } \\
\text { received consistently? Why? }\end{array}$ & $\begin{array}{l}\text { Attention, recall, } \\
\text { understanding and active } \\
\text { engagement. }\end{array}$ & $\begin{array}{l}\text { - Interviews with } \\
\text { random sample of } \\
\text { dental interns. } \\
\text { - Dental interns' recall } \\
\text { and reaction to ISAC. }\end{array}$ \\
\hline Fidelity & $\begin{array}{l}\text { To what extent is ISAC } \\
\text { delivered as intended? }\end{array}$ & $\begin{array}{l}\text { Degree to which ISAC is } \\
\text { linked to theoretical methods } \\
\text { and practical applications } \\
\text { and to determinants. }\end{array}$ & $\begin{array}{l}\text { Narrative analysis } \\
\text { of ISAC concept } \\
\text { booklets against } \\
\text { intervention } \\
\text { mapping matrices, } \\
\text { scripts and } \\
\text { checklists. }\end{array}$ \\
\hline Implementation & $\begin{array}{l}\text { What is the composite score } \\
\text { that indicates the extent to } \\
\text { which ISAC is implemented } \\
\text { and received by dental } \\
\text { interns. }\end{array}$ & $\mathrm{n} / \mathrm{a}$ & $\begin{array}{l}\text { Combining reach } \\
\text { and dose received. }\end{array}$ \\
\hline Recruitment & $\begin{array}{l}\text { What is the procedure used } \\
\text { to approach dental interns? }\end{array}$ & $\mathrm{n} / \mathrm{a}$ & $\begin{array}{l}\text { Convenience sample } \\
\text { (all interns). }\end{array}$ \\
\hline
\end{tabular}


The effect-evaluation questions on health, quality of life, behavior and environment were as the following: how much did the mortality/debilitation and oral cancer cases change in the designated timeframe? What changes in behavior and environmental conditions occurred? Furthermore, the effect-evaluation questions on change objectives were: did the interns participating in the intervention increase their awareness of full oral cancer screenings, patient education, and counseling services? Did the interns who participated in the intervention increase their self-efficacy and skills of practicing full oral cancer examinations, patient education and counseling? Did the participating interns, after the intervention, believe that other dentists are performing the same oral cancer practices, patient education and counseling? The indicators used to measure behavior and the environment were the same as the list of performance objectives. The measurement of these behaviors are likely best conducted by means of observation [29,30]. The indicators used for the measurement of targeted determinants were covered in the matrices of change objectives developed in step 2 (see table 1 and 2). The methodological design for conducting the effect and the process evaluations was described in detail; as seen in table 12. Finally, the measures, such as the questionnaire and checklists, will be developed and tested for instrument reliability and validity using expert evaluations, thinking aloud and piloting. 


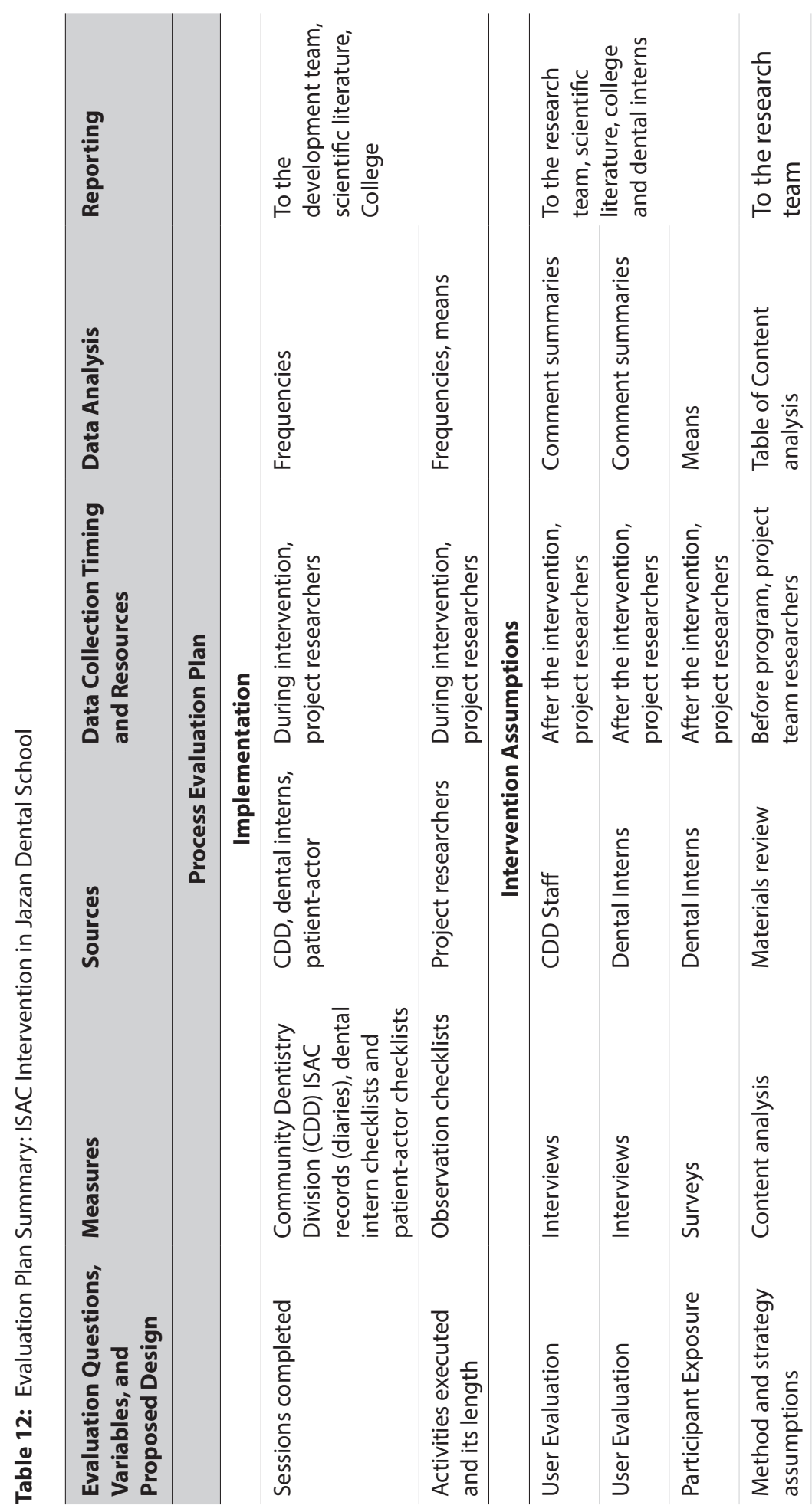




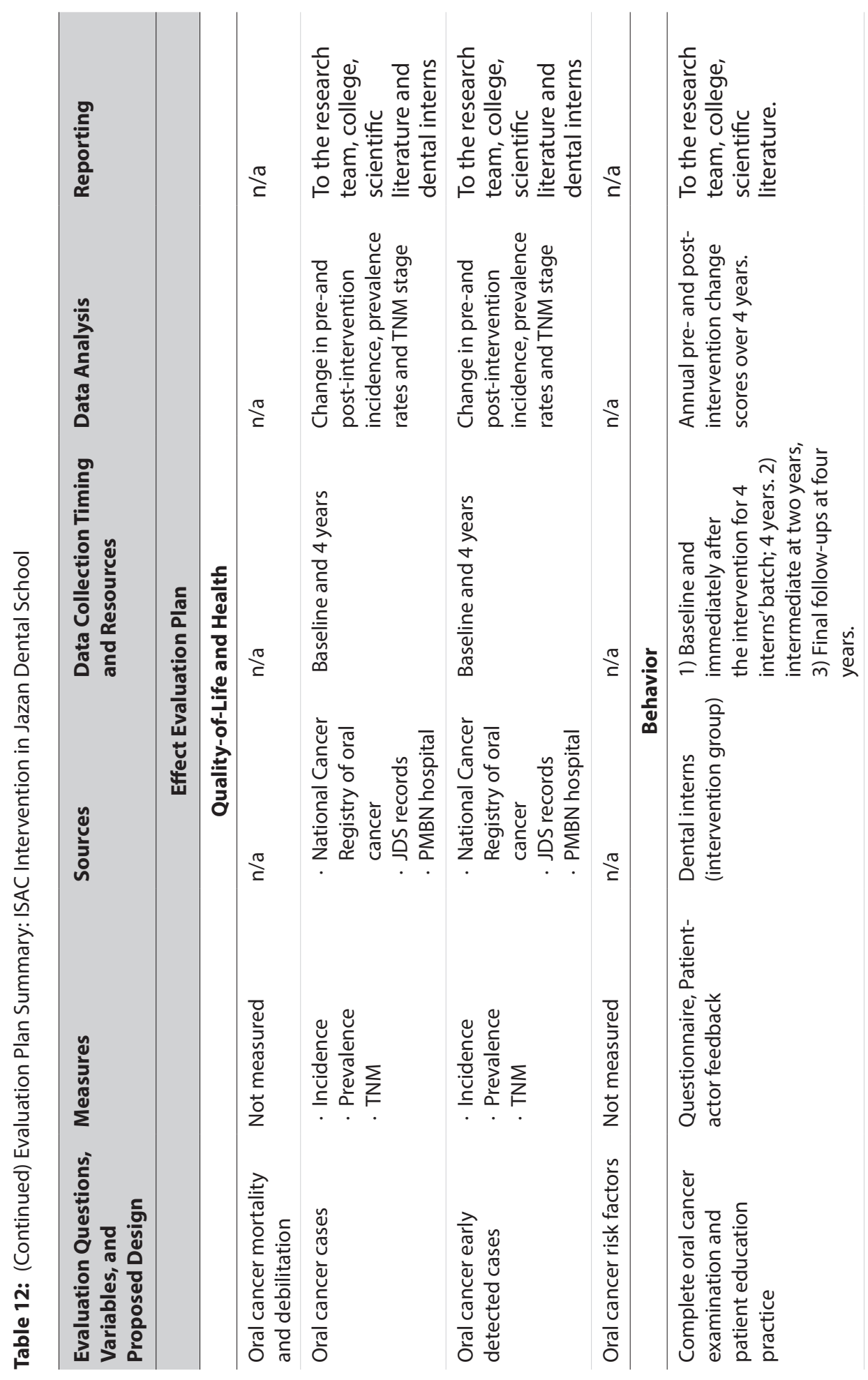




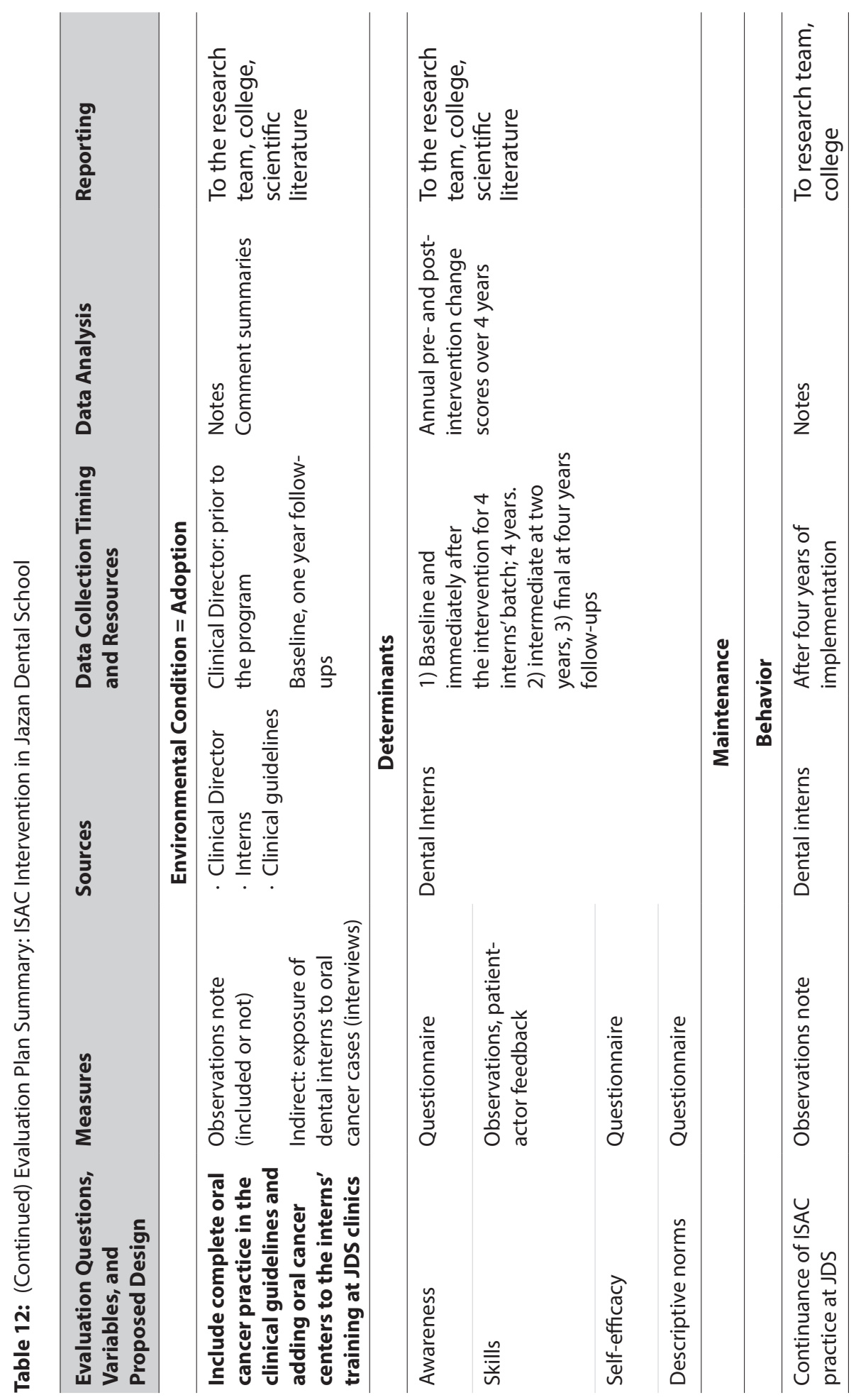




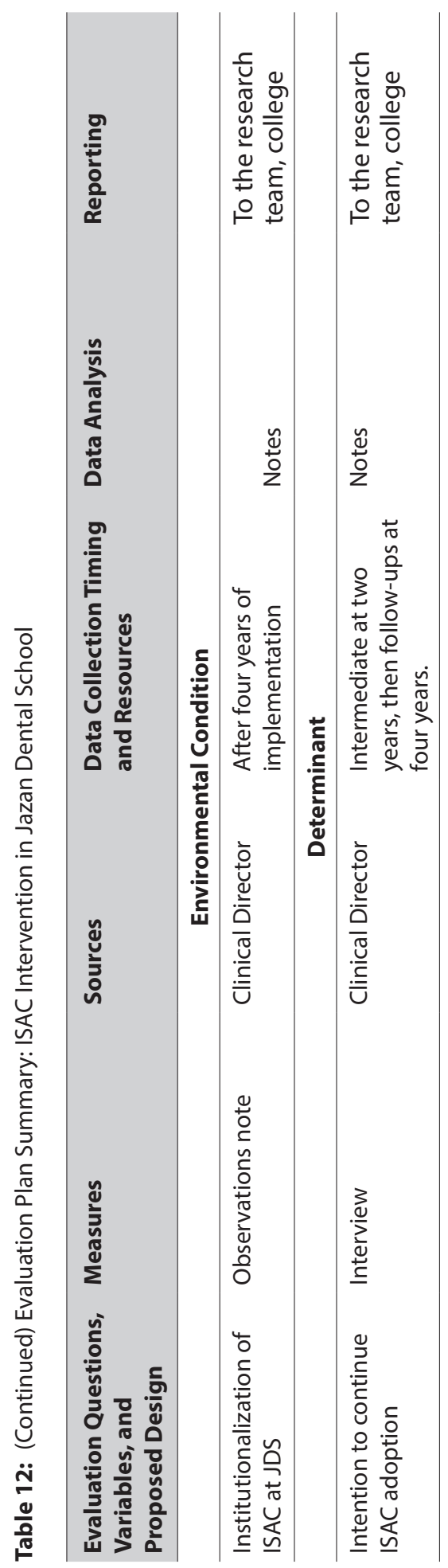




\section{Discussion}

In Jazan, where the prevalence of oral cancer and its risk factors is high [2], there are urgent efforts needed to control this dental public health issue in the region. There had only been limited attempts to raise awareness of oral cancer by a few dental-students' volunteers [4]. Therefore, the Community Dentistry Division of Jazan University, in collaboration with Maastricht University, took the initiative to challenge the oral cancer burden and its risk factors in the region from different ecological approaches. One of these approaches was through utilizing intervention mapping, which engaged stakeholders, oral healthcare providers and citizens in Jazan. As a result, the current developed intervention (ISAC) aimed to improve oral cancer practices at Jazan University by preparing its dental graduates to perform full oral cancer clinical examinations and patient education, which will lead to early detection and prevention of oral cancer.

The needs assessment, at both the level of oral healthcare providers and patients, has revealed major issues relating to dentists' behavior toward oral cancer practice and educating patients - for example, not informing patients of oral cancer examinations, not performing full oral cancer examinations and not educating their patients on the risk factors, if needed, or referring them to tobacco-cessation services $[4,12,14]$. Those major issues were covered in the main pillars of ISAC. Furthermore, upon assessing the contextual characteristics of JDS, several factors were found to be positive in the progress toward implementing the interventions. An interesting example of one of these factors was the implementation climate, which will provide a supportive context for implementing ISAC. The effect of this strategic climate is believed to be most proximal to the effective implementation of the intervention [31]. Moreover, it reflects oral healthcare providers' perceptions toward the priorities of JDS, from what they learned as a shared assumption from JDS policies, procedures, and communications (formal and informal) with JDS leaders [32].

Working towards developing ISAC required extensive work in assessing dental public health issues in a specific context with limited data - and this constituted a great challenge. However, it enriched the research team's understanding of oral cancer in the Jazan region and its local risk factors - for example, the use of Shammah - through investing effort to investigate the issue from different angles, including its clinical practice by oral healthcare providers. Furthermore, the development of ISAC was, in itself, a lesson that casts light on the advantages of engaging multidisciplinary expertise to tackle a dental public health issue like oral cancer. These advantages can be seen clearly when deciding what behavioral and environmental determinants need to be targeted and when weighing these determinants based on their importance and changeability using theoretical and empirical evidence. In addition, the fact that ISAC was a response to JDS administration's 
request to develop an intervention that targets oral cancer and its related health risk behaviors aided in its successful implementation [33]. 


\section{References}

1. Saudi Cancer Registry. Saudi Arabia cancer incidence report 2012 [document on the Internet]. Riyadh, Saudi Arabia: Saudi Cancer Registry; 2015 [cited 2019 Apr 1]. Available from: http:// ghdx.healthdata.org/organizations/saudi-cancer-registry

2. Allard WF, DeVol EB, Te OB. Smokeless tobacco (Shamma) and oral cancer in Saudi Arabia. Community Dent Oral Epidemiol. 1999;27(6):398-405.

3. Moafa I, Crutzen R, Jafer M, Van Den Borne B. Psychosocial determinants of using oral cancer risk factor "Shammah" among adult females in Jazan region, Saudi Arabia: A qualitative study. 2018 (Unpublished).

4. Jafer M, Crutzen R, Moafa I, Van Den Borne B. What do dentists and dental-students think of oral cancer and its control and prevention strategies? A qualitative study in Jazan Dental School. Forthcoming 2019.

5. Sankaranarayanan R, Ramadas K, Amarasinghe H, Subramanian S, Johnson N. Oral cancer: prevention, early detection, and treatment. In: Gelband H, Jha P, Sankaranarayanan R, Horton S, editors. Cancer: Disease Control Priorities [Internet]. 3rd ed (Volume 3). Washington (DC): The International Bank for Reconstruction and Development/The World Bank; 2015 [cited 2019 Apr 1]. Available from: https://www.ncbi.nlm.nih.gov/books/NBK343649/

6. Gomez I, Seoane J, Varela-Centelles P, Diz P, Takkouche B. Is diagnostic delay related to advancedstage oral cancer? A meta-analysis. Eur J Oral Sci. 2009;117(5):541-6.

7. Epstein JB, Huber MA. The benefit and risk of screening for oral potentially malignant epithelial lesions and squamous cell carcinoma. Oral Surg Oral Med Oral Pathol Oral Radiol. 2015;120(5):537-40.

8. Warnakulasuriya KA, Johnson NW. Dentists and oral cancer prevention in the UK: opinions, attitudes and practices to screening for mucosal lesions and to counselling patients on tobacco and alcohol use: baseline data from 1991. Oral Dis. 1999;5(1):10-4.

9. Bartholomew Eldredge LK, Markham C, Ruiter R, Fernández M, Kok G, Parcel G. Planning health promotion programs: An intervention mapping approach. 4th ed. San Francisco: Jossey-Bass \& Pfeiffer Imprints, Wiley; 2016.

10. Bonham CA, Sommerfeld D, Willging C, Aarons GA. Organizational factors influencing implementation of evidence-based practices for integrated treatment in behavioral health agencies. Psychiatry J. 2014;2014:9. doi: 10.1155/2014/802983.

11. Minkler M, Wallerstein N, Wilson N. Improving health through community organization and community building. Health Educ Behav. 2008; 287-312.

12. Jafer M, Crutzen R, Halboub E, Moafa I, Van Den Borne B, Bajonaid A. Dentists behavioral factors influencing early detection of oral cancer: A direct clinical observational study. Forthcoming 2019.

13. Jafer M, Crutzen R, Jafer A, Van Den Borne B. What do dental college clinicians know about oral cancer and its risk factors? An assessment among final year students, interns and faculty members in saudi arabia. J Clin Exp Dent. 2018;10(9):e908-13. doi: 10.4317/jced.55168. 
14. Jafer M, Crutzen R, Ibrahim K.A A, Moafa I, Van Den Borne B. Dental-patients views and needs for oral cancer examination, preventive measure and information in Jazan Region, Saudi Arabia: An exploratory sequential mixed methods study. Forthcoming 2019.

15. Doran GT. There's a SMART Way to Write Management's Goals and Objectives. Management review. 1981;70(11):35-6.

16. Singal AG, Higgins PDR, Waljee AK. A primer on effectiveness and efficacy trials. Clin TransI Gastroenterol. 2014;5(1):e45.

17. Kimberlin $\mathrm{CL}$, Winterstein $\mathrm{AG}$. Validity and reliability of measurement instruments used in research. Am J Health Syst Pharm. 2008;65(23):2276-84.

18. Prochaska JO, Velicer WF. The transtheoretical model of health behavior change. Am J Health Promot. 1997;12(1):38-48.

19. Fleuren $M$, Wiefferink $K$, Paulussen T. Determinants of innovation within health care organizations: literature review and delphi study. Int J Qual Health Care. 2004;16(2):107-23.

20. Bandura A. Self-efficacy : the exercise of control. New York: Freeman; 1997.

21. Basch CE. Research on disseminating and implementing health education programs in schools. J Sch Health. 1984;54(6):57-66.

22. De Vries H. An integrated approach for understanding health behavior; the I-Change Model as an example. Psychol Behav Sci Int J. 2017; 2(2). doi:10.19080/PBSIJ.2017.02.555585.

23. Fishbein M, Ajzen I. Predicting and changing Behavior: The Reasoned Action Approach. New York: Psychology Press; 2011.

24. Fullan MG. Improving the implementation of educational change. J School Organisation. 1986;6(3):321-6.

25. Lewin K. Frontiers in group dynamics: concept, method and reality in social science; social equilibria and social change. Hum Relat. 1947;1(1):5-41.

26. Brownson RC, Colditz GA, Proctor EK. Dissemination and implementation research in health : translating science to practice. Oxford: Oxford University Press; 2012.

27. Judge TA, Piccolo RF. Transformational and transactional leadership: a meta-analytic test of their relative validity. J Appl Psychol. 2004;89(5):755-68.

28. Steckler $A B$, Linnan L. Process evaluation for public health interventions and research. San Francisco, CA: Jossey-Bass; 2002.

29. Swindle T, Selig JP, Rutledge JM, Whiteside-Mansell L, Curran G. Fidelity monitoring in complex interventions: a case study of the WISE intervention. Arch Public Health. 2018;76:53.

30. Breitenstein S, Robbins L, Cowell JM. Attention to fidelity: why is it important. J Sch Nurs. 2012;28(6):407-8.

31. Aarons GA, Hurlburt M, Horwitz SM. Advancing a conceptual model of evidence-based practice implementation in public service sectors. Adm Policy Ment Health. 2011;38(1):4-23. doi: 10.1007/s10488-010-0327-7.

32. Ehrhart MG, Aarons GA, Farahnak LR. Assessing the organizational context for EBP implementation: the development and validity testing of the Implementation Climate Scale (ICS). Implement Sci. 2014;9(1):157. 
33. Chaudoir SR, Dugan AG, Barr CHI. Measuring factors affecting implementation of health innovations: a systematic review of structural, organizational, provider, patient, and innovation level measures. Implement Sci. 2013;8:22. doi: 10.1186/1748-5908-8-22. 

CHAPTER 7 
General Discussion 


\section{General Discussion}

This dissertation aimed to develop a comprehensive intervention at Jazan Dental School (JDS), using the Intervention Mapping (IM) approach, that contributes to the early detection and prevention of oral cancer. To do so, four studies, combining quantitative and qualitative methods, were conducted to develop a thorough needs assessment for the problem from different perspectives. Based on the findings from those studies, as well as relevant theoretical and empirical evidence, the ISAC intervention was developed.

All in all, our studies revealed that early detection and prevention of oral cancer is a wicked public health problem that encompasses multiple actors on different levels and requires an integrated approach. This integrated approach should consider the system in which individuals live and work, as well as the individuals themselves who can make the change happen. Essentially, in this project JDS is viewed as the system that influences individuals, as it represents the largest dental polyclinic center in the region and provides free treatment for the community in different dental fields. Furthermore, it is the only Dental Faculty in Jazan, and its annual alumni ( $>80)$ will likely cover most dental clinics in the government and private sectors of the region. JDS stakeholders, faculty members, interns, students and patients are the individuals who can contribute towards establishing a change with respect to the early detection and prevention of oral cancer. Therefore, the active participation of these individuals in ISAC was emphasized throughout the process of developing ISAC and its implementation plan.

In assessing the contributing behaviors to the early detection and prevention of oral cancer at the dentist level, we found that practitioners were not screening for early signs of oral cancer, not informing their patients about the screening, not educating their patients about oral cancer, and not connecting high-risk patients (users of Shammah, or individuals with premalignant lesions) to specialized clinics and counseling centers (Chapters 3 and 4). These types of behavior can adversely affect the prognosis of oral cancer by leaving this progressive disease to remain undetected for a long time, and opening up the possibility for cancerous cells to invade the adjacent tissue. Therefore, these behaviors represent the main pillars of the ISAC intervention.

In reviewing theories and concepts to explain dentists not practicing oral cancer examinations, we found several factors that are frequently addressed in the literature which were believed to influence dentists' behavior. These factors include dentists' awareness, knowledge, perceptions, experience, confidence and practical skills [1, 2]. The relationship between dentists' knowledge of oral cancer and dentists' practice of oral cancer examination has been demonstrated in previous research [3]. Although JDS dentists had an adequate level of knowledge, we found a deficiency in their familiarity 
with regard to local oral cancer issues (Chapter 2) [4, 5]. This deficiency was unpacked in the third chapter of this dissertation, as the JDS curriculum showed no emphasis being put on local aspects of oral cancer in the Jazan region, such as oral cancer common risk factors and gender distribution. Complex behavior, such as oral cancer examination practices, necessitates mastering several essential sub-behaviors. Understanding of this complex behavior (and its sub-behaviors) also requires an understanding of its determinants.

The effect of knowledge as a determinant alone in regard to such complex behavior patterns is insufficient. As revealed in the fourth chapter of this dissertation, the majority of dentists failed to perform oral cancer examination practices, although they had an adequate level of knowledge. This detected knowledge-practice gap may be attributed to their lack of experience and training on oral cancer examination practices, as well as lacking knowledge and skills in patient education and counseling. The knowledge-practice gap was also evident in different medical fields $[6,7]$. Negative subjective norms accompany dentists' passive behavior towards oral cancer examinations at JDS. When a faculty member who should represent the ideal example is seen not to be practicing oral cancer examinations, dental students' prevailing norms toward this practice would then be more passive. This passiveness is serious, as patients at high risk of oral cancer would miss a chance to detect the disease at an early stage. Culture, on another hand, presents a barrier for Saudi dentists. For example, practitioners may encounter difficulties when conducting oral cancer examinations on the opposite gender and when asking about specific risk factors, such as sexual behavior and drug/substance use (i.e. Shamma). Indeed, the impact of gender dyads on doctor-patient communication was demonstrated in previous reviews [8-10]. This gender concordance (doctor has the same gender as patient) can improve interactions between the doctor and the patient, and increase patient satisfaction and vice versa [11, 12]. However, unlike dentists' beliefs, JDS patients do not see the gender of the dentist or patient as a barrier to performing oral cancer examinations.

JDS patients confirmed dentists' passive behavior towards oral cancer examination practices. Despite the passive behavior of dentists in this regard, patients were in favor of oral cancer examination practices, which may reflect their interest in their own health. In this sense, patient perceptions can be enlightened in view of the Health Belief Model (HBM) [13]. The HBM describes the individual's behavior and their readiness to act in terms of perceived threats and net benefit constructs. Patients' perceived susceptibility and severity of oral cancer and the perceived benefits of receiving oral cancer examinations/ self-examinations were found to be the major constructs that would determine patients' readiness to undergo the examination, and this has also been shown in previous research among the Australian population [14]. JDS patients' positive perceptions toward the practice of oral cancer examinations were more related to their beliefs in respect to the great benefits it would have in reducing the mortality rate (Chapter 5). Cues to take action, 
such as the loss of relatives or friends due to oral cancer, could act as a prompt, activating the readiness to act against oral cancer - as was recalled by some patients in our study (Chapter 5). Although both dentists and patients shared positive beliefs and readiness toward examinations, dentists missed several opportunities to examine and educate their patients about self-examination for oral cancer in their routine dental visits, which could be inferred from patient reports revealing that they lack the knowledge, confidence and skills related to oral cancer examinations.

Therefore, the premise of the ISAC intervention was derived from the main four areas that were deficient among our investigated dental students and dentists, and are as follows: informing patients of oral cancer examinations, screening for oral cancer, advising and educating patients about oral cancer and its examination, and connecting patients to specialized centers if necessary (Chapter 6). That being said, the ISAC intervention materials and components - including the presentation and workshops - will be pre-tested before the implementation of the main intervention, using thinking-aloud, expert evaluation and questionnaire piloting, among groups of the dental interns and the experts. This will be carried out for the purpose of concept testing, checking the readability, clarity, and execution of the messages as well as implementation characteristics that help to identify the assumptions of the JDS Clinical Director and the Community Dentistry Division in terms of ISAC's complexity and readiness for trial, and to predict any possible challenges that might be encountered in the implementation phase. Furthermore, process evaluations - for key components such as context, reach, dose delivered, dose received and fidelity - will also be covered in the pre-testing of the intervention. These aspects will allow for any necessary refinements or adaptions to the intervention, whereas the effects will be evaluated by means of a questionnaire (to be developed) and patient-actor feedback before and immediately after the intervention (after two years and after four years).

The organizational climate for the ISAC intervention was assessed in the light of the model described by Gregory Aarons and his colleagues for the organizational process's role in dissemination and implementation of the research [15]. Upon assessing the organizational context of JDS, several factors were found to be conducive to the ISAC intervention's implementation. The positive implementation climate in JDS can provide a supportive and fertile context for implementing the ISAC intervention (Chapter 6). The transformational leadership type that was observed at JDS is believed to be associated with higher implementer performance rates and positive attitudes toward the active implementation of ISAC (Chapter 6) [16]. This transformational leadership comprises the Clinical Director's and the head of the Community Dentistry Division's (CDD) interest in encouraging faculty members to reach the highest performance, stimulating their intellectual activity to think innovatively as well as recognizing the staff's efforts and achievements. Other factors addressed in the implementation research included the 
organizational readiness for change. Readiness for change is considered an important antecedent to the successful implementation of an innovation in the organization. Factors such as implementers' perceptions towards the intervention, efficacy, and principal support, are often considered the influential factors associated with the organization's readiness for change $[16,17]$, which was evident at JDS.

On the policy level, the Multiple Streams Approach theory (MSA) can help in understanding the process of policy-making and its impacts on ISAC implementation [18]. MSA postulates that policies advance when elements of three streams come together. The first stream represents the problem: the high oral cancer rate. The second stream entails potential policy developments to effectively solve the problem: ISAC. Lastly, the third stream symbolizes the political will and public opinions, which either originate from predictable events or unpredictable circumstances, such as a natural disaster. With the new vision of Saudi Arabia towards public health and primary prevention approaches, a novel intervention such as ISAC is likely to be on the priority list for JDS.

The first international conference for oral cancer in Saudi Arabia was held in Jazan in 2017. It was organized by JDS and included a panel of experts, dentists, political parties, as well as other public leaders. This conference opened a window of opportunity that revealed the aspects of this project to public leaders and the political parties. Therefore, the political environment for ISAC is promising. The ISAC intervention, if found to be effective, would be disseminated on a larger scale to include dental schools, the Ministry of Health clinics, and to other countries that share a similar burden of oral cancer, such as Yemen [19, 20]. 


\section{Methodological Considerations}

This dissertation involves different study designs, including a population-study survey of JDS (Chapter 2); a cross-sectional explorative study design among dentists, stakeholders, dental interns and students (Chapter 3); a cross-sectional clinical observational study design among dentists, dental interns and students (Chapter 4); an exploratory sequential mixed methods study design among JDS patients (Chapter 5); and an intervention protocol (Chapter 6). All the strengths and limitations associated with these designs were elaborated in the previous chapters. In addition to those, this section of the dissertation highlights some methodological considerations more generally related to these designs.

Knowledge was repeatedly reported in the literature as an important determinant for dentists' oral cancer practices. Therefore, the first objective for the research in this dissertation was to investigate the current knowledge of oral cancer and its related aspects among dentists at JDS (Chapter 2). To do so, a JDS population survey was conducted, and included all final year students, all dental interns and dental faculty members. JDS was supporting the research, which meant that almost all the involved groups in the school participated voluntarily in the study. The knowledge of dentists relating to oral cancer clinical practices was found to be adequate in general (Chapter 2) and therefore, an explorative study was desirable to investigate other possible determinants that might influence dentists' practice of oral cancer examinations (Chapter 3).

The second study's methodology was based on Grounded Theory, as we wanted to gain in-depth information about possible determinants and risk behaviors related to the early detection and prevention of oral cancer (Chapter 3). All the interviews in the second study were conducted in the Arabic language. As all the participants were native speakers of Arabic, they were able to express their thoughts without language restrictions. However, there were no software programs that operate in Arabic for the qualitative analysis, which left us with no option other than to perform a manual analysis of data. Translating the data into English, in order to use software programs for the current study's analysis, was not a preferred option because the data would be susceptible to deterioration and loss of valuable information. Therefore, the data analysis was done on the Arabic transcripts. In the third study, we observed dentists' practices in a real clinical setting with patients, using a cross-sectional observation study design (Chapter 4). We controlled for the environmental factors that evidently influenced dentists' behavior in the literature - for example, the amount of time required and previous dental procedures - by involving only new patients and not setting a time limit for the clinical examinations.

For the study on the patients, we utilized an exploratory sequential mixed method design (three-phase procedures), in which the findings from the explorative study (qualitative 
phase) were used to develop reliable and valid measurement instruments to collect data that is generalizable to a larger sample of the same population (quantitative phase) (Chapter 5) [21]. For this purpose, patients were interviewed in the qualitative phase through individual interviews because focus group discussions were not possible. Following that, the generated themes were used to develop an instrument for the quantitative study among patients that would take place afterwards. The instrument for the patients' quantitative study was pre-tested for clarity and content validity among 26 male and female dental patients, using a thinking-aloud procedure, which was followed by a considerable revision to improve participants' understanding of some questions. Another re-evaluation of the modified questionnaire, by means of the thinking-aloud procedure, was conducted among 25 male and female dental patients. After that, the questionnaire was sent to an Arabic-speaking dental public health specialist and two Arabic-speaking health promotion specialists for an overall evaluation, in which no further issues were raised. However, it is necessary to state that self-report questionnaires might be subject to, for example, social desirability bias and acquiescence bias [22]. These possible biases were controlled for with the use of anonymous questionnaires that included a variation of scales and wording, as well as by providing the participants with enough time to complete it.

Another point to be considered is that the sample we used for the qualitative study was not included in the quantitative study, as this would have produced undue duplicates in the responses. In our study, careful attention was paid to this point, as the results from the explorative study sample showed a lack of knowledge regarding oral cancer - and that was contradicted by the results of the quantitative sample, which showed that the level of knowledge was adequate. A possible explanation is that many patients who participated in the follow-up quantitative study were found to have a university-level education, in comparison to the qualitative sample, although both samples were recruited from the same target population. 


\section{Implications for practice}

\section{For dentists:}

- Although some guidance regarding the steps of performing oral cancer screening is taught in the didactic dental curriculum, our studies have shown that most dentists are not screening for oral cancer. Furthermore, most dentists also lack the capacity to perform the associated sub-behaviors, e.g., taking biopsies and educating patients. Therefore, dentists should receive meticulous training on essential skills and be competent enough in the face of oral health challenges in the region of Jazan.

- Dentists and future dentists should bear in mind that patients will not be offended if they practice oral cancer examinations and that asking for oral cancer risk factors and its signs or symptoms is essential for the early detection and prevention of oral cancer, hence, reducing its mortality rate.

- Dental patients share favorable perceptions of being educated and trained on oral cancer and self-examinations. Therefore, dentists should take advantage of that and perform regular practices of oral cancer examination in their routine dental visits, with special attention being paid to high-risk groups.

\section{For dental schools:}

- The majority of dentists were not performing oral cancer examination practices. Dental schools should empower their graduates via education and support. Dental educational courses must emphasize that their dental students acquire effective and essential evidence-based educational materials and skills for oral cancer examinations, be able to provide patient education, and encourage dental students' competencies utilizing authentic experiences during all clinical academic years.

- Although dentists had adequate knowledge regarding oral cancer, there is uncertainty about their knowledge on specific issues of oral cancer in the region, their knowledge regarding the diagnosis of oral cancer and their knowledge to provide patient education and support to oral cancer patients. In particular, local issues regarding oral cancer must receive special attention in educational courses.

- The prevailing negative norms relating to oral cancer examination practices that we found in the school can adversely affect the behavior of dental students, interns as well as faculty members. Therefore, dental school leaders should effectively communicate the importance of oral cancer examination practices in their actions, both verbally and practically - for example, via participating in the training sessions for oral cancer practices, or by providing incentives for good practice. 


\section{For faculty members and dental researchers:}

- Faculty members represent the ideal example for dental students. Therefore, how faculty members behave can greatly influence dental students' behavior. Faculty members should be aware of their passive behavior and its adverse effects on their students.

- This dissertation included studies with a qualitative design, which can add to the technical capacity of the dental researcher to use a different scientific approach. For instance, using Grounded Theory in research to explore the possible determinants for dentists' behavior (resulting in the development of a theory) may aid in explaining such behaviors. Furthermore, it would support the emergence of further studies and targeted interventions for other dental schools in areas that share similar circumstances of high rates of oral cancer, as is the case in Yemen and Sudan.

- Experience and self-confidence are important determinants for the practice of oral cancer examination. Future interventions should consider these determinants when aiming to enhance oral cancer examination practices.

\section{For policymakers:}

- Patients revealed their need for oral cancer education programs that include training on oral cancer self-examination. Thus, policymakers should bear the responsibility of organizing interactive and regular in-reach/outreach community programs for oral cancer.

- Dental interns and students revealed that oral cancer was not emphasized in the dental curriculum. Policymakers can make an active policy that emphasizes oral cancer examination practices.

- The stress of accomplishing a specific number of requirements within a limited timeframe could pose a challenge to dental students performing oral cancer examination practices. Dental school policy should stress the quality of the oral health services provided and not solely the quantity of services. Additionally, the designated time for clinical dental examinations may need to be adjusted to provide the necessary time for oral cancer examination practices.

- We used an evidence-based systemic planning approach to develop the ISAC intervention. The ISAC intervention was developed to provide the most precise and relevant policy plan and was directly derived from integrating different involved groups in intervention planning and development.

\section{Avenues for future research}

- Dental patients' knowledge, perceptions and opinions on oral cancer, its related aspects (including oral cancer self-examinations), as well as dentists' practices, were investigated using a mixed approach in this dissertation. Future research can help in quantitatively assessing the socio-cognitive determinants that are associated with oral cancer prevention among patients. 
- To integrate the right work perception in the dental training curriculum, further investigations into dentists' work perceptions are needed.

- Investigations of factors that are associated with oral cancer in Jazan are highly recommended. These investigations should include the involved groups of individuals in the problem, e.g., Shammah users.

- To ensure a high-fidelity implementation of the ISAC intervention, evaluation studies will be needed to assess the process of implementing the intervention as well as its effects. These studies can aid in recognizing the challenges confronting the implementation and hence adapt/refine the intervention to best fit the context in which the intervention is implemented. 


\section{General conclusion}

In spite of the continuous burden exerted by oral cancer on the people of the Jazan region, active measures to enhance the early detection and prevention of oral cancer appear to be lacking. Similarly, although the groups of the volunteered dental students had initiated a few community programs to address oral cancer, cases of the disease in the Jazan region are still on the rise. The findings of the present studies, supported by theoretical and empirical literature, showed that dentists' passive behavior towards oral cancer examination practices and lack of patient education negatively influence the early detection and prevention of oral cancer. Considering the insufficient knowledge of JDS dentists on the oral cancer status in Jazan, negative subjective norms among dental students and faculty members related to oral cancer practices, the lack of emphasis in the education curriculum on oral cancer, the lack of practical experience of dentists (diagnosis, referrals, patient communication), the low efficacy beliefs of dentists about their capabilities, as well as their lack of necessary skills, all indicate that oral cancer examination practices, patient education and communication skills should be central in dental education courses and be stressed upon in the interventions that target oral cancer.

A targeted intervention named ISAC - as the first step - was built on an integrated approach and guided by Intervention Mapping (IM). ISAC aims for a comprehensive practice of oral cancer examination. The direct beneficiaries of this intervention will be dentists and dental schools and it is expected that, if the ISAC intervention is found to be effective, it will contribute significantly to the early detection and prevention of the disease, and will hence enhance patients' quality of life. 


\section{References}

1. Bandura A. Self-efficacy: the exercise of control. New York: Freeman; 1997.

2. Fishbein M, Ajzen I. Predicting and changing Behavior: The Reasoned Action Approach. New York: Psychology Press; 2011.

3. Hashim R, Abo-Fanas A, Al-Tak A, Al-Kadri A, Abu Ebaid Y. Early detection of oral cancer- dentists' knowledge and practices in the United Arab Emirates. Asian Pac J Cancer Prev. 2018;19(8):23515.

4. World Health Organization. Oral cancer [Internet]. Geneva: World Health Organization [cited 2019 Apr 1]. Available from: http://www.who.int/cancer/prevention/diagnosis-screening/oralcancer/en

5. Quadri MF, Alharbi F, Bajonaid AM, Moafa IH, Sharwani AA, Alamir AH. Oral squamous cell carcinoma and associated risk factors in Jazan, Saudi Arabia: a hospital based case control study. Asian Pac J Cancer Prev. 2015;16(10):4335-8.

6. Afonso E, Lizy C, Blot S. Bridging the knowledge-practice gap: a key issue in the prevention of healthcare-associated infections. Contemp Nurse. 2017;53(6):713-5.

7. Shimpi N, Bharatkumar A, Jethwani M, Chyou PH, Glurich I, Blamer J, et al. Knowledgeability, attitude and behavior of primary care providers towards oral cancer: a pilot study. J Cancer Educ. 2018;33(2):359-64.

8. Group ftl, Delpierre C, Kelly-Irving M, Lepage B, Lang T, Schieber A-C, et al. Do gender differences affect the doctor-patient interaction during consultations in general practice? results from the intermede study. Fam Pract. 2014;31(6):706-13. doi: 10.1093/fampra/cmu057.

9. Roter DL, Hall JA, Aoki Y. Physician gender effects in medical communication: a meta-analytic review. Jama. 2002;288(6):756-64.

10. Sandhu H, Adams A, Singleton L, Clark-Carter D, Kidd J. The impact of gender dyads on doctorpatient communication: a systematic review. Patient Educ Couns. 2009;76(3):348-55.

11. Banerjee A, Sanyal D. Dynamics of doctor-patient relationship: A cross-sectional study on concordance, trust, and patient enablement. J Family Community Med. 2012;19(1):12-9.

12. Jerant A, Bertakis KD, Fenton JJ, Tancredi DJ, Franks P. Patient-provider sex and race/ethnicity concordance: a national study of healthcare and outcomes. Med Care. 2011;49(11):1012-20.

13. Glanz K, Rimer BK, Viswanath K. Health behavior and health education: theory, research, and practice: John Wiley \& Sons; 2008.

14. Jornet PL, Garcia FG, Berdugo ML, Perez FP, Lopez AP-F. Mouth self-examination in a population at risk of oral cancer. Aust Dent J. 2015;60(1):59-64.

15. Brownson RC, Colditz GA, Proctor EK. Dissemination and implementation research in health : translating science to practice. Oxford: Oxford University Press; 2012.

16. Judge TA, Piccolo RF. Transformational and transactional leadership: a meta-analytic test of their relative validity. J Appl Psychol. 2004;89(5):755-68. 
17. Weiner BJ. A theory of organizational readiness for change. Implement Sci. 2009;4:67.

18. Kingdon JW, Thurber JA. Agendas, alternatives, and public policies: Little, Brown Boston; 1984.

19. Halboub ES, Abdulhuq M, Al-Mandili A. Oral and pharyngeal cancers in Yemen: a retrospective study. East Mediterr Health J. 2012;18(9):985-91.

20. Warnakulasuriya S. Global epidemiology of oral and oropharyngeal cancer. Oral Oncol. 2009;45(4-5):309-16.

21. Creswell JW, Clark VLP. Designing and conducting mixed methods research. 3rd ed. Sage publications; 2017.

22. Demetriou C, Ozer BU, Essau CA. Self-report questionnaires. The encyclopedia of clinical psychology [Internet]. John Wiley \& Sons; 2014:1-6 [cited 2019 Apr 1]. Available from: https:// doi.org/10.1002/9781118625392.wbecp507 
SUMMARY 
Summary 

Oral cancer is the eighth most common cancer, with high mortality rates worldwide. In this dissertation, the general term 'oral cancer' is comparable to the World Health Organization's reporting on dental public health matters. It also provides a broader scope for the disease burden, whereby the findings could be used by different health professions, such as oral healthcare providers, health promoters, health policymakers and others. The consequences of oral cancer exert a heavy burden on people's oral, systemic, mental and social health. Comprehensive treatments for oral cancer frequently result in inevitable permanent disability and facial disfigurement. The existing threat of oral cancer in the Jazan region (35\% of all cases in Saudi Arabia) necessitates an innovative approach to the problem. Among the different groups involved in the problem, the important role of dentists in tackling oral cancer is recognized in the evidence. Dentists are the frontline key to fostering preventative efforts for oral cancer - they can actively engage in preventing, educating, and screening for oral cancer, and hence are able to detect the disease at an early stage.

This dissertation was prepared using the Intervention Mapping approach. The general aim was to develop a comprehensive intervention that aids in enhancing the prevention and early detection of oral cancer in Jazan Dental School (JDS). Upon analyzing the possible contributing factors to the late diagnosis of oral cancer in Jazan, an underlying behavior that usually remains overlooked when addressing oral cancer issues came to light: dentists' behavior regarding oral cancer. The health approach, which solely attributes the responsibility for oral cancer to the patient, has made many dental researchers miss dentists' accountability for the problem, which is embodied in the dentists' passive behavior toward oral cancer examination practices, patient education and counseling. Therefore, the role played by dentists to tackle oral cancer in the Jazan region was carefully evaluated in different ways in this dissertation.

The first chapter of this dissertation provides an overview of the state of oral cancer globally as well as locally in the Jazan region. It also discusses the importance of the early detection of oral cancer and the role of dentists. Furthermore, it also describes the possible risk factors/behaviors associated with oral cancer detection and diagnosis, as discussed in the literature. The chapter sheds light on different intervention approaches for oral cancer, in terms of prevention or treatments, their usefulness in tackling oral cancer and how it will fit with Saudi Arabia's new vision for public health by 2030. In addition, the chapter outlines the theoretical framework for this dissertation and the reasoning behind the choices made.

The studies in the first part of this dissertation (Chapters 2 to 4) focus on dentists' knowledge, beliefs and perceptions, and actual practice of oral cancer examinations. The first study shows that dentists have adequate oral cancer knowledge in general, 
but that more emphasis on local issues relating to oral cancer in Jazan needs to be considered in the dental curriculum (Chapter 2). Upon assessing their beliefs, opinions and perceived barriers in relation to oral cancer and its practice in Jazan, dentists share favorable perceptions, but they revealed their lack of experience, confidence and capabilities to perform oral cancer examination practices (Chapter 3 ). The stress of the clinical requirements and the time available to finish the required dental clinical cases are believed to be barriers for paying attention to oral cancer examination practices. Nonconcordance of patients and dentists by gender is also perceived as a barrier for Saudi dentists. The study's findings reveal a passive subjective norm at Jazan Dental School (JDS) related to oral cancer practices, both injunctive and descriptive, and how this passive norm influences students' behavior. Furthermore, dentists emphasize their need for training on patient communication skills. The third study confirms dentists' passive behavior in real clinical settings with patients, in which the majority of dentists failed to perform oral cancer examination practices irrespective of their knowledge (Chapter 4). This chapter also identifies a lack of experience, self-efficacy and skills, as the major factors that are commonly observed in dentists' passive behavior.

In the second part of this dissertation (Chapter 5), patients' related factors were explored and assessed in an exploratory sequential mixed methods study design, which included a qualitative phase, an instrument development phase and a quantitative phase. Dental patients share positive beliefs toward oral cancer examination and articulate the need for oral cancer examinations and education as an essential component in routine dental practice. Patients' beliefs were assessed among a larger sample of dental patients and this further confirmed the results of the qualitative study. The chapter demonstrates that patients have an adequate level of knowledge in relation to oral cancer but lack the knowledge and skills to perform oral cancer self-examinations. Furthermore, the findings provide another confirmation of the third study, of which the results show that dentists are not informing patients about oral cancer, not educating, and not performing oral cancer examination practices. The findings clearly reflect the missed opportunities for preventing or detecting the disease at its early stages because of dentists' passive practice of oral cancer examination. In contrast with dentists' beliefs, patients do not consider dentist/patient gender as a barrier for performing oral cancer practices.

The main outcome of this dissertation is the ISAC intervention (Chapter 6). This dissertation took the initiative to address oral cancer and its risk factors in the Jazan region, by engaging stakeholders, oral healthcare providers and the patient population in the development of this intervention. As a result, the developed intervention (ISAC) aims for a comprehensive oral cancer practice at Jazan University by preparing its dental graduates to perform full oral cancer clinical examinations and by providing patient education. The ISAC intervention emphasizes the four pillars that were found to be deficient among dentists 
as the following: I to inform (verbally and documentation) about oral cancer examinations; $S$ screening which has two parts: thorough history-taking and meticulous screening according to guidelines; A to advise patients at high risk, using tailored health messages and health communication principles; and $C$ to connect patients to specialized centers, and tobacco users to tobacco-cessation services. The ISAC intervention at JDS will target dental interns and will be delivered by the Community Dentistry Division faculties in the form of workshops composed of didactic and practical components. Chapter 6 of this dissertation provides a detailed description of how the ISAC intervention was developed, along with a proposed implementation plan.

The last part in this dissertation (Chapter 7) discusses the major results of the different studies, the methodological considerations, the implications of the research findings for practice as well as possible avenues for future research. 


\section{VALORIZATION ADDENDUM}


Valorization addendum 



\section{Relevance}

Oral cancer carries a heavy burden for individuals' oral, systemic, emotional, and social health, leading to a high overall cost related to the disease [1]. The survival rate of oral cancer is no more than five years in the best situations [2]. The high mortality rate of oral cancer is because it is frequently detected at a late stage, which is associated with poor prognosis and has a negative effect on the survival rate [3]. In Saudi Arabia, the Jazan region has the highest rate of oral cancer cases in the country - 35\% [4].

Evidence has shown that the early detection of oral cancer is associated with a better prognosis for the disease [5-9]. Therefore, it is imperative to control the disease by enacting the best prevention and control interventions. Examinations for oral cancer have been found to be the ultimate strategy for detecting the disease at its early stage [10]. Oral health providers are on the frontline in terms of oral cancer examinations. Therefore, their knowledge, awareness, beliefs, and practices toward oral cancer examination are crucial for the early detection of the disease. Dental schools are the settings where future dentists learn and practice their profession. Furthermore, the majority of Jazan's population receive treatments at Jazan dental school clinics. For this reason, Jazan Dental School (JDS) is the major setting and the main oral health provider where dentists' oral cancer practices can be investigated and clinically observed.

The findings of this dissertation are highly relevant for dentists, dental schools, educational researchers, and policymakers. It draws attention to the gap between knowledge and practice of oral cancer examinations and the possible determinants associated with dentists' behavior towards oral cancer examination practices from different perspectives. In addition, the findings offer insights into ISAC's core components for the active enactment of oral cancer examination practices among dentists, using the Intervention Mapping (IM) approach. Furthermore, the insights gained in this dissertation are highly relevant for other regions that share similar oral cancer issues, such as Yemen and Sudan [11-13].

\section{Target groups}

This dissertation's findings are relevant for dentists, patients, dental schools/organizations and policymakers. For dentists, it reveals dentists' health-risk behaviors associated with oral cancer practices, possible explanations and determinants for their behaviors, the hardships that dentists usually encounter as obstacles to performing oral cancer examination practices, and how to overcome these barriers. Furthermore, it describes what evidence-based methods and tools can be used to implement oral cancer examination practices. This dissertation thoroughly describes ISAC intervention protocols and its implementation plan to engage dentists actively in the early detection of oral cancer. Furthermore, it shows that patients are supportive and in favor of being examined and 
educated about oral cancer, regardless of the gender of the dentist/patient. Therefore, dentists can use the knowledge generated from this dissertation in their routine dental examination practices to contribute towards reducing the morbidity and mortality rate of oral cancer in the region of Jazan and others.

For patients, it could be useful to know that dentists share positive beliefs towards oral cancer examination practices. Patients can use the knowledge generated from this thesis to learn and ask their dentists about oral cancer and self-examinations. For dental schools and organizations, this dissertation has revealed that the prevailing norm in the institute could have a great impact on dental students' behavior. Therefore, dental schools should emphasize developing and maintaining positive and supporting norms toward oral cancer examination practices. It has demonstrated that JDS dental curriculums were not focusing on local issues related to oral cancer in the region. Indeed, dental schools must stress local oral health issues and needs in educational courses. Furthermore, it is very important to ensure that dental students are acquainted with evidence-based knowledge and meticulous training on oral cancer examination practices, as became evident in this dissertation, since experience, efficacy and skills are major determinants observed among dentists.

For policymakers, it would be interesting to know that patients who participated in the dissertation highlighted the need for oral cancer education programs that include oral cancer self-examination training. Quantity over quality in terms of treatments is frequently observed among dentists' passive behavior toward oral cancer examination. Policymakers can use the knowledge generated in this dissertation to emphasize the need to implement oral cancer practices in the current clinical guidelines. The knowledge generated from this dissertation carries valuable information for the Saudi Ministry of Health, the Saudi Oncology Society, the Saudi Dental Association, and others.

\section{Products and Activities}

The central product of this dissertation is ISAC. ISAC aimed for comprehensive oral cancer dental practices by dental interns as the target group and will be implemented by Community Dentistry Division members at JDS. ISAC is an acronym of I=Inform, $\mathrm{S}=\mathrm{Screen}$, $A=A d v i s e$, and $C=$ connect. The ISAC intervention was developed using iterative steps of the IM approach, which included a thorough needs assessment, selecting important determinants and risk behaviors, identifying theory and evidence-based change methods and practical applications. The components of the ISAC intervention were derived from scientific evidence, international guidelines for oral cancer, practical feasibility and the setting features of dental clinics. The ISAC intervention comprises two main components: didactical and practical. The information about each component is covered in the ISAC protocol (Chapter 7). 
The results of the first two studies (Chapters 2 and 3) in the dissertation were presented at the International Conference on Oral Cancer that was held at Jazan University, in 2017. The conference involved panels of experts and prominent international figures specialized in oral cancer and related medical fields, and was publicized by means of a press release and media coverage under the support of the Prince of the Jazan region.

\section{Innovation}

To the best of our knowledge, this is the first study that integrated dentists (students, interns, faculties), stakeholders and dental patients to develop an evidence-based clinical dental policy, to improve the early detection of oral cancer in the Jazan region. Most dental training programs in Saudi Arabia are focused on dental students' knowledge and skills for treating patient's chief dental complaints. An important realm that is often disregarded is the dentists' practice of oral cancer examinations, including their efficacy beliefs, capabilities as well as facilitators and barriers. These factors are incorporated and underlined in the ISAC intervention, including the most suitable evidence-based methods to enhance these factors. Another innovative aspect in this dissertation lies the two studies, which explored and assessed dental patients' perceptions regarding dentists' practice of oral cancer examinations and patient education. Patient beliefs constitute a valuable assessment for dentists' behavior in a clinical setting. Furthermore, this type of work also highlights areas that may not have been previously observable by researchers. 


\section{References}

1. Epstein JB, Güneri P, Barasch A. Appropriate and necessary oral care for people with cancer: guidance to obtain the right oral and dental care at the right time. Support Care Cancer. 2014;22(7):1981-8.

2. Cleveland JL,Thornton-Evans G. Total diagnostic delay in oral cancer may be related to advanced disease stage at diagnosis. J Evid Based Dent Pract. 2012;12(2):84-6.

3. Gomez I, Seoane J, Varela-Centelles P, Diz P, Takkouche B. Is diagnostic delay related to advancedstage oral cancer? A meta-analysis. Eur J Oral Sci. 2009;117(5):541-6.

4. Allard WF, DeVol EB, Te OB. Smokeless tobacco (Shamma) and oral cancer in Saudi Arabia. Community Dent Oral Epidemiol. 1999;27(6):398-405.

5. Rodrigues PC, Miguel MC, Bagordakis E, Fonseca FP, de Aquino SN, Santos-Silva AR, et al. Clinicopathological prognostic factors of oral tongue squamous cell carcinoma: a retrospective study of 202 cases. Int J Oral Maxillofac Surg. 2014;43(7):795-801.

6. Rikardsen OG, Bjerkli IH, Uhlin-Hansen L, Hadler-Olsen E, Steigen SE. Clinicopathological characteristics of oral squamous cell carcinoma in Northern Norway: a retrospective study. BMC Oral Health. 2014; 14:103.

7. Monteiro LS, Amaral JB, Vizcaino JR, Lopes CA, Torres FO. A clinical-pathological and survival study of oral squamous cell carcinomas from a population of the North of Portugal. Med Oral Patol Oral Cir Bucal. 2014;19(2):e120-6.

8. Ling W, Mijiti A, Moming A. Survival pattern and prognostic factors of patients with squamous cell carcinoma of the tongue: a retrospective analysis of 210 cases. J Oral Maxillofac Surg. 2013;71(4):775-85.

9. Dissanayaka WL, Pitiyage G, Kumarasiri PV, Liyanage RL, Dias KD, Tilakaratne WM. Clinical and histopathologic parameters in survival of oral squamous cell carcinoma. Oral Surg Oral Med Oral Pathol Oral Radiol 2012;113(4):518-25.

10. Brocklehurst P, Kujan O, Glenny AM, Oliver R, Sloan P, Ogden G, et al. Screening programmes for the early detection and prevention of oral cancer. Cochrane Database Syst Rev. 2010(11): Cd004150.

11. Halboub ES, Abdulhuq M, Al-Mandili A. Oral and pharyngeal cancers in Yemen: a retrospective study. East Mediterr Health J. 2012;18(9):985-91.

12. Warnakulasuriya S. Global epidemiology of oral and oropharyngeal cancer. Oral Oncol. 2009;45(4-5):309-16. doi: 10.1016/j.oraloncology.2008.06.002.

13. Saeed IE, Weng H-Y, Mohamed KH, Mohammed SI. Cancer incidence in Khartoum, Sudan: first results from the Cancer Registry, 2009-2010. Cancer Med. 2014;3(4):1075-84. 

ACKNOWLEDGMENTS 
Acknowledgements 

First and foremost, to Allah, I offer reverence to you for giving me the opportunity, determination and strength to bring this project to completion.

I would like to thank my supervisors, Prof. Rik Crutzen and Prof. Bart van den Borne, for their guidance, swift feedback and constructive comments, and for the skill and abilities they contributed towards completing this task.

Thank you Dr. Ibtisam Moafa for your contribution to data collection for female participants, delightful thoughts and for your continuous support throughout the entire project.

To my professors, colleagues, staff, students and patients at Jazan University Dental School: I appreciate your kindness, your evaluations and reviews of this project, and for your generous participation. I also extend a special thanks to Prof. Anil Sukumaran and Dr. Mohamed Moukhyer for their encouragement, motivation and inspiration.

To my colleagues at Maastricht University: thank you for your continuous friendship, and I especially would like to thank Leon Kolenburg, Patricia von Schenckendorff and Kim van Hensberg for this.

To my parents, uncles, aunts, brothers, sisters and to Ali Zorair: your unending care has helped me to complete this work.

Finally, to my wife, Atheer, and my children, Raseal, Cera, Warce and Raseam: no words can express, and no act of gratitude can relay what your unfailing support, love and care mean to me. I am so grateful to Allah to have you in my life. 
CURRICULUM VITAE 
Curriculum Vitae 

Mohammed Jafer is from the Jazan region of Saudi Arabia. He has completed his Bachelor's degree in Dentistry (BDS) at King Saud University in Riyadh, Saudi Arabia. He holds a Master's degree in Public Health (MPH) and Dental Public Health Residency (DPHc) as well as a Clinical Periodontics Fellowship (CPF) from Case Western Reserve University in the United States. Currently, he is completing his doctorate degree (PhD) in Dental Public Health at Maastricht University's Faculty of Health, Medicine, and Life Sciences, in The Netherlands. He is the former Vice-Dean of Jazan University Dental School for quality and academic development, Saudi Arabia. Mohammed Jafer has participated in several dental public health projects and scientific meetings at local

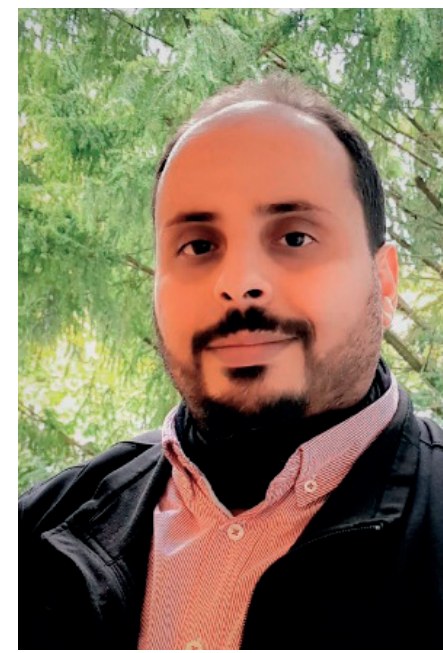
and international levels as well as publishing several papers in reputed journals. He was a key-note speaker at the $1^{\text {st }}$ International Oral Cancer conference in Saudi Arabia and a key-note speaker at the Dental Education conference in Amsterdam. He has an interest in investigating the behavioral contributions to oral cancer and its local risk factors. Consequently, in 2017, he was appointed as the Head of the Oral Cancer Behavioral and Related Risk Factors Research Team in Saudi Arabia, by the First International Oral Cancer Collaboration Committee, and was awarded the Saudi Aramco Prize for Public Services. In 2019, he was nominated for the WHO Prize (Middle East), for his work relating to the prevention of oral cancer. 
PUBLICATIONS 
Publications 

Publication from this dissertation:

Jafer M, Crutzen R, Jafer A, Van Den Borne B. What do dental college clinicians know about oral cancer and its risk factors? An assessment among final year students, interns and faculty members in Saudi Arabia. J Clin Exp Dent. 2018;10(9): e908-13. doi: $10.4317 /$ jced.55168.

Forthcoming publications from this dissertation:

Jafer M, Crutzen R, Moafa I, Van Den Borne B. What do dentists and dental-students think of oral cancer and its control and prevention strategies? A qualitative study in Jazan Dental School.

Jafer M, Crutzen R, Halboub E, Moafa I, Van Den Borne B, Bajonaid A. Dentists behavioral factors influencing early detection of oral cancer: A direct clinical observational study.

Jafer M, Crutzen R, Ibrahim K.A A, Moafa I, Van Den Borne B. Dental-patients views and needs for oral cancer examination, preventive measure and information in Jazan Region, Saudi Arabia: An exploratory sequential mixed methods study.

\section{Work in progress:}

Jafer M, Crutzen R, Moafa I, Van Den Borne B. Introducing ISAC for Oral Cancer Comprehensive Dental Practice.

\section{Other publications:}

Ibrahim A, Abdalla S, Jafer M, Abdelgadir J, De Vries N. Child labor and health: A systematic literature review of child labor on child's health. J Public Health (Oxf). 2018; 41(1): 18-26. doi: 10.1093/pubmed/fdy018.

Idris A, Nandimandalam V, Almutari Dh, Jafer M. Analysis of sugars and PH in commercially available soft drinks in Saudi Arabia with a brief review on their dental implications. J Int Soc Prev Community Dent. 2016; 6(9).

Patil Sh, Rao R, Majumdar B, Jafer M, et al. Oral Lesions in Neonates. Int J Clin Pediatr Dent. 2016; 9(2).

Jafer M, Patil Sh, Hosmani J, Bhandi Sh, Chalissery E, Sukumaran A. Chemical prevention of biofilm-associated oral diseases. J Contemp Dent Pract. 2016; 17(4):337-43. 
Vemina Ch, Marwah N, Jafer $\mathbf{M}$, et al. Prevalence of anterior dental trauma and its associated factors among children aged 3-5 years in Jaipur City, India - A cross sectional study. J Int Soc Prev Community Dent. 2016.

Patil Sh, Jafer M, Sukumaran A. Smokeless Tobacco - Patterns of Consumption, Oral Potentially Malignant Disorders, and Other Oral Health Issue. J Int Oral Health. 2016; 8(4)

Awan K, Patil Sh, Islam S, Jafer M. Early Detection of Oral Cancer - Guidelines for Dental Practitioners. J Int Oral Health. 2016; 8(3)

Nandimandalam V, Idris A, Abuhaya A, Jafer M, Almutari Dh. Assessment of Calcium, Magnesium, and Fluoride in Bottled and Natural Drinking Water from Jazan Province of Saudi Arabia and a Brief Review on Their Role in Tooth. J Int Oral Health. 2016; 8(11).

Jafer M, Quadri MFA, Hendriyani $\mathrm{H}$ and Pramono A. Knowledge, attitude and practice of sweet food consumption and its association with dental caries among school children in Jazan, Saudi Arabia. East Mediterr Health J. 2015; 21(6):403-11.

Jafer M. Oral health and its association with morbidity and mortality in elderly. JOHR. 2015; 6 (4). Available at: http://johr.in/index.php/JOHR/article/view/169

Jafer $\mathbf{M}$ and Quadri MFA. Health information retrieval through different approaches: A literature review. IJMR. 2015;4 (2)

Jafer $M$. The periodontal status and associated systemic health problems among an elderly population attending the outpatient clinics of a dental school. J Contemp Dent Pract. 2015;16 (8)

Chokhandre MK, Mahmoud MI, Hakami T, Jafer $\mathbf{M}$ and Inamdar AS. Vitamin D \& its analogues in type $\mathbf{2}$ diabetic nephropathy: A systematic review. J Diabetes Metab Disord. 2015;58 (14)

Anil S, Jafer M, Preethanath R. Transmission and post-exposure management of blood-borne virus infection in dental practice. Saudi Dent J. 2008;20: (2)

Jafer M, Jafer A and Anil S. Serum nitric oxide levels in smokers and non-smokers with chronic periodontitis. Forthcoming. 



\section{OVERVIEW IN ARABIC LANGUAGE}


Overview in Arabic language 

ن | نبذة

يتوفر في الأطروحة وصف تفصيليٌٌ لكيفية تطوير وتصميم منظومة التدخل ISAC إلى جانب خطة اعتمادها و الخطة التفصيلية المقترحة لتنفيذها، بالإضافة إلى شرح مفصل لآلية تقيمها ودر اسة فرص إدراجها ضمن البرامج التعليمية لأطباء الأسنان في المناطق ذات الاحتياجات المماتلة، وأخيراً تناقش الأطروحة النتائج الرئيسية للار اسات التي أجريت، والاعتبار ات المنهجية، وتطبيقاتها في الممارسة، وكذللك الآفاق المستقبلية لمزيد من الأبحاث في مجال الحد من انتشار سرطان الفم في منطقة جازان. 
أو علاج سرطان الفم في منطقة جاز ان! وأرجعو ا السبب في ذلك إلى غياب الممارسة الفعالة لمكافحة سرطان الفم في المنطقة، إضافةً إلى سلوك طلاب و أطباء الأسنان السلبي تجاه ممارسة فحص سرطان الفم و التثقيف عنه.

إن هذه النتائج تعكس لنا حجم الفرص المهدرة لمنع المرض أو اكتثافه في مر احلَ مبكرة بو اسطة طلاب و أطباء الأسنان بسبب ممارستهم السلبية لفحص سرطان الفم! و على النقيض من اعتقادهم؛ فإن المرضى يعتقدون أن جنس طبيب الأسنان أو المريض لا يجب أن يمثل عائقاً أمام ممارسة فحص سرطان الفم. و تأخذ أطروحة الدكتور اه هذه بزمام المبادرة لأجل مكافحة سرطان الفم ومسبباته و أعبائه في منطقة جاز ان اذ تقدم منظومة التدخل السريري الثامل للكثف المبكرعن سرطان الفم (ISAC)؛ و التي تهدف إلى زيادة ممار سة فحص سرطان الفم و التثقيف عنه و عن مسبباته للحد من تأخر كثف سرطان الفم في منطقة جاز ان؛ من خلال إشر اك طلاب و أطباء الأسنان و المرضى في كلية طب الأسنان بجامعة جاز ان، وتهدف منظومة التدخل ISAC إلى إعداد وتهيئة خريجي طب الأسنان علميا و عمليا لإجراء الفحص السريري الشامل لسرطان الفم ومهار ات التو اصل اللازمة لتثقيف المرضى، وثركز المنظومة على أربعة جوانب: أ) (Inform) -I إخطار المريض لفظيًا وكتابيا عن اجر اء فحص سرطان الفم. ب) (Screen) -S إجر اء فحص سرطان الفم ويحتوي على جزئين أخذ التاريخ المرضي التفصيلي، و الفحص السريري الدقيق وفقًا للقو اعد العلمية. ج (Advise) -A تقديم النصيحة الطبية للمرضى المعرضين للإصابة بسرطان الفم عن طريق الأساليب الصحية المخصصة ومهار ات التو اصل الصحي الفعال مع المرضى. د) ربط المرضى بالمر اكز المتخصصة وخدمات الإقلاع عن التبغ. (Connect) -C (2) وتستهدف منظومة التدخل ISAC بشكل رئيسي أطباء الأسنان بمرحلة الامتياز في كلية طب الأسنان بجامعة جاز ان وسيتم تطبيقها من قبل شعبة طب أسنان المجتمع بصورتيها النظرية و التطبيقية. 
نبذة |

السعودية، بالإضافة إلى الإطار العلمي النظري الفلسفي الذي بنيت عليه هذه الأطروحة وأسباب الخيارات المتبعة له.

تضمنت الاطروحة ـ أيضاً ـ دراسةً علمية تفصيلية للمستوى المعرفي لدى طلاب وأطباء الأسنان و معتقداتهم وتصور اتهم وممارستهم الفعلية لفحص سرطان الفم في كلية طب الأسنان بجامعة جاز ان؛ حيث أظهرت أن إلمامهم يعد مقبو لا فيما يخص فحص سرطان الفم بشكل عام، لكن النتائج أوضحت عدم إدر اج المعدلات الإحصائية لسرطان الفم في جازان ومسبباته وطرق التعامل معها في المنهج التعليمي! وعند تقييم المعتقدات والآر اء و العو ائق المتصورة فيما يتعلق بسرطان الفم وممارسته في جازان؛ أظهر طلاب و أطباء الأسنان في الكلية تصورات إيجابية، على الرغم من أنهم كثفوا عن افتقار هم إلى الخبرة والثقة و القدرات اللازمة لممارسة فحص سرطان الفم سريريا! وأن ضغط المتطلبات السريرية بالإضافة إلى ضيق الوقت المتاح لإنهاء الحالات العلاجية لمرضاهم هما حاجزان رئيسيان أمام ممارسة فحص سرطان الفم لدى طلاب طب الأسنان، وأن اختلاف جنس الطبيب و المريض يُعتبر عائقاً بالنسبة لطلاب و أطباء الأسنان السعوديين، علاوةً على ذللك؛ فقد تجلّت السلبيّةُُ لديهم عند مر اقبة سلوكهم مع المرضى في عيادات الكلية؛ إذ أن غالبية طلاب و أطباء الأسنان فثلو ا في إجر اء الممارسة الثاملة لفحص سرطان الفم بغض النظر عن مستو اهم المعرفي! وقد يعزى ذلك إلى احتمالية افتقار هم إلى: الخبرة، و الكفاءة الذاتية، و المهار ات السريرية؛ باعتبار ها أهم العو امل التي تتم ملاحظة عجزها عادةً مع السلوك السلبي لطلاب و أطباء الأسنان تجاه سرطان الفم.

و على الطرف الآخر؛ تم استكثاف وتقييم العوامل المتعلقة بالمرضى بطريقة التصميم الاستكثافي المتسلسل (Exploratory Sequential Mixed Methods design) والذي أوضحت نتائجه أن مرضى الأسنان يملكون معتقدات إيجابية تجاه فحص سرطان الفم، ويثمنون الحاجة إلى فحص سرطان الفم، وتعليمه كمكون أساسي في الممارسة اليومية لطب الأسنان، كما شكك معظمهم في القدرة على اكتشاف 
فحص سرطان الفم والتوعية الصحية والوقائية من أمر اض الفم والأسنان للفرد والمجتمع ضمن برنامج إعداد أطباء الأسنان، وتوفير الدعم اللازم لأطباء المستقبل للتدرب عليها وممارستها.

حسب إحصائيات مركز الأور ام بمستشفى الملك فيصل التخصصي؛ فإن منطقة جاز ان تقدّم ما يقارب هم \% من مجمل حالات سرطان الفم في المملكة العربية السعودية، ومعظمها في حالات متأخرة مما يؤثر سلبا على نتيجة العلاج؛ ولذلك أصبح لزاماً اتباع نهج جديد للحد من تأخر كثف سرطان الفم في المنطقة ومو اجهة مسبباته وحصر وترثتب الجهات و التخصصات المعنية بسرطان الفم في منطقة جاز ان، وتعزيز الدور الهام الذي يلعبه أطباء الأسنان في الكثف المبكر عن سرطان الفم، و المنصوص عليه في الأبحاث و الأدلة العلمية، و عليه فإن هذه الأطروحة تبادر إلى تطوير برنامج تدخل سريري شامل بساعد في تعزيز الكثف المبكر عن سرطان الفم والوقاية منه في منطقة جاز ان باستخدام نظام الرسم الخر ائطي الحديث للتدخل الوقائي والتعزيز الصحي للفم وأمر اضه (Intervention Mapping). و هنا تجدر الإشارة إلى أن النهج المتبع غالبا في البر امج الطبية التدخلية للحد من سرطان الفم يحمّل المريض وحده مسؤولية المرض؛ ما جعل العديد من الباحثين في مجال طب الأسنان يغفلون مسؤولية وارتباط أطباء الأسنان المتمثلة في بعض سلوكياتهم السلبية تجاه ممارسة فحص سرطان الفم أو تثقيف المريض عنه، وعليه، فقد قيّمت هذه الأطروحة دور أطباء الأسنان في التصدي لسرطان الفم في منطقة جاز ان بعناية وبأساليب متعددة، وحلّت السلوكيات المحتملة و المرتبطة بسرطان الفم في جاز ان من أبعادها الثخصية و الاجتماعية و المكانية والزمنية والاقتصادية، وشملت سبعة أبواب ومختصر وتثمينٍ علمي، قدمت فيه نظرة عامة حول حالة سرطان الفم على الصعيدين العالمي و المحلي، كما ناقشت أهمية الكثف المبكر عن سرطان الفم ودور طلاب و أطباء الأسنان، وبينت عو امل الخطر المحتملة والسلوكيات المرتبطة بسرطان الفم في منطقة جاز ان، كما ألقت الضوء على مناهج التدخل المختلفة لسرطان الفم الوقائية أو العلاجية، وفاعليتها في معالجة سرطان الفم ومدى تماثيها مع الرؤية السامية لجودة الحياة في المملكة العربية 


\section{نبذة مختصرة عن الأطروحة}

"الوقاية خير من العلاج"؛ حكمة تداولتها الألسن بمختلف لغاتها، وتعني أن الوقاية من المرض خير من العلاج منه بعد تجر ع آلامه و همومه وتكبد أنعابه وتكلفته. إلا أن سرطان الفم يعيد صياغتها؛ لتكون: الوقاية خير" إذ لا علاج! فالوقاية من مسببات سرطان الفم كالثمة والنشوق وما شابهها من منتجات التبغ ومن التدخين بكل أنو اعه ومختلف طرق تعاطيه، مثبتةٌ أهميتها في العديد من الأبحاث العلمية الدقيقة عملياً و القوية مُخرجاً.

و لأن اكتشاف سرطان الفم عادة ما يتم في مرحلة متأخرة تكون معها طرق العلاج محدودة وقاسية - إن صح التعبير -؛ حيث ينتهي باستئصال اللسان أو جزء حيوي من الوجه مثلا!، غير المعاناة الثديدة التي يمر بها المريض؛ فان فترة الحياة المتوقعة بعد الإصابة بالمرض حسب الدراسات العلمية الحديثة لا تزيد عن خمس سنو ات فقط! - بعد إر ادة الخالق سبحانه وتعالى -. ويعتلي سرطان الفم قائمة السرطانات الأشد فتكا بحياة الكثيرين حول العالم، و هو الثالث في ترتيب السرطانات بالمملكة العربية السعودية؛ وعليه، و استجابة لأمر خادم الحرمين الثريفين الملك سلمان بن عبد العزيز وولي عهده الأمير محمد بن سلمان، بأن يكون حفظ الصحة العامة - ومنها صحة الفم -؛ سياسة وأولوية وطنية، فإنه يتوجب على المختصين بمجال صحة الفم والمجتمع؛ الثروع في مكافحة سرطان الفم، آخذين بعين الاعتبار جل العو امل المسببة له على جميع المستويات البيئية والاجتماعية، ولأن طبيب الأسنان - غالبا ـ هو أول من يكتثف المرض؛ فإن إلمامه بطرق فحص سرطان الفم وممارسته للفحص الفموي الثامل لكل مريض أمرّ في غاية الأهمية، وكذلك أهية إنقان طرق و أساليب التوعية و الوقاية من سرطان الفم على مستوى الفرد والمجتمع.

و هنا يأتي دور كليات طب الأسنان في إعداد أطباء بكفاءة علمبة وقدٍٍ عالٍ من المسؤولية لاكتشاف سرطان الفم في مر احلَ مبكرة، ومواجهة مسبباته في المجتمع، مع التثديد على ضرورة إدراج مهارات وطرق 
نبذة مختصرة عن الأطروحة 
¿ Maí. 
الكثف المبكر عن سرطان الفم من خلال ممارسة فحص الفم السريزي

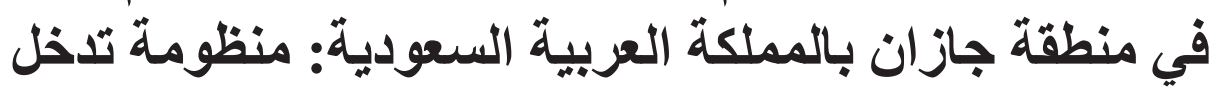

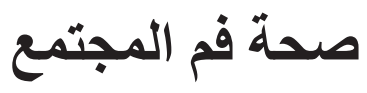


الكثنف المبكر عن سرطان الفم من خلال ممارسة فحس الفم السريري

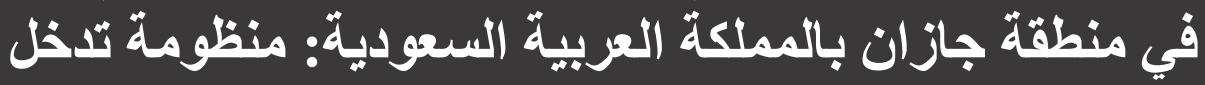

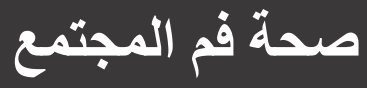

محمد عبدربه جمفز

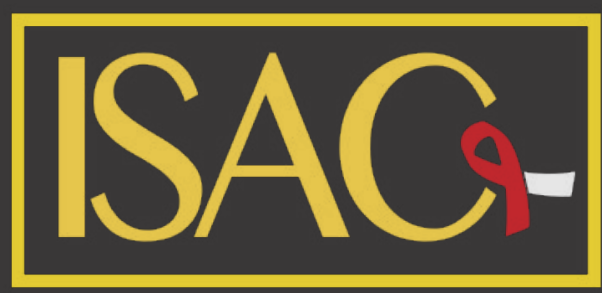

